\title{
Diverse Education for Diverse Economies: The relevance of Rural Training Centres in the Solomon Islands
}

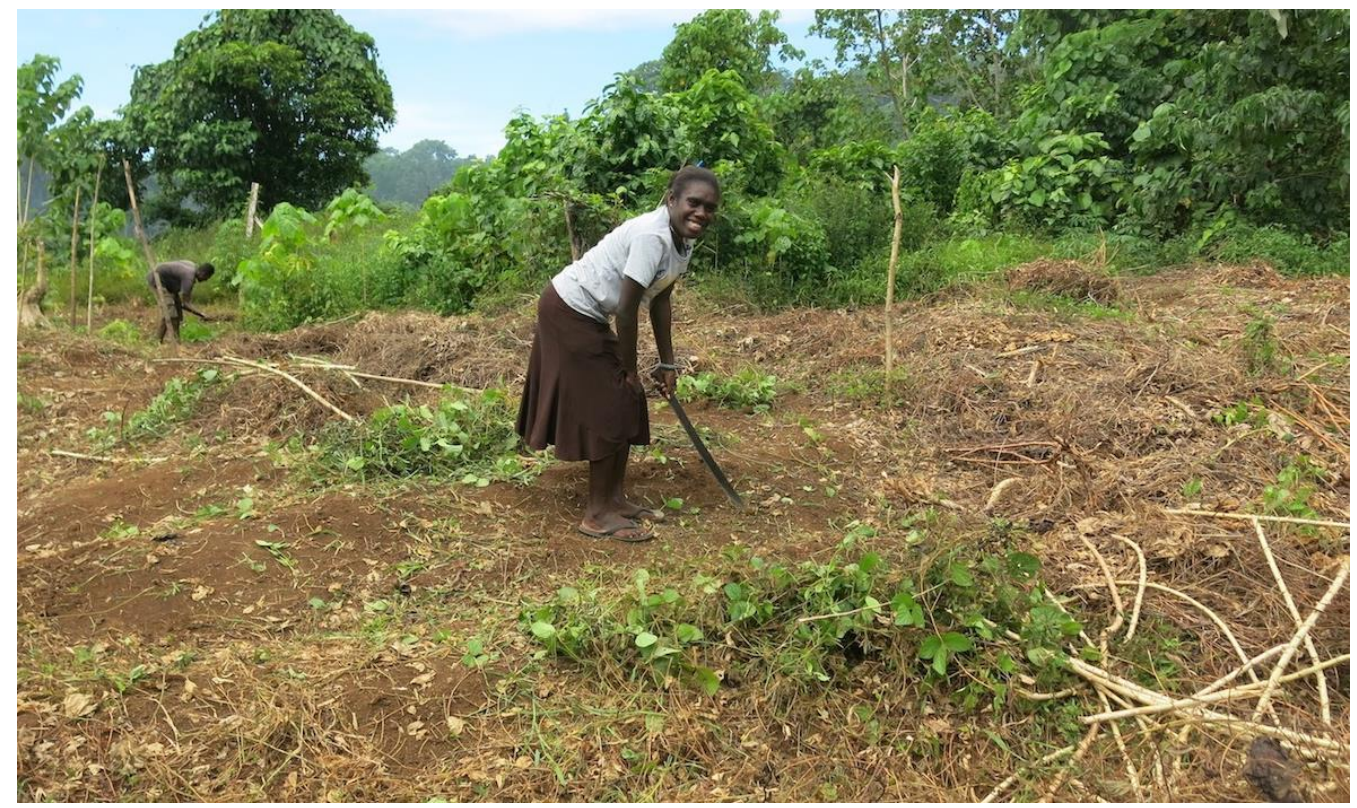

\section{Kathryn Fleming}

SID: 300290179

Supervisor: Marcela Palomino-Schalscha

School of Geography, Environment and Earth Sciences, Victoria University of Wellington,

February 2015

120 point thesis submitted to Victoria University of Wellington in partial fulfilment of the requirements for the degree of Master of Development Studies 
To: Me

Re: Visiting you in the Solomon Islands

Dear Kathy,

I spoke to a man at the Nursing Home today, who went to Solomon Is. You MUST have tablets against malaria. Check with W.H.O. His wife contracted it years ago there. Also it is very hot and humid being near New Guinea and the equator. I may take a rain cheque, as I don't cope with that sort of weather.

Flight Centre had no brochures on the place and no info, except the odd flight. However, I found a 6 day tour via the Ghan train from Adelaide to Alice Springs which seems preferable. Also there are many Solomon Islands, I may not be able to find you!

Lots of love, Mum 


\begin{abstract}
Education is considered the cornerstone of development, essential to achieving economic and social goals. Under the powerful global education agenda, the western model of formal education has been implemented hegemonically in developing countries. This model largely prepares young people for a role in the formal economy in an urban environment, overlooking fundamental questions of purpose and relevance for local context. In the Solomon Islands, where $85 \%$ of the population reside rurally, such opportunities often do not exist or reflect local livelihoods.
\end{abstract}

Rural Training Centres (RTCS) are informal vocational institutions that sit outside of the dominant education paradigm by aiming to prepare young people for local livelihoods. Through informal and vocational learning, they offer an alternative to urbanisation, supporting self derived and locally based livelihoods. Paradoxically, for this very reasons they are often disregarded at the government and donor level.

From a postdevelopment perspective, this thesis considers the roles and relevance of RTCS under a wider conceptualisation of economy and knowledge than is applied in mainstream development practice. Using qualitative and ethnographical methodologies, this research investigates local understandings of RTCS as an education alternative through the voices of young people, women and the wider community. The inter-related aspects: economy, education, and development, are considered in two case study communities, Gizo and Vatu, providing a semi-urban/rural comparison.

Using a Diverse Economies Framework (Gibson-Graham, 2005), this thesis reveals a more realistic picture of the myriad of activities that support local livelihoods exists. The formal economy is found to play a secondary role to informal and direct economic practices. Similarly, under a pluralistic view of education that accepts the legitimacy of traditional, cultural and indigenous knowledge, the aspirations of young people are found to be deeply rooted 'at home'. Yet, this research argues that they do not conform to a simplistic moderntraditional dichotomy. Rather they reflect cultural hybridity, a third space 'in between' where different knowledges are transformed and negotiated. 
Despite criticisms, RTCs were positively viewed at a community level. They were considered to fill a vital gap left by the formal education system, support local livelihoods and help stem the flow of urban migration. They also offer an opportunity to support women in existing gender roles, as well as expand existing cultural educational boundaries. However, RTCs are facing pressure to standardise and formalise in order to attract greater government and donor funding. This reflects wider tensions in development policy and practice that favour the universal and the global over the local, and brings to light the inherent power disparity in the aid relationship. 


\section{Acknowledgements}

This thesis would not have been possible without the inspiration and support of some fabulous human beings. I sincerely thank you each and all:

The Solomon Island participants and RTC staff-for their hospitality and openness in sharing their lives with me

Dominic Hammond - my sanity and my escape Marcela Palomino-Schalscha-ever encouraging and insightful

Ewa Kusmeirczyk - my running relief

My mother - who instilled in me a passion for education

Maria Spies - my role model and the most capable person I have ever encountered

Margaret di Nicola - my wisest friend

Karma, Lhakpa and Tensing - who inspired me with their reflections experiences

Nick Borthwick - the bravest development practitioner I know and an endless optimist

My fellow classmates - for sharing the trial and triumphs of writing a thesis

I would also like to sincerely thank Caritas Aotearoa New Zealand for having the courage to open up their project to research and feedback. 


\section{Contents}

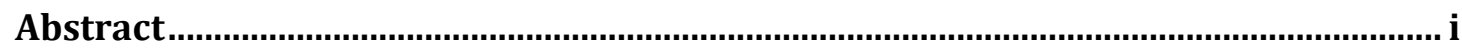

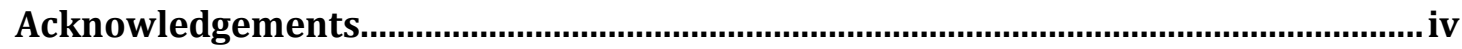

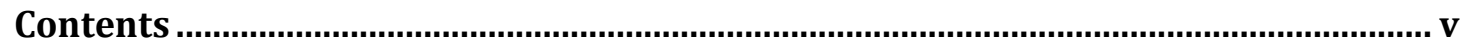

List of tables........................................................................................................................... vii

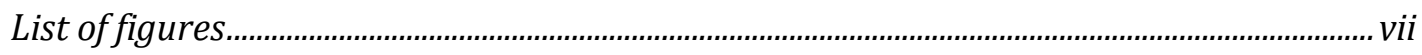

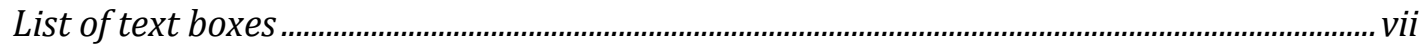

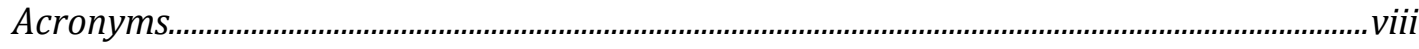

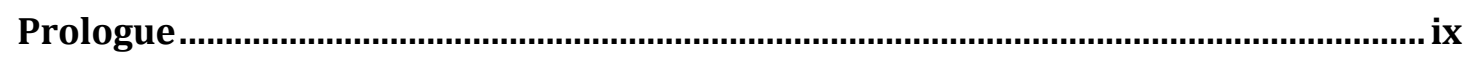

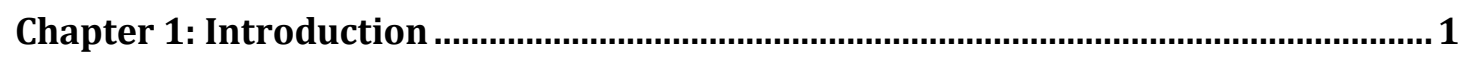

Education, economy and development ......................................................................................... 1

Research aim and approach ................................................................................................ 3

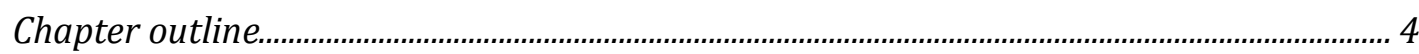

Chapter 2: The Solomon Islands: Global and local context...........................................

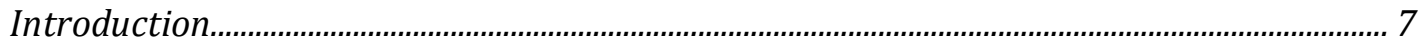

The challenge of being young and finding work ……….............................................................

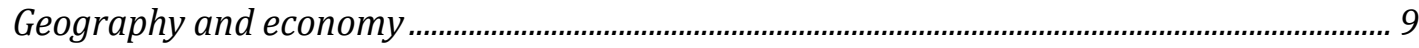

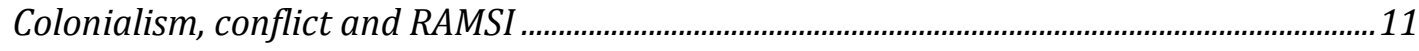

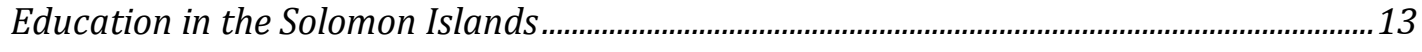

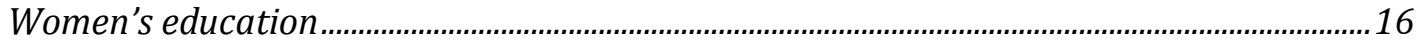

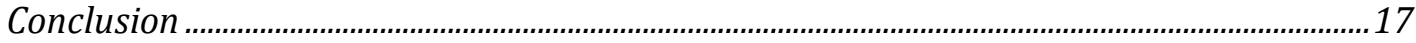

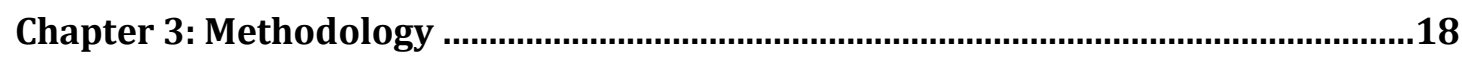

Introduction...................................................................................................................................

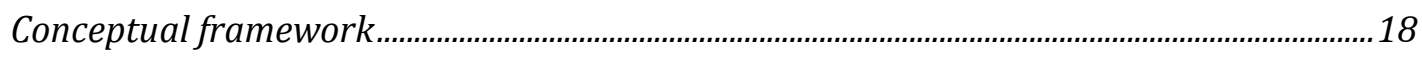

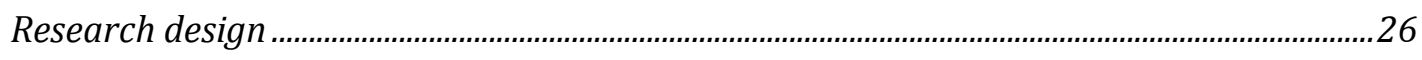

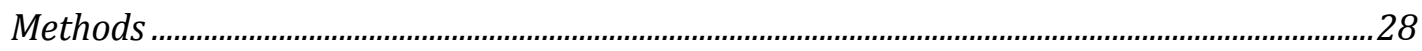

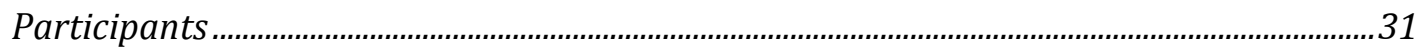

Research integrity ............................................................................................................................

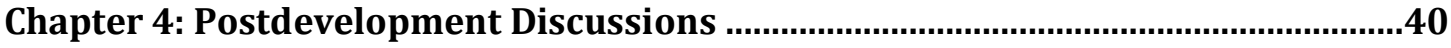

Introduction

Postdevelopment

Where to from here?

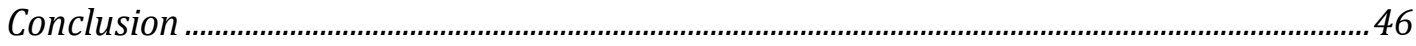

Kathryn Fleming $\quad v$ 
Chapter 5: Monoculture of capitalist productivity and efficiency: The diverse

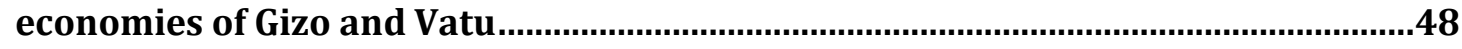

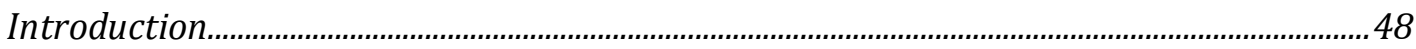

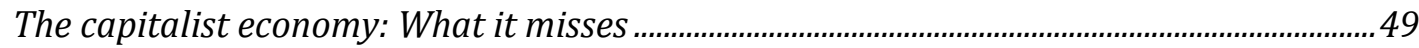

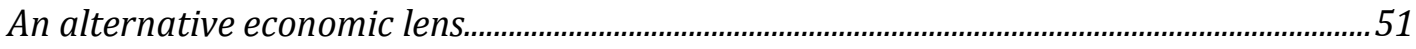

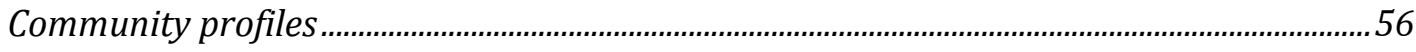

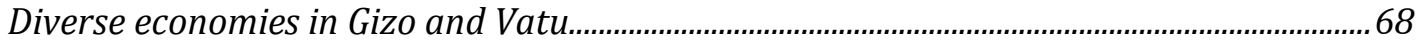

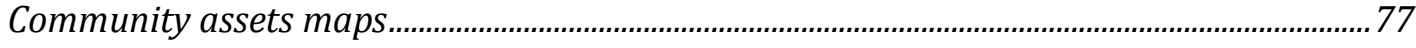

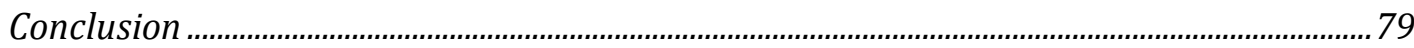

Chapter 6: Monoculture of western scientific knowledge: Non-formal education

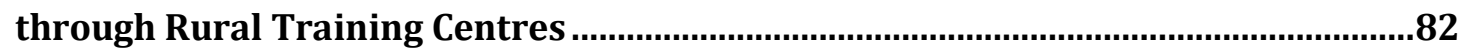

Hegemony of western knowledge and education ......................................................................83

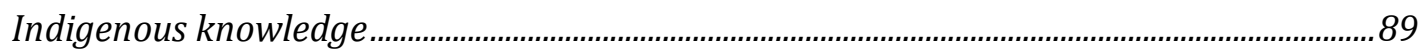

The Rural Training Centres of Gizo and Vatu........................................................................90

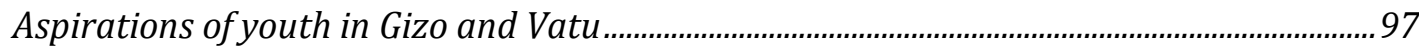

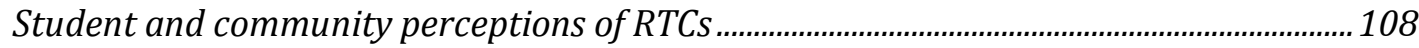

Women: Barriers and opportunities to RTC participation ....................................................112

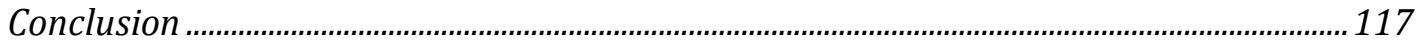

Chapter 7: The monoculture of the universal and the global: Development policy in practice

Introduction

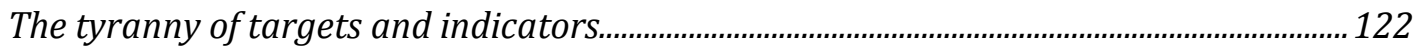

Implications for RTCS................................................................................................... 125

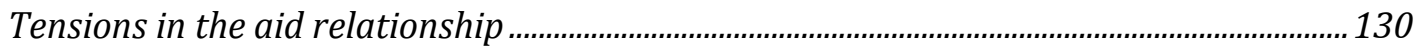

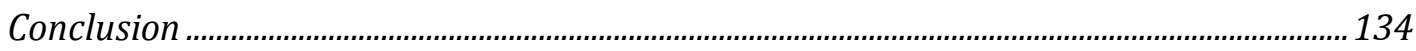

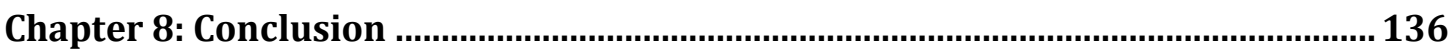

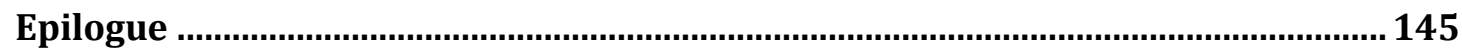

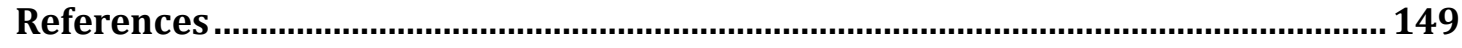

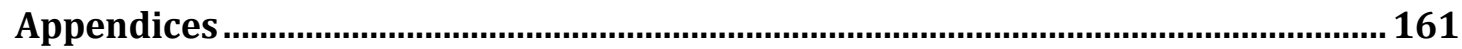

Appendix 1: Participant information sheet and consent form .............................................161

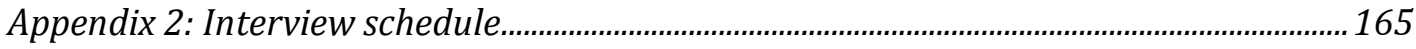

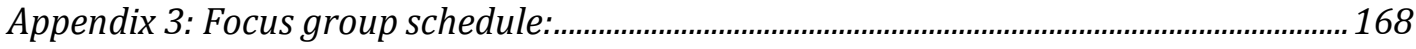

Appendix 4: Human ethics approval .....................................................................................170 


\section{List of tables}

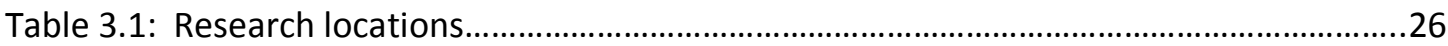

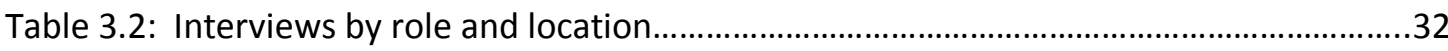

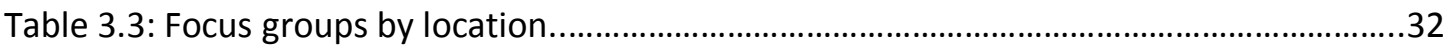

Table 6.1: St Peter's RTC students by course and gender...........................................................91

Table 6.2: Vatu RTC students by gender...............................................................................95

\section{List of figures}

Figure 5.1 Diverse Economies Framework............................................................................53

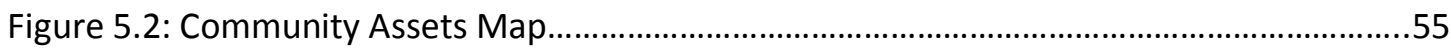

Figure 5.3: Solomon Islands map with locations of Gizo and Vatu............................................57

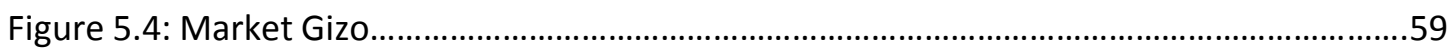

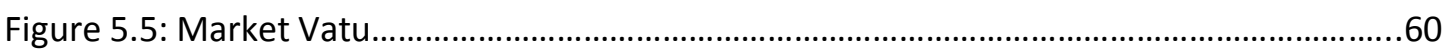

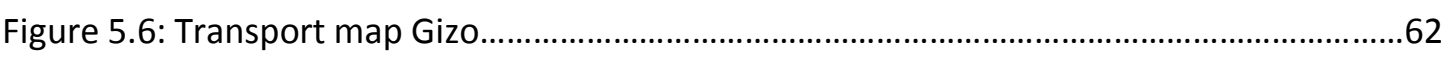

Figure 5.7: Time map Vatu......................................................................................................64

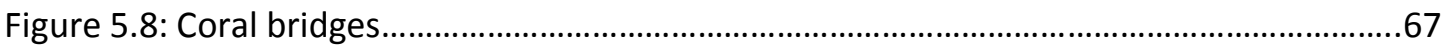

Figure 5.9: Community assets map Vatu..................................................................................78

Figure 5.10: Community assets map Gizo.......................................................................................79

Figure 6.1: Mechanical and carpentry workshop at St Peter's RTC Gizo....................................92

Figure 6.2: Male students weaving a roof from local materials................................................94

Figure 6.3: Author harvesting cocoa with the students............................................................96

Figure 6.4: Aspirations of male student at St Peter's RTC.......................................................99

Figure 6.5: Aspirations of female student at Vatu RTC................................................................101

Figure 6.6: Aspirations of community male youth in Gizo......................................................102

\section{List of text boxes}

Text box 2.1: Literacy and numeracy challenges

Text box 3.1: Running with Father Matthew and debunking 'myths' in the research process

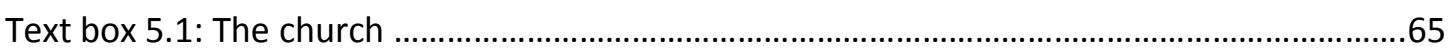

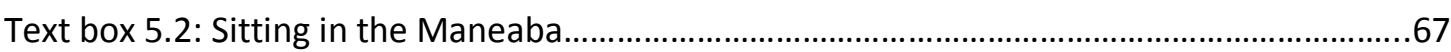

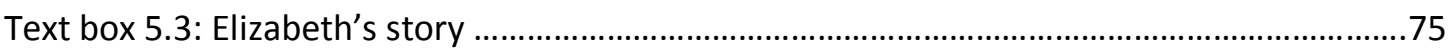

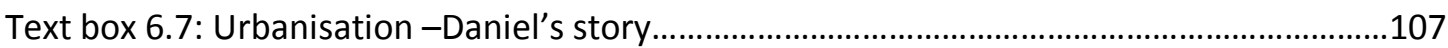




\section{Acronyms}

$\begin{array}{ll}\text { EFA } & \text { Education for All } \\ \text { ILO } & \text { International Labour Organisation } \\ \text { MDGs } & \text { Millennium Development Goals } \\ \text { MEHRD } & \text { Ministry of Education and Human Resource Development } \\ \text { NGO } & \text { Non-Government Organisation } \\ \text { ODA } & \text { Official Development Assistance } \\ \text { RAMSI } & \text { Regional Assistance Mission to Solomon Islands } \\ \text { RTC } & \text { Rural Training Centre } \\ \text { SIAVRTC } & \text { Solomon Islands Association of Vocational and Rural Training Centres } \\ \text { SIQF } & \text { Solomon Islands Qualification Framework } \\ \text { UNDP } & \text { United Nations Development Programme } \\ \text { UNESCO } & \text { United Nations Educational, Scientific and Cultural Organisation } \\ \text { UNICEF } & \text { United Nations Children's Fund }\end{array}$




\section{Prologue}

I had only been walking an hour, but could go no further. Walking for 10 hours each day for the past week, through the steep Himalayan foothills had taken it out of me, and I was sick. Tashi, the porter we had hired gestured that he would take my bag, in addition to his own $25 \mathrm{~kg}$ pack filled with our mountaineering gear. I refused, it would not be fair for him to carry that much. It was only a few more hours to Lukla, so I asked him to speak with the people who owned the houses beside the trail about hiring a porter for the day. After much negotiation between older men, a young man aged around 14 stepped forward and slung my $15 \mathrm{~kg}$ pack over his shoulder not even bothering to do up the waist strap.

A little further on our journey he swapped my pack with the load of child aged no more than 10. The child had been carrying a $25 \mathrm{~kg}$ gas cylinder, stopping every few hundred meters to rest. Of all my experiences watching porters carrying loads of wood, rocks, furniture and food weighing up to $100 \mathrm{~kg}$, this one stuck. I realised the porters carrying bags for tourists, like myself, were lucky by comparison. Over the next month I had many conversations in broken English with Tashi, about his life and family. He did not want his children to end up like him, with a hard life, he wanted them to have an education....

Most stories from trekkers and mountaineers in the Himalaya end there, or shortly after with me offering to sponsor his 16 year old son, Nyima, to go to senior high school. But I wanted to dig deeper. I spent my second month in Nepal with independent guide and friend Pemba. He was from the same village as Tashi, and had arranged for Tashi to be our porter, a method he uses to help poor families in the village by connecting them with employment. I decided to visit Nyima in his village and find out what this young man wanted for his life.

Pemba is one of those incredible people, with a third grade education he is fluent in three languages and able to negotiate western and non-western perspectives critically and with great insight. During our week-long approach to the village we wrestled together in discussion with ideas around Nyima's education. Was it the right thing to send him away from home? Where would he live in Kathmandu? Realistically, what were the job opportunities afterwards? Would secondary education actually give him any useful skills to find work? Like many developing countries, the urban centre of Kathmandu is already over crowded with those looking for work and living in slum conditions. In reality finding employment usually depends on having gone to the right school from a young age, or more 
importantly knowing the right people. Everyone else has to create their own living. What chance did Nyima, a rural boy from a village school, have?

I began to notice the images of local children with their western sponsors hung on the walls of lodges we stayed in. The parents talked about education and migration to Kathmandu as the only option for a better future, and tourist sponsorship as the only way to achieve it. I was approached by people with children as young as 5 attempting to persuade me that I should sponsor their children to go to boarding school because at home they fight with their siblings. What I didn't see then, but recognised on reflection, is that I was hearing a global discourse. After decades of contact with and intervention from western people and organisations, the story of development and progress, with western education the only means of achieving it had been internalised by the local people. They whole heatedly believed formal education was the sole pathway to a better future, a western middleclass future. They seemed blind to the opportunities around them, and overly optimistic about the realities of Kathmandu. Even though some had returned from education in the city with no job, other possibilities were not even being imagined. The benefits of the rural life with land, the ability to grow food, and no pollution, against the backdrop of the most magnificent mountains were marginalised. This was because yak herding, farming and raising animals were now considered inferior to the city life. 


\section{Chapter 1: Introduction}

The experience imparted in the prologue inspired this thesis, causing me to question the dominance of western education in light of the disconnect with the livelihoods of many in developing countries. This question of relevance appears under addressed, with serious implications for young people who are being encouraged on a western education pathway that often fails to deliver the promised economic success. This topic is also the nexus of my professional background in adult education, working with young people who don't fit well in the mainstream education system, and my studies of international development. To support the integration of theory and professional practice, I chose to base this research around a real development project contending with these issues. Hence, I partnered with Caritas Aotearoa New Zealand who were designing an alternative education project with Rural Training Centres (RTCs) in the Solomon Islands aimed at providing a better livelihood future for young people.

This research examines the relevance of Rural Training Centres to their local communities from an economic, education and development perspective. It steps outside of the dominant discourse to explore wider understandings of these concepts, and consequently informs the question of relevance and associated implications based more closely on the reality of everyday livelihoods

\section{Education, economy and development}

Over the past three decades education has received unprecedented global attention. High profile research on the positive impacts of education, particularly girl's education, have demonstrated that it is a means to achieve economic, health and social development objectives (Summers, 1992; UNICEF, 2004, 2011). Education has also attained widespread support from traditionally opposing ideological camps: Human Rights based development and economic approaches to development. Hidden in the shadows of development's new panacea, the negative consequences of this concentrated focus have received little attention. The resultant global education agenda has promoted certain types (formal western) and levels (predominantly primary) of education, causing investment to be redirected from other areas, such as informal and vocational education (Mundy, 2006). On the basis of assumptions around the superiority of western scientific knowledge formal western education has also side-lined indigenous knowledge and traditional skills that are highly 
relevant to livelihoods in many societies (Coxon \& Munce, 2008). Meanwhile such education has failed to fulfil promises of a "rich, cultivated and happy life" in many developing contexts (Nordtveit, 2010, p. 325).

Underpinning the dominance of formal western education are beliefs about the nature of the economy and desired development trajectories. The prevailing capitalist view of economy values formal economic activities over informal activities. The aim of education therefore, is to produce a productive labour force for the formal economy, supporting economic growth (Tikly, 2004). While this is the view reflected in the dominant development discourse, it does not reflect the reality of life in much of the developing world where informal, subsistence and rural living remain central to livelihoods. Gibson-Graham (2005) challenge the notion that development can only be achieved through a capitaliocentric model of economy by seeking to reveal the myriad of diverse economic activities that support livelihoods in reality. A broader perspective of economy, that encompasses all the aspects that support local livelihoods, necessarily provokes questions around the relevance or primacy of formal western education to these activities (Nordtveit, 2010).

\section{Education in context}

The Solomon Islands has a burgeoning youth population. With the proportion of youth under the age of 15 years at $40 \%$ and increasing, high youth unemployment presents a major challenge (Close, 2012). Low quality basic education and early exit from the school system leaves large numbers of youth illiterate, innumerate, and lacking the cognitive and practical skills to satisfy employers. Consequently there is a skills shortage in the formal employment sector (WYG International, 2012). Although unmet demand exists in the formal employment sector, there is also wide-spread acknowledgement that the domestic labour market will not be able to accommodate the growing population of youth (Close, 2012). Furthermore, over $80 \%$ of Solomon Islanders reside rurally, with limited access to formal wage earning opportunities. The reality for most Solomon Islanders is a livelihood built on subsistence living and agricultural practices (Close, 2012). The failure of the formal education system to produce real outcomes for young people, and the disjuncture between what is taught and the livelihood reality call into question the relevance of the formal western education system in this context (Coxon \& Munce, 2008). 
Technical Vocational Education and Training through an existing network of 38 Rural Training Centres (RTCS) presents a second chance for the majority of Solomon Island youth who do not complete secondary school. RTCs offer a potential alternative, a skills bridge to formal employment and a pathway to gain practical skills to support informal livelihoods in the local community. RTCs sit outside the formal education system and are generally perceived as second-rate by government and donors. They have been criticised for having poor facilities, inexperienced teachers, low management capacity, few female enrolments, and a general lack of common standards (Close, 2012; WYG International, 2012). However, this view is largely based on the inherent prejudices of the global education agenda and wider development discourse. In response to some of these criticisms and resourcing needs the aforementioned NGO project aims to strengthen the quality and relevance of eight RTC through teacher training, leadership, infrastructure and community outreach. This prompts the need for a local understanding of relevance, based on the perspective of the community and students themselves and in relationship to livelihood activities in the local economy..

\section{Research aim and approach}

The central purpose of this research is to examine the relevance of RTCs to their local communities. The interrelationship between education and the intended outcome of education, a productive livelihood, is critical to the question of relevance, and interwoven with the ambitions of development. Consequently for this research I have broken down the relevance of RTCs into these three areas: local economy (livelihoods), education, and development. Specific attention is paid to the education of women as a disadvantaged group. Two case study sites were selected on the basis of their involvement in the NGO project and differing demographic composition. The following sub-questions were used to guide inquiry into these three areas:

What supports livelihoods in these communities?

What are the aspirations for the future of young people in these communities?

What is the perception of RTCs amongst students and the communities in terms of their relevance to livelihoods?

What are the barriers and opportunities for women to engage with RTCs?

How do global development policy and dynamics affect RTC education at the local level?

One of the benefits of qualitative research is that it allows room to explore issues that emerge during the research progresses. The role of development policy and practice in supporting and constraining RTCs became apparent as a significant part of the inter- 
relationship between education, economy and development. Hence, the final question was retrospectively incorporated into the scope of the research.

The research uses ethnographic and participatory methods, via observation, interviews and focus groups, to seek insight into the world of the participants as they experience it (Crang \& Cook, 2007). It focuses on two principal case study sites, Gizo and Vatu, each with a RTC and surrounding community. The selection of a semi-urban and rural case study site provides the basis for comparison. Consistent with a wider critical and post-structuralist framework, the research draws on latter postdevelopment theory to dismantle dominant discourses and reveal alternative understandings and practices of economy, education and development.

\section{Significance linking theory and practice}

An additional driver in this research was to undertake a project that contributes to development practice. This commitment is based on my belief that theory and practice can (and indeed should) complement one another. Academic research can offer exploration and a deeper understanding of the wider context surrounding what is happening, while development practice remains grounded in the realities of implementation, forcing practical application of theoretical constructs. Thus, as well as contributing to the small body of literature on education and development in the Solomon Islands, this research provides indepth context and practical insights to guide the design and implementation of the NGO project. It contributes to the practice of development as informed by a post development perspective, that is taking the additional step beyond critique to a constructive and imaginative space that can be implemented in practice. This research also traverses scale, connecting global debates and discussions with the local and practical impact of these on everyday lives.

\section{Chapter outline}

The thesis follows an unconventional structure that aims to balance theory with practical reflections from the field. Rather than a standalone literature review, literature on areas of economy, education and development is integrated into chapters of analysis and discussion. text boxes are used provide specific illustrations of the themes in the lives of individuals or situations.

Chapter 2 provides a contextual overview of the geography, economy, and education system in the Solomon Islands, setting the scene for the importance of local context to this research. 
It also explores some of the historical influences on the Solomon Islands and the specific challenges for women.

Chapter 3 outlines the research methodology, explaining why an ethnographic and participatory approach was selected, and the different groups of participants. It also discusses some of the ethical and practical tensions of conducting research simultaneously for academic and organisational purposes.

Chapter 4 discusses the foundations of postdevelopment theory that have guided this research and the limitations of a purely critical approach. It moves to latter postdevelopment theory which aims to go beyond critique, introducing Santos's (2004) work on the sociology of absences, which provide a thematic framework for analysis.

Chapters 5, 6 and 7 are themed around three of Santos's (2004) monocultures, focussed on the areas of economy, education and development respectively. Each chapter contains a more specific literature review, analysis and discussion of the findings.

To consider the question of RTC relevance to the local community it is necessary to gain a picture of what supports livelihoods in local economy. Themed as the monoculture of capitalist productivity, Chapter 5 challenges the dominance of a narrow capitalist view of economy in development. It considers the numerous livelihood activities overlooked by this framework. The alternative 'diverse economies approach' of Gibson-Graham (2005, 2006, 2008 ) is used to analyse the local economies of the two case study sites.

Chapter 6 looks more closely at the structure and activities of RTCs themselves, considering their relevance from the point of view of the students and surrounding community. Under the theme the monoculture of western scientific knowledge it considers the way in which formal western education has been promoted and exported by the global education agenda, marginalising other forms. Relevance is considered from a broader perspective of education that incorporates traditional and indigenous knowledges. This chapter also contains a specific section on the barriers and opportunities women face to education in the Solomon Islands more broadly, and to RTCs specifically. 
Chapter 7 uses the theme the monoculture of the universal and the global to shift the focus to development policy and practice. This chapter draws on observations of development actors in the field and policy documentation to examine the impact of universal targets and global indictors on RTCs and wider policy in the education sector. It also considers the underlying tension in the aid relationship, fuelled by power asymmetry and issues of ownership.

Chapter 8 concludes the thesis by reflecting on the new position reached, an expanded view of economy, education and development from which the relevance of RTCs has been explored. It identifies how this research has already been used to connect theory and practice and the potential areas of future research. 


\section{Chapter 2: The Solomon Islands: Global and local context}

\section{Introduction}

This chapter begins by discussing the issue at the heart of this research; the difficultly young people face in navigating education, employment and the economy to establish a future livelihood in the Solomon Islands. It provides the necessary background information about the geographical setting, economic situation, years of conflict, the education system and the situation for women. Moreover, this information helps the reader to understand the findings of this research, why life is different in different places, the importance of informal livelihoods, the position of Rural Training Centres in the education system, and the cultural influences on women. It also introduces the post-structuralist approach taken to this research, connecting the above topics with postdevelopment ideas that critique the conventional understanding of development and explore new options. I aim throughout this thesis is to reveal what has been omitted or devalued by dominant discourses, and construct a more empowering picture of people and communities.

This chapter is information rich. However, in the interest of brevity only aspects of direct significance to this research are examined in detail. Other areas of context have been covered extensively elsewhere (M. G. Allen, 2012; Bedford \& Hugo, 2012; Dinnen, 2002; Fraenkel, 2004; McDougall, 2004).

\section{The challenge of being young and finding work}

Adolescence has been deemed "an age of opportunity", yet it is also the age where the critical transition from education to employment is made, and the period in which poverty can be transmitted inter-generationally (UNICEF, 2011, p. 2). Globally the world is facing a youth unemployment crises with 77 million young people out of work, equating 13\% of the world population. Youth unemployment is an issue in most nations, and most heavily felt by developing countries where $88 \%$ of the world's adolescents live (International Labour Organization, 2013).

In this pressured job environment, urbanisation and the movement towards more a modern economy based on skills and knowledge has placed increased expectations on education. Those with low levels of education are particularly vulnerable, having missed the opportunity to build the knowledge and skills to make them attractive to employers or equipped for 
productive self-employment. While education is increasingly demanded, a lack of formal employment opportunities exist in developing countries. As a result, early school leavers tend to find themselves in irregular, poorly paid and informal employment (International Labour Organization, 2013).

This situation is currently playing out in the Solomon Islands. The youth population is large, with $40 \%$ of people under the age of 15 years and 57\% under the age of 24 (Close, 2012). The high population growth, $2.5 \%$, means this youthful trend is increasing. While this offers a demographic opportunity to increase the proportion of working population, a position many developed countries would envy, high youth unemployment presents a major challenge (International Labour Organization, 2009; UNdata, 2014). More than $80 \%$ of youth (15-24 year olds) are not engaged in labour market employment and $56 \%$ are not in education, employment or engaged in domestic activities (Close, 2012). This situation is precipitated by two main factors:

\section{Low education levels leading to skills shortage}

Although the Solomon Islands has come a long way to increasing participation in primary education (net primary enrolment has risen from $74 \%$ in 2000 to $91 \%$ in 2010 ) this growth has exceeded administrative and resource capacity compromising quality. Increased demand has also revealed major gaps at the secondary level (Close, 2012). Secondary school attendance is amongst the lowest in the world, hovering around $30 \%$. Issues of poor teaching quality, inefficient management of resources, poor leadership and the ever present physical access challenges have been identified as reasons for the low participation (UNDP, 2010; UNICEF, 2013). This low quality basic education and early exit from the formal school system is leaving large numbers of youth illiterate, innumerate, and lacking the cognitive and practical skills to satisfy employers (Close, 2012; WYG International, 2012). Meanwhile the existing formal employment sector is facing a skills shortage, currently understaffed by more than $50 \%$, due to unavailability of suitable candidates (WYG International, 2012). Seemingly a gulf of skills and basic education lies between the needs of employers and the youth attempting to enter the labour market.

\section{Lack of formal employment opportunities}

Despite unmet demand in the formal employment sector, there is wide-spread acknowledgement that the domestic labour market will not have capacity to accommodate 
the growing population of youth (Close, 2012). Furthermore, over $80 \%$ of Solomon Islanders reside rurally, with limited access to formal wage earning opportunities. The reality in rural communities is a future built primarily on a subsistence economy made up of informal employment and self-employment (Close, 2012).

While the above reading of 'the problem' is valid, it represents a certain perspective, that of the dominant development discourse. This creates a disempowering picture implies the need for a specific kind of development intervention (Esteva, 2010). Moreover it omits the diversity of economic and educational activities in communities that currently contribute to livelihoods, and point to other possibilities and opportunities. This research will explore these theoretically and practically by listening to the perspectives from the 'other side', those in the communities of the Global South (Rahnema, 1997).

\section{Geography and economy}

The Solomon Islands faces numerous development challenges in the provision of education and decent employment opportunities. This is partly a result of its remote and dispersed geography, and peripheral position in the global economy. Other key factors, including the legacy of colonialism and historical tensions will be discussed in the section Colonialism, conflict and RAMSI on page 11.

\section{The challenges of a remote geography}

In the vast expanse of the southern Pacific Ocean, the 992 islands that comprise the Solomon Islands, of which 147 are inhabited, are spread across 1.35 million square kilometres of water (UNDP, 2010). To give an idea of scale, this is equivalent to a landmass the size of Belgium spread across an area as big as South Africa: it is dispersed to say the least. Hence, even though the Solomon Islands has a relatively large population by Pacific Island standards at 560,000, the average person lives over $200 \mathrm{~km}$ from the capital Honiara (World Bank, 2014). Transport costs over land and water make most activities expensive and the population distribution make it difficult to provide core services in a centralised manner or take advantage of economies of scale. Physical access for communities to education, along with other important human services such as health has remained a prominent issue (UNDP, 2010).

\section{Economics on the periphery}


Economically, the small population of the Solomon Islands and isolated location situate them at 'the margins' of the global economy. The nation exhibits the typical features of a Pacific Island economy: a limited domestic market, high transportation costs, and low levels of capital investment (International Labour Organization, 2009). Gross National Income (GNI) per capita is just 1610 USD (World Bank, 2014). Combined with the challenges of human service provision, the Solomon Islands ranks poorly on the Human Development Index (HDI) at 157 of 187 places (UNDP, 2014a). The HDI represents a combined measure of health, economy and education. The Solomon Islands scores below average for the region in particular due to poor education performance. Mean years of schooling, 4.5, are less than half of neighbours such as Fiji and Vanuatu at 9 plus (UNDP, 2014b). Consequently, the Solomon Islands is considered one of the world's Least Developed Countries (UNDP, 2013).

The Solomon Islands economy is largely traditional and agricultural with economic vulnerability on the few commodities exported: timber, cocoa, copra, tuna and palm oil (International Labour Organization, 2009; UNDP, 2013). Since the 2003 conflict, economic growth has been achieved through flows of international aid and rapid expansion of the forestry sector, to the point where the latter is near exhaustion (World Bank, 2010). New sources of growth are now being sought under the premise that "most countries have improved living standards by moving from a reliance on agricultural production towards manufacturing and services, with accompanying urbanisation" (World Bank, 2010, p. i). While the importance of small hold agricultural farming continuing is acknowledged for food security, greater integration with the global economy is considered essential. New sources of growth being promoted are the optimisation of Solomon Islands natural resources, including gold, nickel, fisheries, forests and tourism, as well as the creation of a "mobile international workforce" to take advantage of labour migration to regional nations (World Bank, 2010, p. i).

Domestic economic opportunities are highly localised depending on the availability of natural resources and access to markets to capitalise on such resources. For example, some areas have rich tuna stocks that are consumed locally and exported, others have fertile land used to grow food for local markets and copra for export, while others have potential for tourism based on their natural beauty and accessibility. Historically, location based resource pressures have driven internal migration. Most notably, the Malaitans were driven from their resource and investment poor province to migrate to Guadalcanal, ultimately 
underpinning the economic, political and cultural tensions that erupted into violent conflict in 1999 (Pollard, 2005). Much development investment has focussed on Honiara, with few formal employment opportunities outside of the capital, driving urban migration (Dinnen, 2002).

The distinct challenges the Solomon Islands faces in reducing poverty, arising from their geographical remoteness, small population and political unrest, are recognised by the international community, and have been responded to with development assistance investment. Aid is considered to have a "central and long-term role" in the Solomon Islands to maintain peace and security, and strengthen public administration and boost social development (World Bank, 2010, p. ii)

This economic representation of the Solomon Islands clearly categorises it as underdeveloped by global standards. Yet this understanding relies on a narrow view of economy, a capitalocentric view that counts certain activities, those contributing to GDP, and invisibilises others. This research takes a more holistic view of economy that gives credibility and value to all the activities that actually support livelihoods on a daily basis (Gibson-Graham, 2005). The significance of aid also warrants exploration, as to the role global indicators and donors play in shaping education policy in the Solomon Islands.

\section{Colonialism, conflict and RAMSI}

The colonial history and cultural diversity of the Solomon Islands played a key part in the conflict of 1999-2003, the emergence of which is discussed below. The subsequent Regional Assistance Mission Intervention (RAMSI) to restore law and order over the past decade has shaped much of public administration and economic policy that exists today.

Contact with Europeans began in the 1870s with slave traders 'blackbirding' Solomon Islanders as indentured labourers for Queensland and Pacific plantations (Pollard, 2005). This practice of exploiting cheap labour, through labour migration, continued during the period of British Colonisation from 1893 until independence in 1978, though in a less oppressive form. Largely, labourers from Malaita were bought over to work, on the plantations on the island of Guadalcanal, home to the country's capital. Unequal investment and wealth distribution between geographic and ethnic groups, played on the already heterogeneous cultural makeup of the Solomon Islands (M. G. Allen, 2012). The 80 different language groups are "disparate communities" with a close kinship systems of loyalty and history of ethnic tension 
(Dinnen, 2002, p. 285). Despite being the most populated part of the Solomon Islands, Malaita received little development investment. The shallow soil and heavy rainfall, unfamiliar to European farmers, were deemed unsuitable for major agricultural development (Gegeo \& Watson-Gegeo, 2002).

Post-independence, the previous under-investment and population resource pressure in Malaita ensured the practice of migration to Guadalcanal for economic opportunity continued (Pollard, 2005). By the 1990s there were numerous large Malaitan settlements on Guadalcanal and growing tensions between migrant Malaitans and the local people of Guadalcanal who felt they were not benefitting fairly from the economic opportunities around them. This, combined with land disagreements and cultural differences, boiled over into violent conflict in 1999 when thousands of Malaitan settlers were driven out by armed militia groups (Pollard, 2005).

By 2003 the Solomon Islands was on the brink of becoming a failed state. There was open violence, corruption and no functional system of law and order to restore control. The economy had collapsed, and debt repayments were unable to be met. Government institutions largely ceased to function, halting the delivery of basic services such as health and education (RAMSI, 2013). The RAMSI intervention arrived in 2003 on invitation from the Prime Minister. RAMSI, as the name implies, was a regional response, comprising 15 countries under the oversight of the Pacific Islands Forum. Spearheaded by Australia and New Zealand, the initial goals of RAMSI involved the restoration of law and order, stabilising the government finances, and restoring basic services. With the violent aspects of the conflict quickly quelled, the focus soon moved to capacity building in the area of law and justice governance, and the promotion of economic recovery (RAMSI, 2013).

A decade on, RAMSI recently (as of mid 2013) withdrew to a regional policing role. The intervention was widely viewed as a success, with free and fair democratic elections held in 2010, a balanced budget achieved, and the police force considerably strengthened (RAMSI, 2013). However, under the dominant influence of Australia and New Zealand, the state building activities of RAMSI left their stamp on the economic architecture and policy of the nation, as will be explored Chapter 7 
The violent clashes that took place over 1999-2003, are often portrayed as ethnically based. However, they were also fuelled by the colonial legacy of unequal resource, governance, and power distribution (Dinnen, 2002). Hence, some have come to view the conflict as the result of the unravelling of Colonial rule rather than the collapse of a functioning state (Pollard, 2005). While the development challenges of the post-conflict period largely mirror those of the pre-conflict period, that is difficulty in accessing core human services, poor education and employment opportunities in rural areas, the conflict further disrupted and intensified these issues (Pollard, 2005).

\section{Education in the Solomon Islands}

\section{Formal education}

Formal western-style education was introduced to the Solomon Islands by Christian missionaries in the 1900 s as a means of proselytisation and remained church administered until independence in 1978 (Pollard, 2005). Historically it has been a system of elitism, with less than $5 \%$ of the population completing primary school by independence (Whalan, 2010). Following independence, the government took over management of the school system and education was encouraged as a pathway to formal employment, from a rural to urban life. This discourse of a guaranteed job after completing secondary education plagued efforts to offer vocational education in rural areas; it being viewed as an inferior alternative (Pollard, 2005). With primary enrolment rates rising to $70 \%$ by the 1990 s, the rapid expansion of primary schools created unmet demand at the secondary level and exceeded the capacity of government to administer (Whalan, 2010). To meet the rising demand community based forms of education were introduced, particularly Community Based High Schools teaching the lower years of secondary education. Consequently, "unplanned growth and expansion of schools has created a disjointed and complex system characterised by an unnecessarily large volume of schools and poorly linked administrative and management structures" (Pollard, 2005, p. 160)

In the tertiary sector, most higher education was sought overseas through an unhealthy system of scholarships (Close, 2012). As of 2012 the Solomon Islands College of Higher Education was upgraded to become the nation's first university, the Solomon Islands National University, which will hopefully curb the culture and expenditure on international scholarships (Solomon Islands National University, 2014). 
The education system in the Solomon Islands has continually been plagued by a number of issues above and beyond the disruption caused by the conflict. Rapid growth at the primary and secondary level has surpassed the governments ability to fund teacher's salaries, training, maintenance and infrastructure (Whalan, 2010). Hence, the education sector has received high levels of donor support from the EU, Australian Aid, New Zealand Aid, UNICEF and UNESCO. Donors have largely harmonised funding and reporting, taking a sector-wide approach aligned to the National Education Strategic Framework 2007-2015 and MDGs (UNDP, 2010). Issues of quality and consistency of standards remain, with many who leave school still unable to read or write, an issue explored further in Text box 2.1 below (WYG International, 2012). Finally, the burgeoning youth population combined with limited formal employment opportunities has resulted in a system that still caters for the elite, limiting places through a number of assessment based bottle necks and language barriers that see students pushed out at various stages. This means many do not make it into secondary school (forms 1-7), and those who do are further filtered out at subsequent stages (WYG International, 2012).

\section{Text box 2.1: Literacy and numeracy challenges}

Less than $40 \%$ of those who finish primary school have satisfactory literacy and numeracy, and community rates of functional literacy are estimated to be around $17 \%$ (Close, 2012). While this may appear to reflect a shockingly poor standard of education, beneath the surface the situation is more complex. The statistics above are based on levels of English literacy. English, and even Pijin are often a second or third language for students and teachers alike. Although English is the national language of instruction, in reality it is not the language of the classroom. Teachers themselves have insufficient English to pass on to students (Close, 2012). This raises a fundamental question - is the right measure being used? If the language of the people is Pijin or a local tongue, is it accurate to label them as illiterate for not communicating in English? In a similar fashion to 'poverty' in the MDGs, the indicator has come to narrowly define the concept (Saith, 2006). Such an understanding of literacy paints a picture of failure and ignorance, disregarding the importance of local languages and the strength of an oral based culture. Rather than measure literacy in a predefined way influenced by global targets, a broader view of development might acknowledge the bi or trilingual ability of most people. 
The dominance of formal western education in the Solomon Islands, propagated by colonial attitudes and more recently by the powerful global education agenda, has largely overlooked issues of context. Western education chiefly prepares young people for livelihoods within the formal economy and urban environments. In the Solomon Islands, where $85 \%$ of the population reside rurally and rely on subsistence or informal means, relevance is questionable (Coxon \& Munce, 2008). This research takes a more expansive view of education, beyond the western and formalised, to consider the relevance of alternative pathways and indigenous knowledge to the future of young people (Gegeo, 1998)

\section{Rural Training Centres}

Rural Training Centres (RTCs) offer a second chance for the majority of Solomon Island youth who do not complete secondary school. The vocationally based 'learn by doing' curriculum provides a skills bridge to formal employment and a pathway to gain practical/financial skills to optimise self employment or informal opportunities within the local community (WYG International, 2012). The existing network of 45 RTCs has a wide geographical spread, covering all provinces, in both urban and rural areas (SIAVRTCs, 2014a). The Solomon Islands Association of Vocational Rural Training Centres (SIAVRTCS) is the umbrella organisation, owned by its members, responsible for coordinated liaison with government and donors, advocacy and reporting. The centres were initiated by local churches in response to the need for youth to gain practical skills to support their lives in rural communities and continue to be run independently by a variety of church groups (SIAVRTCs, 2014b). While not part of the formal education system, RTCs have been able to secure some government funding; since 2004 teacher's salaries are paid and an annual per student grant issued (Interview with representative of SIAVRTCs, Honiara, 27/03/14).

High-level analysis of RTCs has revealed major capacity issues. The quality of training varies from centre to centre with many teachers lacking industry experience and/or knowledge of pedagogy. There are no common teaching or learning standards across the network and poorly equipped facilities limit the delivery of practical training (WYG International, 2012). With an overall ability to only accommodate $10 \%$ of youth, girls are at a greater disadvantage. Administrative and management capacity has been deemed low and coordination amongst the independent church authorities is challenging given the geographical spread (WYG International, 2012). 
This research brings together a diverse view of economy and an expansive understanding of education to discuss the relevance of RTCs to their local communities. Through the two community-RTC case study sites, Gizo and Vatu, the varied economic practices of local economies, aspirations of youth and community perceptions of RTCs will inform the question of relevance. The capacity issues cited above also considered, in their context of adherence to universal targets and global standards.

\section{Women's education}

The Solomon Islands performs poorly on gender equality indicators with women and girls experiencing disadvantage in education, employment and social status. Disparities emerge post primary school, with fewer females enrolled in secondary and tertiary education. This is reportedly the result of limited female dorm facilities, attitudes that place women's education as a lower priority and limitations on course entry (World Bank, 2013). In employment, the labour participation of women is $10-20 \%$ lower than that of men, comprising a third of the workforce nationally. Women earn less than their male counterparts and are far less likely to hold senior positions (World Bank, 2013). Violence against women is alarmingly high with $64 \%$ of women experiencing physical abuse in their lifetime, and 37\% experiencing sexual abuse before the age of 15 (World Bank, 2013). The importance of gender equality is being recognised, at least at a policy level, with goals to increase the number of women in leadership and in parliamentary representation, better incorporate women's groups into the policy process, and introduce policies to curtail violence against women (Solomon Islands Government \& RAMSI, 2011).

Women and girls comprise less than $25 \%$ of RTC students, typically enrolled in Agriculture and Life Skills (cooking, sewing and nutrition) courses. This fits with cultural roles traditionally held by women, and wider gender norms in technical training. The lower number of female enrolments at RTCS has been attributed to fewer available training places, lower value and investment by families in female is education, and females being obligated to stay close to home to meet family responsibilities and perform domestic work (WYG International, 2012). However, the education of women and promotion of earning potential, is widely beneficial with income earned by women more likely to be spent on essential household items and benefit families as a whole. In rural areas the generation of income through informal livelihoods is critical to women with "investing in women's livelihoods and improving financial literacy are most likely to impact positively on families and children, 
therefore generic financial programmes should be implemented specifically aimed at women" (WYG International, 2012).

Many of the activities of women, such as raising a family and managing a household, are viewed as non-economic, and consequently given a lower value than those that generate income. Development is often guilty of trying to integrate women into the formal economy, rather than acknowledging their present contribution (Midgley, 2006). This research explores the livelihoods of women, giving credibility to their activities, and considering the relevance of RTCs to their current and desired livelihoods. It also seeks to understand in greater depth the pressures and barriers women face to education, particularly RTC education, and explore new opportunities for women to participate in RTC education based on a broader understanding of development practice.

\section{Conclusion}

This chapter has outlined the global and local context of the Solomon Islands, giving the broader milieu of the economy, education system and development situation in which this research takes place. In particular, it has explored these in relation to the primary research participants, young people and women.

The Solomon Islands shares the challenges of many developing countries trying to integrate with a global economy that is not tipped in their favour and cope with an expanding youth population. Additionally the small size, remote location and dispersed geography of the Solomon Islands make the transition from education to economic independence particularly hard for young people. The formal education system is failing to produce the promised employment outcomes for youth or live up to international standards. RTCs, positioned outside the formal system are attempting to respond these challenges, by providing an alternative pathway to local livelihoods.

This research uses a postdevelopment lens to critique the dominant view of economy, education and development underlying this widespread and disempowering picture of the Solomon Islands. It seeks to expose what has been marginalised by dominant discourses in order to recognise existing assets and abilities in these communities, and that more than barriers can constitute the basis for diverse development pathways. As a result, the future for youth and for women can be read in a different light, opening discussion for new opportunities and a chance to do development differently (Gibson-Graham, 2005). 


\section{Chapter 3: Methodology}

\section{Introduction}

This chapter explains how the purpose of this research, to examine the relevance of Rural Training Centres to Solomon Island communities, was implemented in practice. It is structured innovatively to provide the reader with the relevant details of method, research design, analysis and ethical considerations, punctuated by actual examples of how this theory shaped and constrained what I did in the field. Writing in this way highlights the ethnographic and participatory methodology underpinning this research.

The length and depth of this chapter reflects the value placed on the research process, particularly that it be empowering for the participants and contribute to development practice. A significant section of this chapter is dedicated to the tensions and benefits of conducting research that bridges theory and practice, by working in partnership with an NGO and contributing to the design of a real development project.

\section{Conceptual framework}

The inspiration for this research grew out of the observations I made during a trip to rural Nepal in 2012, the story of which is told in the Prologue. I observed education, in particular formal western education being exalted as the panacea to a better future, in stark contrast the mismatch of such education with the livelihood reality of the rural people. Only later did I understand this to be an outcome of a 'discourse of power'. This discourse equates western society, and consequently western education, with notions of progress, development and prosperity that denigrate other options (S Hall, 2002). The seeds were sown for a conceptual framework in this research that questions the bigger picture of global power relations capable of producing such a contradicting reality. Accordingly, this research takes a critical understanding of the world, concerned with power relations, domination and constraint, whilst simultaneously seeking to engender change. Critical geography promotes an awareness and interrogation of power structures (Best, 2009). This is evident in the selection of postdevelopment used to analyse this research, questioning the dominant development discourse and global economic system in silencing and omitting alternative ways of living and knowing (Santos, 2004). Critical geography also scrutinises the role of scientific research as a part of dominating power structures, prompting reflection on the 
research process itself. This frames the research reflexively, and acknowledges the situated nature of knowledge production (Best, 2009).

\section{Post-structuralism and social change}

Post structuralism views knowledge and the processes by which knowledge is created as socially constructed, particularly through the vehicle of language (Woodward, Dixon, \& Jones III, 2009). Language sets out a system of representation, conjuring up images and ideas that reinforce hegemonic discourses and become an unquestioned reality. Language often creates and maintains binaries, by representing something as 'is', such as 'developed' an opposite is created rendering all that 'is not' as 'undeveloped' (S Hall, 2002). The 'other is excluded through this binary (Woodward et al., 2009). Consequently, "development discourse defines and leads more than half of humanity to perceive themselves as underdeveloped" (Agostino, 2008, p. 228). Post-structuralism aims to deconstruct and such discourses and question the power relations embedded and reinforced through their use. The choice of such an epistemology is made in an attempt to challenge the 'claims of truth' around western education and capitalist economic thinking and that have been normalised by the dominant development discourse (Kitchin \& Tate, 2000). Rather, this research seeks to recognise alternative meanings and discourses, giving credibility to diverse understandings and pathways of development. In doing so it brings attention to the 'other' that was previously represented as inferior, omitted or excluded (Santos, 2004).

No object or practice exists outside a system of representation, therefore there is no way of knowing that is objective or truthful; all knowledge is mediated in some way (Woodward et al., 2009). Rather than seek objective truth, a post-structuralist epistemology embraces a plurality of 'truths' and the relativism of such truths (Kitchin \& Tate, 2000). Young people and women were selected as the focus for this research as groups whose views are traditionally marginalised in the development arena, under the premise that "no-one's voice should be excluded from the dialogue" (Kitchin \& Tate, 2000, p. 16). Going beyond critique, by the "uncovering of non explicit processes and relations", this research aims to "promote progressive social change" for example uncovering the rich and diverse economies that support livelihoods (Murray \& Overton, 2003, p. 21). The related concepts in critical geography of positionality, power, and representation are also reflected in the tone and content of this chapter (Merriam et al., 2001) 


\section{A qualitative approach}

A qualitative approach was used in this research, consistent with the central aim to describe, explore and understand human experience within the natural setting of rural Solomon Island communities (Stewart-Withers, Banks, McGregor, \& Meo-Sewabu, 2014). Any declaration of a qualitative approach is typically followed by a defence of its legitimacy and explanation of how it will still be scientifically rigorous. The post-structuralist epistemology underpinning this research casts doubt upon the validity of such arguments, questioning concepts of objectivity and subjectivity, thus placing this research as contextual and constructed rather than a statement of fact (Woodward et al., 2009). The benefit of a qualitative approach in this research is the generation of rich detail about the context in which these communities sit and activities that support peoples livelihoods. It has allowed the exploration of the complex topics, such as peoples perceptions of education and livelihood opportunities, according to their own values and meaning. This has enabled practical insights to be drawn on the relevance of RTCs to the future of these communities. Is this way, qualitative research can be illuminating and inductively add new knowledge to bodies of theory rather than deductively test a hypothesis (Stewart-Withers et al., 2014).

Qualitative research is also concerned with understanding social structures and how they shape experience (Winchester \& Rofe, 2010). These multiple layers are a key part of this research. The perceptions of the individual are considered within their community context and within the wider social structures of government and donors at a policy level in reference to the way in which these creates or constrain what happens. Reflexivity, involving self-critical examination at all phases of the research, is central to ethical conduct of qualitative research and is reflected in the ethical considerations and examples illustrated later in this chapter (Dowling, 2010).

\section{Ethnography and participation}

An ethnographic and participatory methodology was chosen for this research in alignment with the central aim to gain a rich and deep understanding of the communities in an empowering way. Ethnography differs from the conventional scientific approach of seeking to measure variables, by taking a localised and holistic view that requires in-depth observation in the field in order to be understood. This gives the research both theoretical and practical importance (Crang \& Cook, 2007). This approach pursues an understanding of 
the world as it is experienced by the participants themselves, in their community and cultural context (Crang \& Cook, 2007).

I used the ethnographic method of immersion, living with the research communities in a way that allowed me to participate in daily activities, then reflecting on the conversations and observations that ensued (O'Leary, 2010). Ethnography requires cultural empathy and build trusting relationships to appreciate the world as it is seen from the participants view point (Kitchin \& Tate, 2000). This enables the research to not just understand what is, but gain insights into why it is that way (O'Leary, 2010). The methods used in this research combined observation with interviews and participatory focus groups to gain this deeper understanding of livelihoods, perceptions and community practices underlying the research questions. Ethnography partners well with a participatory approach, as it acknowledges the inter-subjective nature of research, whereby knowledge is constructed between the researcher and participants rather than being an external entity that can to be obtained (Crang \& Cook, 2007). An example of the interrelationship between the researcher and the research community is given in Textbox 3.1, over page.

A participatory methodology aligns to the critical and post-structural conceptual framework of this research through its appreciation of power relationships and the impact that dominant western concepts of knowledge can have in undervaluing local knowledge and capabilities. The three main components of a participatory methodology, facilitator behaviour, sharing without boundaries and tangible methods with groups were enacted in this research (Chambers, 2007). I attempted to treat participants as experts on their community, for example by placing them in charge of where we went on observational transect walks, and asking them to explain what we saw from their own perspective. Interviews were semi structured to allow participants to direct the conversation into a broad range of topics and share without boundaries. The focus groups conducted with young people utilised visual and tangible methods such as voting, drawing and brainstorming to hand the group process over to the participants themselves, and help navigate language barriers.

Key to a participatory methodology is the concept of empowerment, focussing on bottom up rather than top down processes of constructing knowledge and prioritising community driven outcomes (Stewart-Withers et al., 2014). Whilst I cannot claim to have embraced such 
an approach to the degree of relinquishing all power and control in the research process, a commitment to community empowerment influenced the design of research questions, implementation and facilitation techniques and the representation of the results of this research, as is discussed more fully later in this section.

Text box 3.1: Running with Father Matthew and debunking 'myths' in the research process

Traditional sciences aim for objectivity in research, or at least a veneer of objectivity. In contrast, Social Sciences deal with the complexity of conducting research on society, where the researched and the researcher are subjective beings laden with a world view and social context (O'Leary, 2010). Living ethnographically with the community in which the research takes place means one cannot just objectively extract information from the community, without sharing ones own self, thoughts and feelings in the process. During the research period I used my awareness of how the community in which I was immersed was itself immersed in wider social, geopolitical and economic communities to deconstruct myths about western society as the ideal to which all societies should aspire (Crang \& Cook, 2007). Through conversations with community members, I openly shared about the problems faced in the developed world and the pitfalls of society steeped in capitalocentric economic thinking and the pursuit of the dominant development discourse (Cameron \& Gibson-Graham, 2007). These opportunities emerged in various ways. For example when going for a run with a local church priest, the conversation settled on questions of if life was better in New Zealand and why. In turn, I responded that life was different but arguably not better; many of the valuable attributes of society having been sacrificed to capitalist productivity and consumerism. On a different occasion, at the conclusion of the research, I was asked to speak an encouraging message to the teaching staff of the RTC. Mindful of the staff themselves being the experts on RTC teaching, I shared about the global issues of unemployment and education faced by youth, often in developed countries, giving the message that west did not have it all figured out. During these periods of sharing I was revealing my own subjective biases that have influenced this research, while taking steps to manage these subjectivities so as not to muddy the waters of rigor by restricting such conversations to non research participants, or waiting until after data collection was complete (O'Leary, 2010). Walking this line was a reflexive process of constantly questioning the boundaries of research, when one is and is not researching and need not be in 'research mode'. 


\section{Empowerment in the research process}

A participatory approach aims to transform the power dynamic between the researcher and researched by empowering communities to analyse and interpret their own context, thereby unveiling other epistemologies (Chambers, 2007). Participatory methods are noted for prioritising community empowerment over information obtained (Stewart-Withers et al., 2014). Like many researchers in the field of development, this research was conducted precisely because the researcher wished to take action to progress issues of inequality and injustice (Crang \& Cook, 2007). The way in which I conducted the research was designed to be an empowering process, rather than just as a potential outcome of findings.

Language is an important component of constructing knowledge. Consequently the way in which the phrasing of questions determines the discoveries made. While a full Appreciative Inquiry model espoused by Reed (2007) was not adopted, research questions were designed and phrased to focus on what supports life in the community and foster potential rather than centring around problems and deficit. Interviews and focus groups began with a discussion of strengths and opportunities, using questions such as:

What do you like about living in this place?

What are the good things about this RTC?

What are the opportunities for young people in this place?

The aim was to bring these to the surface and shape the subsequent conversation.

The research was also influenced by Gibson-Graham's (2005) work on 'Community assets maps'. These, as opposed to needs naps traditionally used in participatory development, focus on the strengths and resources held by communities rather than the problems they face, thus opening the door for conversations about new possibilities. The assets map model was used and is shown in the findings of this research. Conducting research in this way invited the opportunity for social transformation in participants to be an impact of the research process itself, through the realisation of potential and possibilities, regardless of the results taken away by the researcher (Reed, 2007).

The Dreaming Exercise, used in the participatory focus group with young people was the most explicit method used to try and make the research process empowering. Participants were asked to draw what they would like their life to look like in five years time, or as proved e easier to communicate 'their dream for the future'. This became a powerful exercise for 
engaging shy and quiet young people in a reflection about their own goals and aspirations for the future. Participants often shared personal goals about family, work and who they wanted to be with the group. As a facilitator I considered the risk that the exercise would create unmet expectations, but found the drawings to be grounded in the livelihood realities of the community with occasional far-reaching ambitions. Where possible I followed the exercise with a discussion of what steps were needed to connect them to this future. However, the need for complex English created a barrier in such verbal discussions, an issue discussed in the section Navigating language and literacy on page 30. While one cannot know the true impact on participants, their reflective manner and the enabling nature of the exercise seemed empowering in and of itself.

However, in my aspiration to foster empowerment, I am also aware that I am perhaps guilty of the narcissism Kapoor (2005) acknowledges regarding participatory development; giving the veneer of empowerment through a 'feel good' community experience whilst secretly taking pride in being the conduit of the empowerment.

\section{From 'Missus' to 'Aunty': Positionality inside or out?}

In ethnographic research the inter-subjective relationship and power dynamics of the research process are acknowledged. A discussion of positionality challenges the assumptions made about the access, power relationships and commonality the researcher has with research participants (Merriam et al., 2001). It is a reflexive process that keeps the researcher aware of the various influences on the data they are capturing (or not capturing) and how relationship to the research subject shapes the research process (England, 1994). Positionality explores this notion of where one stands in relation to the 'other', with reference to dimensions such as gender, class, education, age and culture (Merriam et al., 2001). Rather than being fixed, positionality is conceptualised as fluid, continually negotiated in relation to the context (Sultana, 2007).

During my time in the Solomon Islands I held multiple positionalities in relation to multiple others. In the initial period, as part of the multi-organisational design team for the NGO project, I was the only female in the five-person team, the youngest and the only student. This positionality within the team resulted in certain treatment, such as being the only person accompanied to the ATM for safety reasons and being treated as an observer rather than full participant in meetings. Despite being in a country and context where my 
colleagues were those with whom I was supposed to share the most in common, I felt an outsider as I did not represent an organisation or field of expertise. However, as Merriam et al. (2001) notes, there can be advantages to being an outsider, just as there can be disadvantages to being an insider. My positionality in contrast to my middle-aged male team mates gave me greater access to the community, particularly to the women. My position as a women and a non-expert was seen to give me a status that would be less threatening, encouraging people to open up to me, form deeper connections and enable me to discuss topics with women that may not be possible for a man. I found myself playing off these different aspects of my positionality as the research unfolded (Crang \& Cook, 2007). I used my commonalities to build rapport, and my outsider status and the power afforded under my relationship to the development project to gain help in organising and accessing participants (Sultana, 2007). Once the design team departed I was left without this contrast; the outsider dimensions of my positionality were more obvious, my white skin, affluence, education and language. Yet, as Merriam et al. (2001) reflects, positionality is not linear, lying on an insider/outsider spectrum. There are multiple dimensions where by one can be an insider an outsider simultaneously, and positionality moves as both a function of that dimension and the weight that dimension carries at any particular time.

To illustrate, I will discuss an example of my positionality changing with reference to the participants as my relationship with them deepened. I entered the second, rural research location alone, staying above the women's dormitory at the RTC. Some of my first actions at the centre were to connect with the young women who lived below, taking the opportunity to harvest cocoa together. Through the hours we sat, cracking cocoa pods and making small talk I noticed that they called me 'Missus', a term with colonial undertones. I asked them why they called me this. They replied that I was different because of my white skin and that it is a title of respect. I responded by saying that I did not want to be 'Missus', yes my skin is white, but inside I am the same. Over the coming days the young women invited themselves up to my residence frequently, where they sat and watched me cook, chatted in their limited English and my limited Pijin. In the evenings, I participated in their social activities teaching sharing games and dances together. After a few days the young women began to call me 'Aunty', a term used locally by to address a women who is older than you. Through my genuine participation and interest in their daily lives I transitioned from 'Missus' to 'Aunty'. My new position had been dialogically constructed between the young women and myself (England, 1994). 


\section{Research design}

A case study design was chosen for this research to enable in-depth exploration of the nuances and contextual influences in each location (Baxter, 2010). The two case study sites, Gizo and Vatu, each comprised a RTC and surrounding communities. The country's sole RTC teacher training institute, Vanga Teacher Training College was also included at the request of the NGO. While it does not form part of the central focus of the research, information gathered proved important to the wider context of the research, particularly the funding and policy discussions in Chapter 7. Table 3.1 below shows the location, size and nature of the case study sites:

Table 3.1: Research locations

\begin{tabular}{|c|c|c|c|c|}
\hline Name & Location & Demographic & RTC size & Community size \\
\hline $\begin{array}{l}\text { St Peter's Rural } \\
\text { Training Centre }\end{array}$ & $\begin{array}{l}\text { Gizo, } \\
\text { province }\end{array}$ & Semi-Urban & $\begin{array}{l}59 \text { students } \\
6 \text { teachers } \\
\text { (plus } 3 \text { assistant } \\
\text { teachers) }\end{array}$ & $5000-7000^{1}$ \\
\hline $\begin{array}{l}\text { Vatu Rural } \\
\text { Training Centre }\end{array}$ & $\begin{array}{l}\text { Northeast } \\
\text { Guadalcanal }\end{array}$ & Rural & $\begin{array}{l}34 \text { students } \\
7 \text { teachers }\end{array}$ & $\begin{array}{l}\text { Surrounding } \\
\text { villages of } 50-100 \\
\text { people }\end{array}$ \\
\hline $\begin{array}{l}\text { Vanga Teacher } \\
\text { Training College }\end{array}$ & $\begin{array}{l}\text { Kolombangara, } \\
\text { Western Province }\end{array}$ & Rural & $\begin{array}{l}40 \text { students } \\
5 \text { teachers }\end{array}$ & N/A \\
\hline
\end{tabular}

The case study sites were selected from a subset of eight involved in the NGO project on the basis of their ability to encompass different geographical locations, population densities and expand beyond the scope of previous research that has primarily focussed on Honiara. The locations were also chosen for practical reasons such as the availability of accommodation, safety of conducing research as a solo female and willingness of the RTC to participate. It is important to acknowledge that the RTCs in this study were in no way randomly selected. They had already been assessed as well functioning in order to participate in the NGO project. Hence, the results of this research cannot be seen to represent a picture of all RTCS in the Solomon Islands.

Case studies have been criticised for their lack of generalizability. To mitigate this, multiple sites and multiple participant groups were incorporated, allowing for spatial and group

\footnotetext{
${ }^{1}$ Exact population figures were not available, this is an estimate based on various sources including local NGOs, lonely planet and conversations with local people.
} 
comparison. Through a mixture of rich detail and cross comparison, result can speak to a broader picture of understanding and have potential for transferability to other sites (Baxter, 2010). The semi-urban vs rural design of this study proved critical in revealing the hidden assumptions, and providing contrast. For example the assumption made in Gizo that the ocean was a key source of food and livelihoods for communities on the coast, was dispelled in Vatu, where although coastal, livelihoods depended on the land.

\section{Timing: research during a natural disaster}

The research took place over a four-week period in March-April 2014, to coincide with the design phase of the NGO project. Climatically, it was the end of the wet season and for the most part the weather was fine and stable, a key consideration when visiting rural areas. However, this research was very nearly aborted midway with the advent of a natural disaster.

The trip to the rurally located Vatu RTC involved five hours on a local truck (4WD) and three river crossings. Shortly after my arrival it began to rain. The heavy tropical rain fell continuously for five days. A seemingly unbelievable amount was absorbed by the sandy soil and vegetation, but after the third day the water began to rise. I found the RTC staff, who had previously expressed a nonchalant attitude towards the weather, digging trenches to save their flooded kitchens and the gardens, and promptly joined in. As we worked in vain up to our thighs in water and mud, with nowhere for the water to drain on the flat coastal plains our isolation in this potentially disastrous situation became apparent. Road access was now cut off by the flooded rivers and sea access compromised by floating debris. With no phone or internet reception in the area, the shortwave radio became the sole source of information. However, being solar dependent we could only listen for short periods and were unable to transmit outgoing messages. Whilst listening, I heard the prime minister declare a State of National Disaster, with extensive flooding across the region, loss of property and lives. The scariest moment came that evening when an earthquake struck in the middle of the night. As the bed shook, and I wondered if I was dreaming, concern about the impact of a tsunami on our low-lying position a few hundred metres from the ocean entered my mind. Our vulnerability and isolation hit home as I realised that if such an event did take place there would be no warning and very little we could do. The research location from which I had just come, Gizo, was devastated by a Tsunami in 2007. 
Fortunately the rain cleared before flooding became extensive. Later I discovered that we were actually in a much better position than those in urban Honiara where flooded rivers swept away houses and lives. Apart from causing worry amongst my family and nearly missing my flight, the worst effect of these events for me was a reduced time-period in which I could conduct research with the surrounding communities. The flooded rivers and poor weather made moving beyond the RTC premises impossible for four of the six days. This limited the number of the community interviews and extent of observational information I could collect from outside of the RTC, however it did not significantly hamper the results. Remarkably, my actual experience within the RTC community during the disaster was one of bonding, relationship building and growing understanding. I was left with a stark impression of the vulnerability of rural communities, particularly in the face of the climate change. This was contrasted with the calmness and acceptance the community displayed towards the events, and capable way they managed under their own self-reliance.

\section{Methods}

Three main methods, observation, interviews and participatory focus groups, were employed in this research. Drawing from ethnographic and participatory methodologies, reflects the eclectic pluralism that often signifies contemporary research (Chambers, 2007). The use of participatory methods also reflect the intention of this research to be grounded in development practice, as these are widely accepted in the development landscape (Chambers, 2007).

\section{Observation}

Observation typically refers to a process of immersion where by the researcher lives/works amongst the community in order to understand the way of life from a participants perspective (Kitchin \& Tate, 2000). Wogan (2004) encapsulates this nicely in the phrase "deep hanging out" (cited in Crang \& Cook, 2007, p.37). Living in the Catholic Church compound (Gizo) and in the RTC compound (Vatu) enabled me to engage in everyday activities and have informal conversations with community members where they explained what was happening from their world view (Crang \& Cook, 2007). More formal modes of observation were also utilised including, transect walks and a stock take of businesses in the area. Observational notes were collected in a field diary, and revised as persistent observation deepened my understanding beyond a superficial level (O'Leary, 2010). 
Additionally, non-community based observation of development policy and processes was performed. The first six days of the research period was spent with the multi-organisational NGO design team attending meetings with representatives of government, donors and civil society organisations. The multi-disciplinary make up of the team resulted in discussion of a a wide range of topics, such as curriculum, funding, political leadership, literacy, the labour market and the issues faced in development implementation. This information has been treated sensitively and is not be attributed to individuals or organisations, in acknowledgement of the privileged position I held in these meetings and that my research, while declared, was not the focal point. Policy documentation that is not readily accessible, or would not have been otherwise known about was also gathered in this period. Together, these observations and documentation have enabled an additional layer of analysis to be added to this research, focussed on the impact of development policies, attitudes and practices on the Education sector, and consequently the operation of RTCs.

\section{Interviews}

While observation and informal conversations helped form an understanding of the context and frame interview questions, formal interviews enabled in-depth discussion of topics and personal experiences (Crang \& Cook, 2007). A semi structured style was employed to achieve a balance between ensuring important known topics were covered, whilst allowing exploration of unknown but important topics (Crang \& Cook, 2007). Interviews were conducted in locations chosen by the participant, such as their office, an eating place or a seat in the garden, facilitating a more relaxed environment reflective of the participant's context (O'Leary, 2010). All interviews were audio recorded to avoid disruption in the conversation, with the exception of one that took place unexpectedly, where contemporaneous notes were taken. Interviews ranged in length from ten minutes to an hour depending on the role of the participant and the number of relevant topics to be discussed. Appendix 2: Interview schedule provides an outline of questions used to guide discussion.

\section{Focus groups}

Before departing for the field I planned to lead participatory focus groups with young people and women, as a means of capturing data from a large number of participants more efficiently than with interviews (Bradley, 2004). On arrival, it became obvious that such 
groups would be simple to organise with young people around the existing group of RTC students. However, the constraints of complexity, busy lives and timeframes meant that arranging focus groups with existing groups of women was not feasible, and individual interviews were conducted instead (Stewart-Withers et al., 2014). Asking a young person to talk to a strange foreigner about their life can be intimidating. Focus groups have been criticised for potentially leaving some participants marginalised, however they were an effective means of lowing barriers to engagement with young people through peer support (O'Leary, 2010). Ice-breaker games were also used at the commencement of focus groups to create a non-threatening environment and build rapport.

Participatory techniques bring the advantage of being low technology, suitable for a rural setting, and incorporate visual elements to cater for different levels of literacy (StewartWithers et al., 2014). Participatory techniques used in focus groups included:

Answers on cards - participants wrote as many answers as they choose to a question on different cards, which were then categorised. This technique encourages all participants to contribute and enables a large amount of information to the gathered quickly (Bradley, 2004).

Group brainstorming - this involved the group calling out the answer to a question and the researcher writing the responses on a large sheet of paper visible to everyone.

Bridge model - a tool to help people identify where they are, where they want to be and the steps involved in getting there by establishing the starting point, endpoint and the bridge in between (Bradley, 2004).

Dreaming exercise - each individual was asked to draw a picture of what they would like their life to be like in the future ( 5 years) and explain their picture to the group. Voting - participants were given a tokens and asked to vote on a range of smiley faces, indicating their level of satisfaction.

Appendix 3: Focus group schedule provides a full outline of the activities and questions used to guide these interactions.

\section{Navigating language and literacy}

The focus group plans comprising all of the above techniques over five exercises were developed and tested in my home setting. Once in the field, the ambitious scope of so many 
exercises and dependency on high levels of literacy required revision. The first participatory focus group was conducted with student teachers, likely to be most literate and fluent in English of the groups. Under such a heavy agenda I found myself becoming instrumental, using participation as a means to accomplish my pre-defined goal of gathering data efficiently, rather than an 'end in itself (Nelson \& Wright, 1995). In addition, the participants were obviously struggling with the written exercises, having a lower level of literacy than my information had suggested. Communicating verbally in English also proved challenging making the complexity of the questions an issue and resulting in short superficial answers.

Accordingly, I dramatically simplified the plan for future groups, removing the written components, and focussing on the visually based dreaming exercise, with a small amount of brainstorming and voting. This eased the pressure on participants (and myself), and resulted in a more equal level of participation within the group. In response to the language barrier, I tried several times to engage an interpreter, but found the gatekeepers to be resistant to this concept, insisting that the young people could understand what I was saying and it was best if I conduct the group directly. It was difficult to communicate that it was not just the young peoples understanding I was concerned with, but mine. The language barrier limited their expression and therefore the quality of the discussion. In alignment with a participatory approach, which aims to hand control of the process over to the community, I relinquished these efforts and found other means to navigate the language barrier by learning more Pijin, translating the questions into Pijin, and encouraging the participants to express their answers in Pijin if they were limited by English (Chambers, 2007).

\section{Participants}

A total of 61 participants contributed to the research through 13 interviews and eight focus groups. In the first case study site, Gizo, seven interviews were conducted, while in the second site, Vatu, only four were possible due to the time restraints with the surrounding community caused by the flooding. Interview participants have been classified into three roles reflecting their primary association with the research topic. Table 3.2 gives a full breakdown of interviewees by role and location. The separation between 'RTC' and the 'community' is important for establishing an understanding of each independently to be able to discuss linkages and relevance between the two. Men and women in the community have been disaggregated, reflecting the aim of this research to capture a picture of women's livelihood activities and barriers/opportunities for women to engage with RTCs. Two further 
interviews took place outside of the case study sites, one at Vanga Teachers Training College, and one of an official in Honiara.

Table 3.2: Interviews by role and location

\begin{tabular}{|l|l|l|l|l|l|}
\hline $\begin{array}{l}\text { Location } \\
\text { Role }\end{array}$ & Gizo & Vatu & Vanga & Honiara & $\begin{array}{l}\text { Total } \\
\text { Interviews }\end{array}$ \\
\hline Community Man & 3 & 0 & N/A & N/A & 3 \\
\hline Community Women & 2 & 2 & N/A & N/A & 4 \\
\hline RTC administrators & 1 & 2 & 1 & N/A & 4 \\
\hline Young people & 1 & & & & 1 \\
\hline Officials & N/A & N/A & N/A & 1 & 1 \\
\hline \hline Total participants & 7 & 4 & 1 & 1 & 13 \\
\hline
\end{tabular}

Focus groups were conducted with at total of 48 young people aged between 16 and 25 years. The majority of groups (six of the eight) were made up of RTC students, with one group comprised of student teachers from Vanga Teacher Training College, and the other a mixed community group of young people in Gizo. The slight male majority amongst participants, $58 \%$, is representative of the higher proportion of males enrolled in RTCs. Tables 3.3 give a breakdown of the groups and participants by location and gender. For the purposes of the results, young people have been treated as a single group, as disaggregation was not seen as contributing any additional benefit.

Table 3.3: Focus groups by location

\begin{tabular}{|l|l|l|l|l|}
\hline $\begin{array}{l}\text { Location } \\
\text { Role }\end{array}$ & Gizo & Vatu & Vanga & Total groups \\
\hline Young people & $\begin{array}{l}* \\
*(7 \mathrm{M} 8 \mathrm{~F})\end{array}$ & $\begin{array}{l}4 \\
(20 \mathrm{M} 5 \mathrm{~F})\end{array}$ & $\begin{array}{l}1 \\
(1 \mathrm{M} 7 \mathrm{~F})\end{array}$ & $\mathbf{8}$ \\
\hline \hline Total participants & $\mathbf{1 5}$ & $\mathbf{2 5}$ & $\mathbf{8}$ & $\mathbf{4 8}(28 \mathrm{M} 20 \mathrm{~F})$ \\
\hline
\end{tabular}

* Denotes number of male and female

\section{Representation - who is the community?}

In recruiting participants to be part of the research, I was aware of issues of representation. Ethnography and participatory methods have been criticised for assuming homogeneity and consensus in communities, and thereby overlooking diversity and conflict. There is the added 
difficulty of placing boundaries around an area and calling it a 'community' (Berner \& Phillips, 2005; Crang \& Cook, 2007). Yet, practical decisions had to be made in each location to define who was the community. For example, in Gizo, did the community include the people who sold produce at the market but lived on other Islands? Which surrounding villages would be chosen as the community in Vatu? These decisions are in many ways arbitrary, as the concept of community is a construct and people can be part of multiple communities.

Additionally, communities themselves do not operate on an even power landscape. When interacting with development processes, such as this research, power relationships influence who gets to represent the community (Nelson \& Wright, 1995). The recruitment of my participants relied on existing power structures through gatekeepers, namely leaders of the RTC and affiliated church with whom the NGO had a relationship. I also found myself tending to recruit interviewees that I could communicate easily with in English, usually meaning they were privileged with a high level of education and employment, or were prominent community members perceived as able to speak on behalf of many. Consequently, while on the surface the participatory methodology I used was inclusive, seeking to involve marginalised groups of women and young people, power relations still resulted those in advantageous positions being favoured (Stewart-Withers et al., 2014). As England (1994) points out, being aware of power relationships does not take them away.

\section{Serving two masters - balancing organisational and academic expectations}

Postdevelopment literature has produced a large body of critique on development practice. While an important reflective exercise for the development sector, it has itself been reproached for offering criticism rather than alternatives to respond to issues of poverty and inequality (Matthews, 2008). The result is an "unintended widening of the gulf between the theories produced by Northern academics and the priorities of their Southern subjects" (Nagar \& Ali, 2003, p. 359). A commitment to conducting research that is grounded in realities of and makes a contribution to development practice deeply underpins this research. Attempting to bridge the gap between theory and practice involved a continued balance of academic and organisational expectations. I have highlighted some of the tensions this created, both advantageous and disadvantageous in this section. 
Organisations, particularly NGOs, operate on a landscape of efficiency, trying to achieve as much as they can, for as many as they can in the shortest time and for the lowest cost. While academic research takes a comprehensive and deep approach to narrow fields of focus.

In designing this research, I found myself negotiating between the two schools of thought around the scope, scale and timeframe of the research. The academic lens, with a participatory and ethnographic, approach argued for longer timeframes and fewer locations, while the organisational lens pushed for short efficient visits. The result was a compromise, taking the middle ground of the two perspectives to decide on four weeks and two locations. With the NGO partially funding the travel costs of the research, and formally writing the research into funding applications, there were also tensions around ownership and autonomy over the direction of the research as it evolved on the ground. I was not able to take the opportunities I saw to change the focus of the research in respect for the commitments I had made to the project. This resulted in discussions in the field around the differences between what was required for an academic thesis, and what would be valuable to the organisation. Through discussing, exploring and thrashing out these conceptual and practical issues, the research was enriched. I remained in touch with practical outcomes, avoiding the pitfall of much academic research to "complexify, theorise and debate problems that have been constituted by our disciplines...but produce knowledge that has little impact on real-world politics" (Messer-Davidow, 2002 cited in Nagar \& Ali, 2003, p. 357).

The NGO has commented on the immense value of our continued dialogue. It provided a forum to discuss the development issues in an informed manner outside of the organisation and brought a fresh perspective to the project. The completed report has provided some written outcomes of the research, however the dialogue has had the greatest impact on the design and approach to delivery of the project. For example, the research resulted in retaining the delivery of numeracy and budgeting training to the community when under pressure to remove this from the scope. This was based on the research finding that these skills were essential to women's livelihoods and could be used as an outreach tool for RTCS to promote female enrolment.

The benefits for both sides of a research-NGO partnership far outweighed the additional limitations and demands this placed on the research. The positive relationship the NGO held with the community provided an immediate connection of trust and facilitated access to 
participants. This enabled the research to be conducted in a shorter time frame than would have been possible without established relationships. It also gave legitimacy to the research in the community's eyes, providing a rationale for why it was taking place. Many organisations see research students as an additional drain on already stretched resources. Yet if done well, there are obvious benefits in time and cost savings for the organisation, which gains additional knowledge and information to inform their work. The relationship between the NGO and researcher is critical to a mutually successful outcome, and is not without risk. I was aware of risking my professional reputation through the expectations placed on the research by the NGO. At the same time, the NGO trusted me with their organisational reputation amongst their stakeholders. Without an understanding and appreciation of each other's position, such a process like this could easily turn sour. However, with a commitment to maintaining focus on common objectives, and resolving diversions in interest as they arise, both can learn a huge amount from the process. The results of this research have already contributed to the design of the project and formed a guide to implementation. Academically, this relationship has grounded the research in an appreciation of the real issues faced in development practice, and kept the research true to it's intention to go beyond critique the failings of development and explore new possibilities.

\section{Research integrity}

\section{Ethics}

In qualitative research greater emphasis is given to the reflexive approach required to manage the ethical issues that arise out interactions between the researcher, participants and existing social structures (Dowling, 2010). Crang and Cook (2007) refer to two kinds of ethics, those beginning with a capital ' $E$ ', addressing standard issues and satisfying ethics authorities, and those with a small ' $\mathrm{e}$ ' that consider power relationships and conduct in the field. On the formal level, ethics approval was gained from the Victoria University Human Ethics Committee (see Appendix 4: Human ethics approval) and conduct in the field bound by the Caritas Employee and Volunteer Code of Conduct. All participants were provided with an information sheet that included the purpose and use of the research, along with my and my supervisor's contact details (see Appendix 1: participant information sheet and consent form). In respect of the oral culture in the Solomon Islands, and limited literacy of participants, this information was explained verbally and consent sought orally, to ensure it was understood, rather than just agreed. (Ethical boundaries were also put in place to prevent the associated NGO from having access to raw data in order to avoid the unintended consequence of such data becoming the subject of Solomon Island and New Zealand 
government audit procedures, thereby compromising the confidentiality of participants. In the analysis of results, pseudonyms have been used and positions generalised to role to protect the identity of participants.

The close relationships built between the researcher and participants in ethnographic research introduce issues power that can influence research results and have implications for participants. While a participatory approach prides itself on equality between researcher and participants, the positionality of the researcher and external social structures mean this is rarely possible (Stewart-Withers et al., 2014). I entered the field with the institutional power of the University, and organisational power of the NGO project. (Scheyvens, Nowak, \& Scheyvens, 2003). This created an asymmetrical relationship of power that could easily lend itself to exploitation in the recruitment of participants, and create false expectations around the outcomes of the research. In the field, I had to carefully manage how the participants understood my identity and their expectations of the outcomes of my research. To do this I frequently declared my independence from the NGO. However, it is acknowledge that participants still may have felt unable to be critical given my association to the project and their vested interest. Managing this balance between independence and applicability crossculturally and cross-linguistically was not easy, and on several occasions I had to correct assumptions around expectations of the outcomes of my results. For example in asking about what skills women in the community would like to learn, I was not offering skills programs in these areas. Power dynamics cannot be removed from the research process, rather a reflexive manner and continually checking the understanding of the participants was used to modify my behaviour where required (Dowling, 2010).

\section{Reliability and validity}

Ethnographic research does not seek to separate subjective and objective, but rather concentrates on the development of "inter-subjective understandings between the researcher and the researched" (Crang \& Cook, 2007, p. 37). Similarly, the researcher is not considered objective, nor is the local culture and context seen as a pure substance that can be understood (Crang \& Cook, 2007). While this kind of research cannot be judged by the same positivist scientific criteria of many disciplines, a rigorous process is still required to ensure the research has credibility and authenticity (O'Leary, 2010). I attempted to implement such rigor using a number of different techniques. Firstly, the multiple methods of inquiry used, interviews, observation, and focus groups provided a form of triangulation. 
Although data could not be cross-referenced on every topic, themes grew in prominence as they were supported by multiple sources of data. For example, information gained in interviews on the livelihood opportunities in an area were verified by the types of business and informal livelihood activities observed. I utilised member checking extensively, testing my understanding of the picture I saw emerging in informal conversations with various community members, allowing them to critique or correct my knowledge (O'Leary, 2010). The sample size of this research reflects the ethnographic commitment to the quality rather than quantity of responses. Rather than seeking a representative sample from the community or RTC, an approach of theoretical sampling was used whereby the participants teach the researcher about the research problem from their perspective. In taking such an approach I have taken the positionality of the participant into consideration in the findings, rather than treating them as a pure representative of the communities' view (Crang \& Cook, 2007). Finally, critical reflexivity has been essential to managing dynamics of positionality, ethics and power discussed earlier in this chapter and forming the subjective and intersubjective knowledge emerging (Dowling, 2010). This thesis represents one story, of the many that could be told, but aims to draw on an authentic and critical foundation for that story to have integrity.

\section{Analysis}

Qualitative data is often unpacked through coding and discourse analysis, to establish themes and corresponding prominence (Crang \& Cook, 2007). This approach was considered and discarded as the best fit for this research given that some of the methods used were not all textually based (e.g. drawings, observations) and the multiple layers of social structures in play. A thematic approach was instead adopted. Three themes, below, were selected from Santos' (2004) work, on the basis of their resonance with the issues and concerns emerging from the data:

Monoculture of capitalist productivity and efficiency - focussed on economy

Monoculture of western scientific knowledge - focussed on education

Monoculture of the universal and the global-focussed on development policy and practice

Under this approach data moves between inductive and deductive reasoning, with knowledge of the data informing the selection of the themes, and the themes used as a lens to deductively view the data (O'Leary, 2010). Within these broad themes, more detailed analysis using specific frameworks, such as the Diverse Economies Framework of GibsonGraham (2005), have been used. Where possible the representation of the data is supported 
by transcribed sections of interviews and focus groups to frame the results from the perspective of the participants themselves.

\section{Research limitations}

Ethnography focuses on depth rather than breadth of participants. However, this research could have benefited from having a wider range of participants. Most of the youth involved were RTCs students. Expanding this to those not engaged in education, and those engaged in the formal school system would have provided valuable comparison and given the findings more representative weight. However, this competed with what was manageable in my timeframe.

The limitations caused by the language barrier have already been noted as a factor constraining the depth of responses from youth and having a selective effect on community interviewees. Given more time, the resistance of the RTCs to involve an interpreter could be navigated, or an alternative means found.

Finally, the availability of development documentation and statistical information on the Solomon Islands was both a limitation and a strength of this research. Little is available online or in the public arena, for example the Ministry of Education and Human Development (MEHRD) does not have a website. Consequently much of the documentation used came from individual connections or via the partner NGO.

\section{Re-presenting knowledge}

Giving voice to those often marginalised in the development process, young people and women, was a central aim of this research. Their voices and my observations form the research data. The process of attaching meaning to data necessarily involves interpretation. Hence, Social Science research acknowledges the presence of the researchers voice as part of the resulting dialogue (Clough \& Nutbrown, 2012). In presenting the information I used participant quotes as often as possible in an attempt to amplify their own voice. I also included participant drawings and images to augment the readers own interpretation and create a deeper sense of context and place. Yet, I acknowledge my role as an active producer of the findings, choosing which artefacts to include (and omit), rendering the surrounding context and selecting the theoretical framework. Rather than represent the findings, implying objectivity, I have re-presented them (Alldred, 1998). 
The process of writing involved being removed from the field, meaning decisions about interpretation and re-presentation were made without the participant engagement (Cupples \& Kindon, 2003). Given that most participants resided in rural areas of the Solomon Islands without email or phone access, there was little opportunity to maintain contact. I found listening to interview recordings, rather than just viewing the transcripts, an effective way to navigate this distance and reconnect with the participants. This enabled me to conjure up their image, mannerisms and elicit greater meaning from what was said. Away from the field it is easy to become absorbed by theoretical ideals of how the world should look. I found that regular meetings with the NGO to discuss my findings and the progress of the project were essential in keeping me grounded in the reality of development practice.

A thesis is a product created for consumption. Being aware of your potential consumers impacts the way in which information is re-presented (Clough \& Nutbrown, 2012). I found myself balancing academic priorities, my professional reputation and the organisational expectations of the NGO, while trying to remain faithful to the participants. As a result I made the decision to produce a separate report for the NGO, giving me greater academic freedom in my thesis without the burden of organisational risk. The pressure of "writing for others" was particularly strong in Chapter 7 discussing development policy and practice (Cupples \& Kindon, 2003, p. 227). It is easy to criticise the practice of others, particularly large institutions or those in powerful positions. However, being acutely aware of the small group of government and donors about whom I was writing, made me cautious and led me to write in generalisations rather than specifics. This awareness also kept me grounded in the politics and realities of development practice, considering multiple perspectives, and extending the bridge between research and practice. 


\section{Chapter 4: Postdevelopment Discussions}

\section{Introduction}

This chapter is a short theoretical discussion of the foundations of postdevelopment theory that frame the approach, analysis and discussion of this research. It is not intended as a traditional literature review, as each of the analysis/discussion chapters include a distinct literature review focussed on accompanying theme. Rather it lays the foundation for the tone of the thesis as a whole and is the binding link between the separate bodies of literature later used.

It begins with a general overview of the key elements of Postdevelopment, derived from some of its classic authors. This is balanced with acknowledgement of the gaps and criticisms postdevelopment faces. In light of this, the different positions held by theorists on what postdevelopment looks like in practice is discussed, settling on a way forward for this thesis that uses postdevelopment to deconstruct experience, but does not reject development entirely. Rather new frameworks for practicing and thinking about development are embraced. Accordingly, the chapter concludes with an outline of Santos' (2004) work around which the remaining chapters are themed; replacing the sociology of absences omitted and silenced by development, with ecologies of knowledge through their unveiling and elevation.

It is important to comment on the terminology used going forward. Development literature sees waves of appropriate vocabulary for referring to those at whom development is directed, such as the 'Third World', the 'Developing World', the 'other' and the 'Global South'. Debate of the best term is a conversation best held elsewhere. Throughout this thesis I will use these interchangeably, mostly true to their author. This does not legitimise one expression over another, as though there is an accurate term for which we can refer to such a diverse group of people without drastically over-generalising (Matthews, 2008).

\section{Postdevelopment}

Postdevelopment emerged in the late 1980s - early 1990s in response to dissatisfaction with mainstream development rhetoric and practices. Until that point, theories of development, such as modernisation and dependency theory, were seen to have come from within the same paradigm of development thinking. Postdevelopment invites dialogue that goes 
beyond scrutinising how to do development better, by questioning the very concept of development itself (Ziai, 2007a). Postdevelopment has its theoretical roots in poststructuralism and has been heavily influenced by the work of Foucault, particularly through its focus on discourse as the means by which reality is constructed (Pieterse, 2009). Postdevelopment aims to expose the assumptions hidden in the concept of development, and in doing so the dismantle the power it has wielded as a dominant discourse (Esteva, 2010; Sachs, 2010). It also takes a subversive role, aiming to look at development from the other side, by listening to the voices and values of the people of the Global South, whom development is supposed to be serving (Rahnema, 1997). Whilst more a collage of theories than a single coherent body, postdevelopment can be described by three central tenants:

\section{Development as failure}

In the seminal postdevelopment text The Development Dictionary, Sachs paints a picture of development as failure, a promise held up before the world that failed to deliver and instead committed numerous atrocities along the way. "The idea of development stands like a ruin in the intellectual landscape. Delusion and disappointment, failures and crimes, have been steady companions of development and they tell a common story: it did not work" (2010, p. $x v)$. Ultimately development has failed in its promise to bring the rest of the world up to the standards of advanced modern society. On the contrary, rather than close the gap between the 'haves' and the 'have nots', the development process has deepened inequality within countries, and widened the gulf between countries. In addition to the billions wasted failing to address poverty and inequality, development has instead raised issues of environmental degradation, massive international debt and fuelled numerous conflicts (Thomas, 2000; Ziai, 2007a). The conclusion reached is that the promise on which development rest is false, even deceitful, holding up a middle class lifestyle as the aspiration for all when it is simply not achievable for the majority of the world (Pieterse, 2009). As Escobar summises "the achievement of development clouded awareness of the impossibility of fulfilling the promises that development seemed to be making" (1997, p. 92).

\section{Development as discourse}

Discourse does not objectively reflect reality, instead it actively creates and reinforces a socially constructed reality (A. Storey, 2000). According to postdevelopment, the power of development is created and maintained by the dominant development discourse. Truman's 1949 speech, in which he defined two-thirds of the world as 'underdeveloped', is often 
attributed with ushering in this discourse. While development was not a new concept at the time, a binary was instantly created between the 'developed', synonymous with American and European hegemony, and the 'underdeveloped' other who required western intervention (Esteva, 2010). The term 'development' was appropriated from the life sciences and is associated with ideas of evolution, growth and progress. Implicit within this concept is the idea that these changes are always positive. Thus, by contrast, the 'underdeveloped' become the opposite of these things, defined by lack, inferiority and negativity (Esteva, 2010).

The power of development discourse operates through normalisation rather than overt oppression. It controls what knowledge is produced, and has "created a space in which only certain things could be said or even imagined" (Escobar, 1997, p. 85). Over time this becomes a regime of truth, that legitimises western hegemony, reinforcing the existing power imbalance. Western goals, values and standards are universalised and held up as the yardstick by which all else is measured (A. Storey, 2000). Even worse, by defining others externally, rather than allowing them to define themselves, it leads the other to think of themselves as inferior (Esteva, 2010).

\section{Development as violence}

While postdevelopment highlights the failure of development, it is in fact more scared of development's success. Development has effectively destroyed cultures, the environment and undermined the autonomy of the very people it claims to serve (Pieterse, 2009). Postdevelopment asserts that development succeeded colonialism as a means of exploiting the resources of the Third World, normalising western dominated power relations through the appearance of sophisticated structures like the global economic market and Bretton woods institutions (Esteva, 2010). Against the back drop of the cold war, it has gone further than financial influence, and been used to universalise western culture against the threat of communism (Thomas, 2000). This cultural imperialism has homogenised the 'other' as a single group defined by their inferiority and lack. It has violently destroyed the fabric of social life through a "merciless war" against "age-old traditions", stripping away diversity and values, and ignoring the complex and interconnected reality of the world (Esteva, 2010; Rahnema, 1997, p. x). This cultural destruction has been justified as the inevitable price of progress, yet it acts to serve the interests of a few post-colonial expansionists rather than the large majority of people it is claiming to help (Rahnema, 1997). 
The autonomy of the 'underdeveloped' is further undermined by the authoritarian, technocratic and managerial approach of development. By appealing to supposed universal standards, western development experts define the goals and pathways of development. From this position of power, decisions are made about what will be sacrificed in the name of development, be it the environment, social practices or alternative ways of life (Ziai, 2007a). This discourse of progress and responsibility is inherently interventionist, used to tell others what to do and how to do it (Pieterse, 2009). The concept of development itself has become so powerful a discourse on which to call that it has been used to justify wide scale impoverishment, destruction of the environment, exploitation of Third World resources and the extermination of indigenous populations (Escobar, 1997). Ultimately it is a discourse that undermines the autonomy of people to set their own goals and describe their own trajectory, instead it enforces a pre-defined framework based on western values, ideals and interests (Rahnema, 1997). Development, intended to achieve progress for all human beings, has somehow become a dehumanising process lacking values of humanity (Corbridge, 1998).

\section{Critiques of postdevelopment}

The idea that development is inherently good and its values universal has certainly become questionable under postdevelopment (Ziai, 2007a). However, postdevelopment has not escaped criticism, particularly for committing many of the sins of which it accuses development. Postdevelopment criticises development for homogenising two-thirds of the world, yet postdevelopment itself homogenises the concept of development, treating it as a single entity and ignoring diversity in theoretical approaches and practices (Pieterse, 2009). In doing so, it generalises development as a failure, discounting achievements, such as relief from abject poverty, increased life expectancy and greater access to education (A. Storey, 2000; Thomas, 2000). Moreover, despite purporting self determination, postdevelopment applies another sort of cultural imperialism, ignoring the desire of many for development or viewing it as the result of deception rather than a legitimate aspiration (A. Storey, 2000).

Postdevelopment has been accused of romanticising the lives of the poor creating a binary, between modernity and anti-modernity where the former is entirely bad and the latter is entirely good (Corbridge, 1998). In its objection to modernity, postdevelopment tends to retreat to upholding pre-modern traditional life as a preferred means (Rapley, 2008). Exalting traditional life as preferable in fact commits the same crime as it accuses 
development, promoting one form of life as superior to all other forms. The lives of the poor are simplified to overlook problems and complexity, and idealised as authentic in contrast to the false and inevitably destructive modern way, producing a "wobbly romanticism" where "only the rich get lonely, and only the poor live hospitably and harmoniously" (Corbridge, 1998, p. 139). This 'new medievalism' in practice is often far from ideal, involving fundamentalism and concentrated power in reaction to globalisation, rather than the envisaged grassroots power sharing (Rapley, 2008).

Finally, a strong criticism of postdevelopment is its focus on critique without offering an alternative. Rejecting development entirely and promoting a non-interventionist approach, which simply acknowledges the poor have agency, essentially lets the rest of the world off the hook (Pieterese 2009). Our privileged position in the First World arose and is maintained at the expense of others. Therefore we have a moral and human obligation to respond to issues of poverty and inequality (Matthews, 2008). This position is adopted by this research, committed to moving beyond critique to explore ways to conceive of and practice development differently.

\section{Where to from here?}

Despite its weaknesses, postdevelopment has opened up the landscape to new ways of thinking about development, ending the dominance of the conventional development paradigm, at least in theory (Escobar, 2007). It has bought together theorists and practitioners from a variety of disciplines, such as anthropology, sociology, philosophy and economics, fostering linkages and introducing a wider variety of approaches from other paradigms to contest with the issues at hand (Escobar, 2007). This is particularly reflected in the position different postdevelopment theorists hold on the question of 'where to from here?' regarding what postdevelopment looks like in practice. Authors like Rahnema and Esteva, take an anti-development stance. Rather than seeking an alternatives to achieve development goals, they advocate an alternative to development itself (Ziai, 2007a).

Others have taken a less revolutionary position, wishing to move beyond anti development, "as though there were a space of purity beyond", to imagine and practice development differently (Gibson-Graham, 2005, p. 6). The shift in postdevelopment thinking is evident the movement from the grand metaphors of failure used by Sachs (1992) to open The Development Dictionary and the scathing critique offered in Rahnema and Bawtree's (1997) The Postdevelopment Reader, to the more balanced and optimistic view presented in Ziai's 
(2007) text Exploring postdevelopment: theory and practice, problems and perspectives. The latter turns its attention to theoretical alternatives that can underpin development and how these can be enacted in practice. Postdevelopment cannot simple stop at deconstruction, it needs to go further to create something new (McGregor, 2009). The next three chapters will draw on the thinking and practice of scholars and practitioners such as J-K Gibson-Graham, David Gegeo and Boaventura de Sousa Santos to consider new discourses and expanded possibilities for development policy and practice.

\section{Sociology of absences to sociology of emergences}

Santos (2004) is concerned with what has been silenced, absented and discredited under the western scientific and capitalist model of development. The underlying ontological assumptions of this model about what it means to be human, and epistemological assumptions, about what constitutes knowledge, act to deem alternative ways of thinking and doing non-existent or incredible. Santos (2004) labels a number of monocultures responsible for this sociology of absences. These maintain the hegemony of the dominant model of development and actively produce the non-existence of alternatives. Three of these monocultures, have been selected as themes for the literature, analysis and discussion of this research:

The monoculture of capitalist productivity and efficiency "privileges growth through market forces" (Santos, 2004, p. 239). It is used in a utopian fashion, whereby any failings of the system, such as unemployment or poverty, are seen as a failure to apply the laws or the market completely or in their pure form. Whatever sits outside of the narrowly defined capitalist economic activity is rendered by being non-productive and therefore a waste of resources, and therefore irrelevant or non-existent.

The monoculture of western scientific knowledge has become the "sole criteria of truth", with no alternatives considered able to measure up to its efficiency and coherence (Santos, 2004, p. 238). Any knowledge not endorsed by this cannon is deemed to not exist, considered a form of ignorance. Thus alternative epistemologies are excluded from the legitimate ways of discussing or seeking solutions to the problems the world faces.

The monoculture of the universal and the global favours that which can be applied universally as a common standard for all. Anything that does not achieve the same dominant 
scale is defined as local or particular and consequently not considered as a credible alternative. Under this monoculture contextual fit is over-ridden by universality.

These monocultures have been selected because they help to deconstruct the three key aspects of this research, economy, education and development, that underpin the relevance of RTCs to the future of Solomon Island communities. They illuminate what has been marginalised, absented and distorted by development, and the implications this has. Working from a positionality of the Global South, Santos (2004) is interested in supporting counter-hegemonic alternatives. He argues to go beyond the deconstructive agenda of postdevelopment to transform the sociology of absences into sociology of emergences by taking that which has been silenced and rendered inferior and making it visible and credible. In doing so alternatives can be explored as legitimate options. Accordingly, the above monocultures are expanded to reveal an ecology of productivity, ecology of knowledge and an ecology of trans-scale, opening up the space for new development goals and new development trajectories.

This thesis will attempt to expand beyond the monocultures produced to develop an expanded view of economy, education and development. In Chapter 5 the concept of economy will be expanded through a diverse economies approach, considering all the activities that support livelihoods in the community. In Chapter 6 the concept of education will be expanded to give credibility to the use of indigenous skills and informal education used by RTCs. In Chapter 7 a broader view of development will be taken to acknowledge the importance of contextual relevance and local development goals in contrast to the power of the universal and the aid relationship.

\section{Conclusion}

This chapter has considered the emergence of postdevelopment in response to the failure of development to deliver on false promises, its hegemonic reign of discourse, and violent destruction of cultural diversity and autonomy. The critical agenda of postdevelopment has been useful in diffusing the power of the development discourse, and clearing the landscape for new forms of discourse and practice to arise. While postdevelopment theorists have different opinions on the way forward, a body of optimism around how development can be conceived and practiced differently has emerged. In the following chapters postdevelopment critique will be used to deconstruct concepts and experience and providing insight, without coming to the conclusion of rejecting development entirely (Pieterse, 2009). More recent 
postdevelopment concepts will be used to look beyond critique to explore a way forward; discussing the opportunities and possibilities this unveils to think about and do development differently, in awareness of its limitations and failings. 


\section{Chapter 5: Monoculture of capitalist productivity and efficiency: The diverse economies of Gizo and Vatu}

\section{Introduction}

This chapter sets the scene of the local economic context of the communities of Gizo and Vatu, from which the broader topic of the relevance of Rural Training Centres can be discussed. It begins with a condensed review of the literature related to the monoculture of capitalist productivity and efficiency that considers the myriad of livelihood activities overlooked and devalued through a capitalist view of economy, with particular attention to women. In opposition to this narrow view of economy, an alternative view is proposed: the diverse economies approach (Gibson-Graham, 2005). The diverse economies approach uses an expanded understanding of economy to incorporate all the activities that support material life and wellbeing. Before proceeding to undertake a diverse economies analysis of the two community case study sites, Gizo and Vatu, an overview of each place is given. These community profiles establish a rich sense of local context for the reader, comparing the similarities and differences between Gizo, as a semi-urban, and Vatu, as a rural location. This descriptive section is an essential foundation for this chapter and for the remainder of the thesis, given the importance of local context to the question of the relevance of Rural Training Centres to Solomon Island communities.

Using extracts from interviews and observational notes, a diverse economies analysis of Gizo and Vatu considers the role of the Formal, Alternative and Direct economic activities in supporting livelihoods, and the implications this has for development discussion and practice. Finally, the chapter returns to the constructive theme of this thesis, presenting a community assets map for Gizo and Vatu that highlights the strengths and resources of these communities, as opposed to focussing on their needs and lack. With a fuller picture of what constitutes the economy, the opportunity for a new development discussion is created that asks what nourishes these communities and can enhance their resilience and autonomy for the future. 


\section{The capitalist economy: What it misses}

\section{Development and capitalism}

The dominant development discourse is entangled with the dominant capitalist view of economy, recognisable by its emphasis on economic growth and the mediation of the market. The two have become synonymous, with the capitalist economic system underpinning development policy and practice so heavily that development must be analysed in relation to it as the 'global reality' in which we operate (Thomas, 2000). The capitalist model of economy has risen to such stature that it is treated as a separate entity, represented as some sort of independent mechanism rather than a social and historical construct (Esteva, 2010). This stature of rationality and superiority is legitimised by scientific discourse that discredits alternatives as unable to compare to its coherence and efficiency, making it an unquestionable force and a singular pathway through which all must travel (Santos, 2004). Capitalist economic activity therefore becomes the model for all economic activity (Gibson-Graham, 2006). Consequently, the project of development has become one of fixing the problems seen from the perspective of this system, rather than seeking an alternative model that does not produce these problems (Thomas, 2000). Accordingly, the pursuit of development has largely become a pursuit of economic growth, defined by a narrow set of indicators and a restricted view of what constitutes economic activity. In recent years, postdevelopment has questioned who benefits from such a model, its longterm sustainability and what has been veiled by its dominance.

\section{Criticisms of the capitalist economic system}

Critics of the capitalist economic system argue that it is the cause rather than the cure of the world's problems. It is a system that creates and perpetuates poverty and inequality by its very nature (Harriss-White, 2006; Max-Neef, 2010). Capitalism produces inequality by valuing the creation of wealth for a minority over the needs of the majority (Cammack, 2009). It is a form of economic hegemony, under which development can be seen as a tool used to legitimise and integrate the poor into the global system in order to maintain capitalist interests (Cammack, 2004). Polanyi, an early dissident of this model, saw poverty as the cost of development, a necessity for economic growth to occur (Thomas, 2000). Moreover, the greed and emphasis on mass consumption associated with perpetual growth is widely regarded as environmentally short-sighted and unsustainable. As Daly states we have the choice between facing a "political impossibility", re-thinking our capitalist model of 
economics, or a "biophysical impossibility" trying to infinitely grow the economy with finite natural resources $(2005$, p. 102).

\section{The narrow view of economy}

Against the backdrop of these broader criticisms, this chapter will focus on how the capitalist economic system as a powerful monoculture devalues and omits an abundance of activities that support livelihoods, creating a distorted picture of reality. Under a 'capitalocentric' view, a term used by Gibson-Graham (2005) to describe this dominant paradigm of thinking, whatever exists as outside of this paradigm is not only overlooked, it is actively produced as "non-existent, that is as a non credible alternative to what exists" (Santos, 2004, p. 238). Other activities are "considered important only from the moment their economic impact and benefit can be demonstrated" (Carmen, 1996, p. 137). People, practices and objects become defined by the way in which they intersect (or fail to intersect) with the capitalist economy. Esteva describes how this effectively transforms "commons into resources, men and women into commodified labour, tradition into burden, wisdom into ignorance, autonomy into dependency", taking the assets of a community and reproducing them as articles of lack and need (2010, p. 15). Interactions with the world and people become economic transactions as they try to legitimise themselves within this hegemonic discourse. Once identified in relation to the capitalist economy, a need is created for the mediation of the market, reinforcing its dominance; the survival of people now suddenly depends on the market (Esteva, 2010).

While on one hand reducing everything to its economic value, the capitalocentric view is remarkably narrow in what considers 'economic'. Informal activities (those which are remunerated in an alternative manner) and non-formal activities (those which are not remunerated) are excluded, not represented in economic statistics, and discouraged from taking place (Gibson-Graham, 2008). Max-Neef aptly refers to this as the 'invisible economy' (cited in Carmen, 1996). This economic colonisation of the informal and non-formal sectors has ensured that "innumerable economies, otherwise perfectly capable of looking after themselves and of providing, precisely, the quality of life [they desire]...have been obliterated or become extinct" (Carmen, 1996, p. 140). The terms informal and non-formal are themselves tainted as somehow backward or retrograde, associated with the undeveloped and traditional. In reality non-market based transactions (informal) and unpaid household work (non-formal) constitute between $30-50 \%$ of economic activities in First and 
Third world countries alike (Ironmonger, 1996 cited in Gibson-Graham, 2008). The devaluation, and discouragement of these activities generates a misleading picture of what effectively supports livelihoods, leading to decisions and practices based on a false conception of reality. Consequently instead of development activities fighting poverty, they fight the poor themselves as those resisting the dominant concept of economy (Esteva, 2010). In this research, the role of these invisible activities will be brought to light under a diverse economies perspective, and the existing assets of the community recognised under an asset mapping approach.

\section{Economic value of women's activities}

Establishing economic value in the narrow terms confined by capitalocentric thinking, actually involves de-valuing social activities. The values inherent in the capitalist economic system, and consequently development, have largely made women "invisible in their role as producers" and "tended to perpetuate their subordination" (Escobar, 1997, p. 90). From a feminist perspective, the capitalist economic system rests on a masculine discourse of progress, development and rationality. Consequently, the activities of women, particularly rural women, that are strongly linked with the roles of wifehood and motherhood, are seen to reside in a domestic sphere outside of the economic sphere (Midgley, 2006). An enormous amount of activity that women perform to support livelihoods (caring for children, preparing food, maintaining the household etc...) is thus considered 'non-economic' and correspondingly of lesser value than income generating activities dominated by men. Moreover, development often reinforces this perspective by trying to increase the economic participation of women through running small businesses or working part-time, rather than acknowledging the economic value and contribution of their current activities (Midgley, 2006). Through a diverse economies approach, Gibson-Graham (2006) attempt to dedomesticate household and unpaid labour, giving them due credibility as economic activities. Accordingly, this research will highlight the activities of women that support livelihoods under this broader perspective of economy, and consider the issues women face around perceptions of gender roles and a changing economy.

\section{An alternative economic lens}

Working from a postdevelopment perspective, Gibson-Graham aim to broaden the narrow capitalocentric view of economy to one that is more representative of the myriad of activities and practices that support livelihoods in reality: a 'diverse economy'. They see themselves performing an 'ontological intervention' that seeks to change the world not by 
understanding it better, but by changing our understanding of it, "our challenge to the mainstream development project focuses on the singular vision that the only viable economy is a capitalist one and that the only dynamics that will produce economic development are those of capitalist productivity" (Gibson-Graham, 2005, p. 12). Under a diverse economies perspective activities that have to date been marginalised and hidden under the dominant model are revealed and given credibility. The power of the hegemonic capitalist system is consequently diluted. It is reconceptualised as simply a set of practices amongst multiple other options, performed in multiple places, such as within the family, community, states, and private enterprises (Gibson-Graham, 2008) .

Gibson-Graham (2005) consider their work to fit with Santos' sociology of emergences. Their work deconstructs the way in which the monoculture of capitalist productivity and efficiency dominates and constrains life, and unveil what is absented and hidden. It goes further to create an alternative counter-hegemonic pathway with the ethical, social and environmental considerations of postdevelopment (Cameron \& Gibson-Graham, 2007). The grounding of their work in development practice fits well with this research by going beyond theorising to practical application in the field through participatory action research, supporting numerous development projects, and creating accessible literature and tools for others to utilise (Cameron \& Gibson-Graham, 2007; Community Partnering for Local Development, 2010b). What began as a disruptive challenge to the prevailing view of economy in the mid 1990s, has come a long way giving rise to a vibrant community of research and practice extending across the globe (Gibson-Graham, 2008).

\section{A more holistic view: Diverse Economies Framework}

A diverse economies approach begins with recognition of the variety of economic practices already in operation around the world. Some of these activities operate within a capitalist framework of private wealth accumulation, yet many others that are non-market and non-capitalist underlay the fabric of society in developing and non developing countries alike. From this standpoint of recognising viable and existing alternatives, the possibilities to strengthen, explore and promote them emerge. They become a visible part of the economy rather than an invisible subordinate (Cameron \& Gibson-Graham, 2007).

The Diverse Economies Framework, shown in Figure 5.1 below, is an analytical too that reveals the plethora of work, exchange and enterprise activities that take place under the 
surface of the capitalist economy. The top row describes aspects of the mainstream capitalist economy; market transactions, wage labour and capitalist enterprise. The lower rows contain the overlooked, yet more prevalent, alternative practices and outside activities (Gibson-Graham, 2005). Gibson-Graham speak of the need to "practice a new lexicon" that reflects an anticapitalocentric reading of the economy, and activates a diverse economies discourse as credible (2006, p. 72). For this reason, I have added to their framework a label for each row that describes this section of the economy by what it is rather than in comparison to the Formal economy. Hence, rather than use the term 'Informal' for the second row I have used 'Alternative', and instead of 'Non-formal for the third role I have used 'Direct'.

Figure 5.1 Diverse Economies Framework

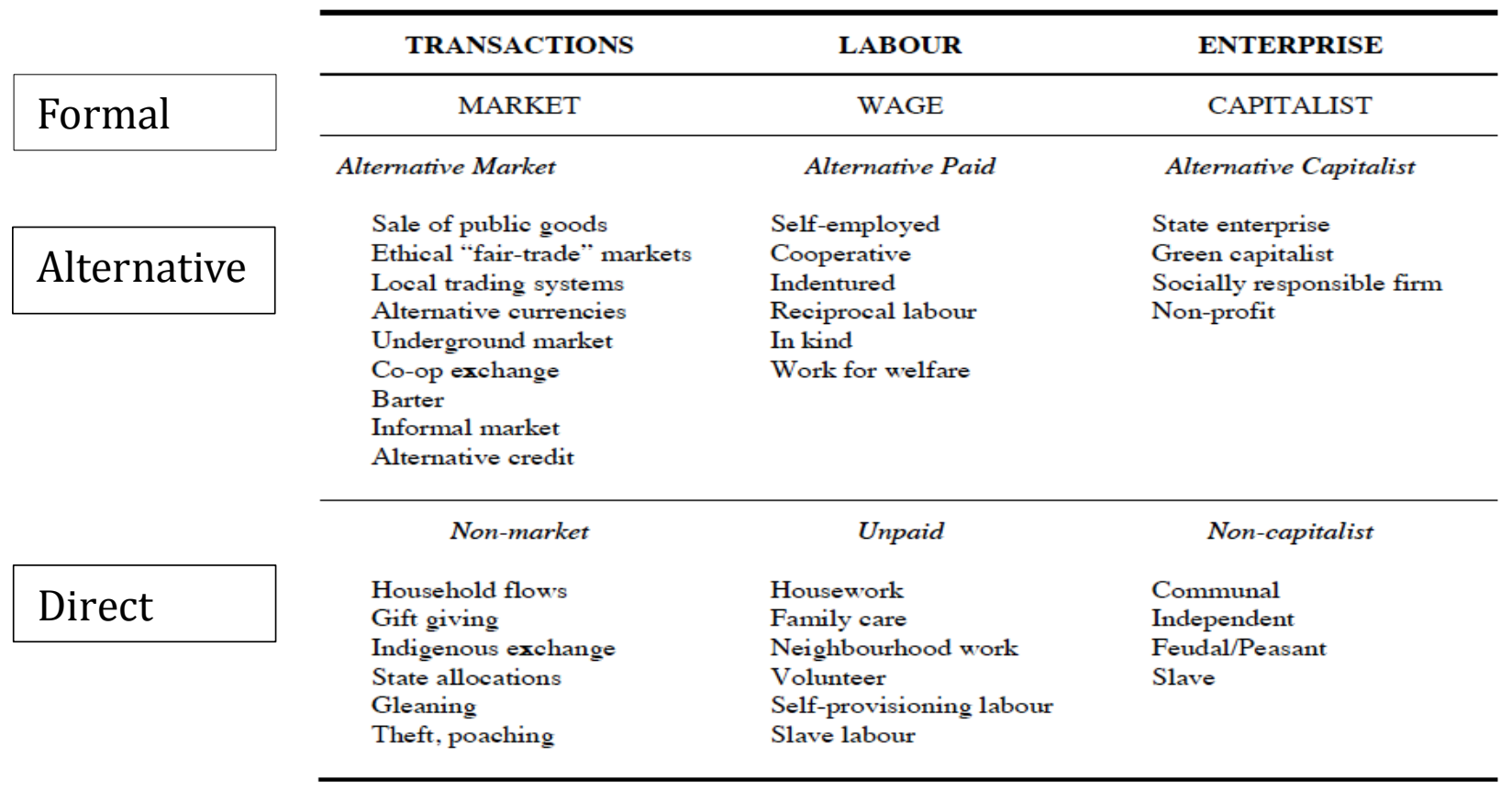

(Adapted from Gibson-Graham, 2005, p. 12)

Transactions - The first column, transactions, viewed in this manner, considers all the ways in which goods circulate, encompassing alternative market activities, such as barter exchange and informal markets, and non-market based activities such as household flows and gifts (Gibson-Graham, 2008). They are not bound by the same rules of commensurability as formal market transactions that rest on strict laws of supply and demand. Rather they reflect 
the incommensurable context in which many transactions take place, as a negotiation of relationship, power or tradition (Gibson-Graham, 2006).

Labour - Similarly the notion of labour, the second column, is broadened to include all the activities that support material well-being, with various forms of associated compensation. This may be an alternative form of payment, such as in-kind or reciprocal labour. Also included is unpaid labour, by far the most prevalent form of labour in the world, involving activities such as caring for the house or family may not result in material compensation. Instead it may involve social or relational compensation, as well as enjoyment of the fruits of ones labour, such as a clean house or cooked meal (Gibson-Graham, 2006). This is particularly seen in subsistence work, where the compensation comes as sharing in the goods that are produced.

Enterprise - The third column, enterprise, refers to the organisations that produce and distribute surplus (Gibson-Graham, 2008). The framework differentiates between the different ways in which this surplus is appropriated. In capitalist enterprises, such as private and public companies, the surplus is appropriated by the owners, be they a family or board of directors distributing to shareholders. Alternative capitalist enterprises, such as NGOs and social enterprises, may rely on funding with no surplus or distribute surplus to community activities. Also recognised are non-capitalist enterprises, such as worker owned cooperatives and sole proprietorships, in which a wage is given in compensation of labour and the surplus distributed separately by the workers or sole proprietor (Gibson-Graham, 2006, 2008). Viewing the economy under this fuller picture "dislodges the discursive dominance of capitalist economic activity and reclaims it as a contested space of representation" (GibsonGraham, 2006, p. 54).

The Diverse Economies Framework will be used to analyse the economies of the community case study sites of Gizo and Vatu. This analysis highlights the centrality of Alternative and Direct economic activities to supporting the livelihoods of people in these areas, and considers the implications this has for education and development practice.

\section{Community assets maps}

Traditionally participatory development has utilised community need analysis as a tool to establish the needs of a community and determine development priorities. While well 
intentioned as a 'neutral' information gathering exercise, this processes unconsciously reinforces the dominant development discourse, positioning communities as lacking and in need of western development intervention (Gibson-Graham, 2005). The Community Assets Map, pictured in Figure 5.2, put forth by Gibson-Graham instead focuses on what a community has rather than what it lacks.

Figure 5.2: Community Assets Map

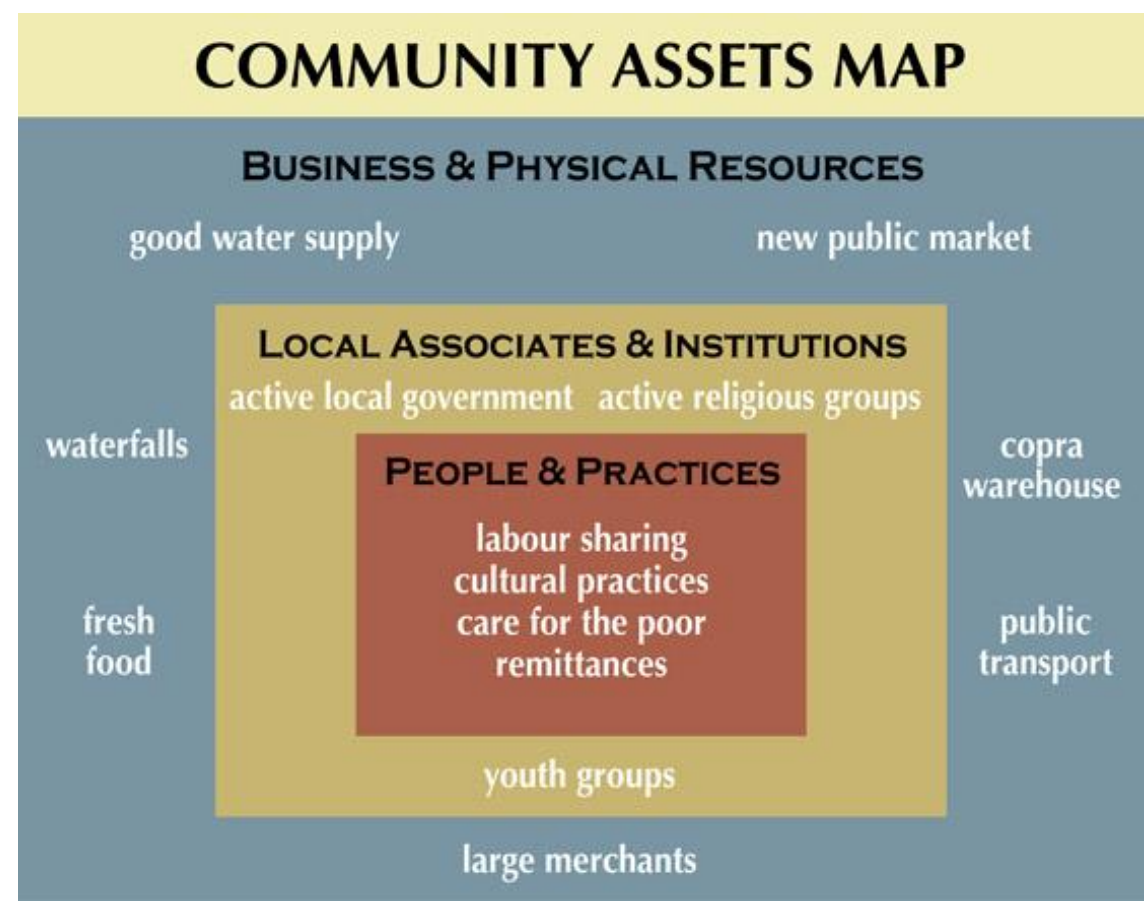

(Community Partnering for Local Development, 2010b)

By looking at the strengths of a community and what is working well, the foundation is laid for a different development conversation. Community capacity is realised and possibilities for what can be built upon open up (Gibson-Graham, 2005). Moreover, the agency of the community is recognised and alternative pathways that "strengthen the resilience of the local economy and that reduce dependence on external forces" can be explored (GibsonGraham, 2005, p. 9). As part of this research a community assets map, based on observational and interview data, has been developed for Gizo and Vatu laying the foundation for discussion of a full picture of possibilities of development. 


\section{Community profiles}

Before launching into a diverse economies analysis of the two community case study sites, Gizo and Vatu, it is important to establish the context in which they sit. A rich community profile of the physical and business environment, infrastructure and services, and people and practices in these sites has been developed using observational and interview data for two reasons. Firstly, it gives rich background context of two very different sites in which the NGO project will operate. By going beyond the RTCs, around which the project is focussed, and looking at the wider context of the community, it allows assumptions to be checked and avoids a one size fits all approach (Gibson-Graham, 2005). True to a postdevelopment approach, the importance of relevance and fit for local context is central to this research (Santos, 2004). Secondly, it aims to situate the reader in the environment of the research participants, to listen from their point of view. This section will be used as a reference point for the rest of this chapter, and subsequent chapters, as a foundational level of knowledge. Figure 5.3, over page, gives an overview of Gizo and Vatu, preceding a more detailed analysis. 


\section{Gizo overview}

Location: Western Province

Environment: Semi-urban, second largest urban centre outside of Honiara. Population: No reliable figures available - estimated 5000-7000.

Gizo is the Provincial Capital and 'service hub' for the region. People are drawn to Gizo for education, employment and business opportunities. However, life in Gizo still very much relies on informal and rural livelihoods, making it a semi-urban rather than urban location. While people come into the town from the surrounding villages and islands to do business, particularly to generate income through sales at the loca market and to use the banking and government services, the core of what supports most peoples lives is still subsistence living supplemented with self-generated income. There are few formal employment opportunities. Even for those with paid employment, the wages are low and insufficient to support the cost of town life. With a plentiful sea and surrounding land, people are not lacking food, but rather are cash poor, needing to come up with means to generate cash to pay for things like school fees, water tanks, generators, and rice, is increasing in a modernising world.

\section{Vatu overview}

Location: East Guadalcanal

Environment: Rural, a collection of small villages spread 2-3 km apart Population: Varies 20-100 in each village

Strictly speaking, Vatu only refers to the Rural Training Centre itself, consisting of the land and housing for staff and students. However, for the purposes of this research, Vatu is used to refer to the surrounding communities. These villages, dotted along the coast or inland (the 'bush') are typically the source of RTC students and give an idea of the social, economic and physical environment of their lives.

Despite being located on the same island as the capital Honiara, Vatu is very much a rural environment. The land is incredibly fertile, with agricultural subsistence the backbone of livelihoods. Subsistence life is supplemented with income from copra and cocoa plantations, which are transported to Honiara in order to be sold. Infrastructure, such as solar panels or water tanks, tends to be localised according to village resources. There are very few businesses or services, apart from a smattering of schools and a small medical clinic. For the most part, people need to travel to Honiara to engage with government services and purchase goods.

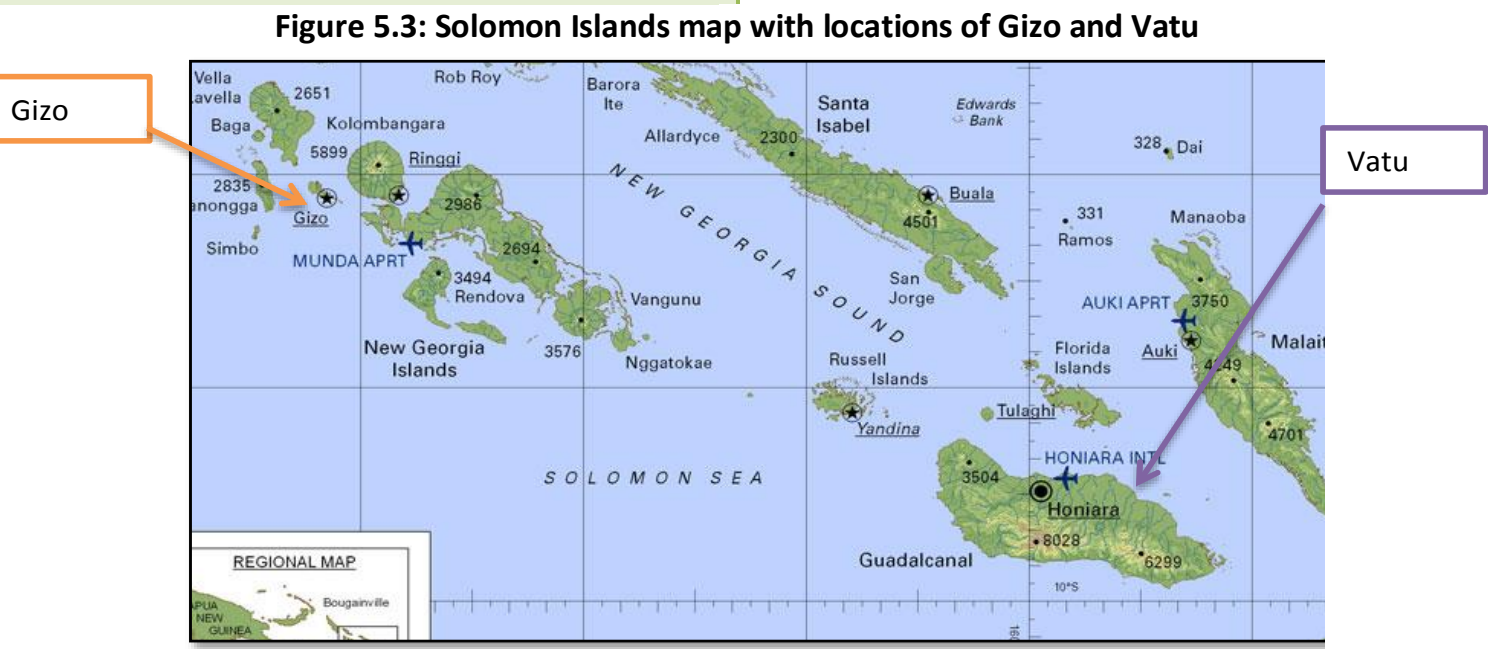

(Joint geospatial support facility: NZ Defence Force, 2007)AM 


\section{Physical and business environment}

\section{Physical environment}

They key environmental difference between Gizo and Vatu is one of reliance on the sea vs the land as the foundation for livelihoods. Gizo is located amongst crystal clear waters and coral reefs that are home to an abundance of sea life. Those in the town of Gizo and the surrounding villages and islands depend on the sea for food and a source of income. Motorboats of various sizes leave early in the morning arriving back in time to populate the daily market with wonderfully colourful fish. In contrast, Vatu, while on the coast opens to rough waters, not sharing the abundance and access of a coral reef. A few non-motorised boats fish when weather permits. The foundation of life in Vatu however is agriculture. The fertile lands means that fruit such as papaya and coconut literally drip from the trees, and every family has a kitchen garden growing a variety of cassava, local potato, kumara, cabbage, and eggplant. Land is relatively abundant in contrast to Gizo, where those in town face housing pressure and lack the room to have a garden. As a result they rely on purchasing produce from other islands and surrounding villages.

\section{Industry}

There are three major industries surrounding Gizo: forestry, tuna and tourism. The forestry activities on the nearby island of Kolombangara are less a source of employment for the communities in Gizo, as they are a customer to its market, businesses and services. Most employees come from Malaysia or the Philippines and there is a fairly negative sentiment around their behaviour and the environmental degradation of forestry activities. The waters surrounding Gizo are well known for tuna, with commercial fishing boats and a large tuna canning factory 1.5 hours away (by boat) a major source of employment. Tourism in Gizo is an emerging market with incredible potential. The turquoise waters, white sands and abundance of diving rival some of the best know places in the Pacific for beauty and tranquillity. Currently, there are a few small foreign owned resorts, some locally owned homestays, a handful of restaurants and a dive shop, but business is slow. Tourism in the Solomon Islands, as mentioned in Chapter 2, has been earmarked as a key source of future economic growth (World Bank, 2010). Gizo is naturally the hub for such tourism given its picturesque location and availability of basic services. However, local operators cite a lack of investment in local infrastructure (such as a tourism office), the high cost of flights to Gizo and the failure of political rhetoric to result in an effective national tourism campaign as impediments. 
Vatu does not have the volume of industries seen in Gizo, with the forestry the only major industry in the area. There are two sizeable logging camps nearby that employ a mixture of Solomon Islanders and international workers. The forestry industry in these parts is less of a customer for local produce and more of a potential supplier of timber for building. Yet the same environmental reservations exist with people complaining that logging activity has changed water flow patterns and resulted in more frequent flooding of their gardens and crops.

\section{Markets}

One of the most apparent differences between Gizo and Vatu is access and relationship to markets. In Gizo, many rely on the local market to supply their food (fish, fruit and vegetables) while others travel from the surrounding villages and islands to sell their fish and produce to generate cash income. Those without land or a boat, typically women who live in town, sell cooked food, such as banana bread and fish and chips, to earn an income. The red roofs of the outdoor market that line the waterfront are the centrepiece of life in the community, as pictured in Figure 5.4 below:

Figure 5.4: Market Gizo

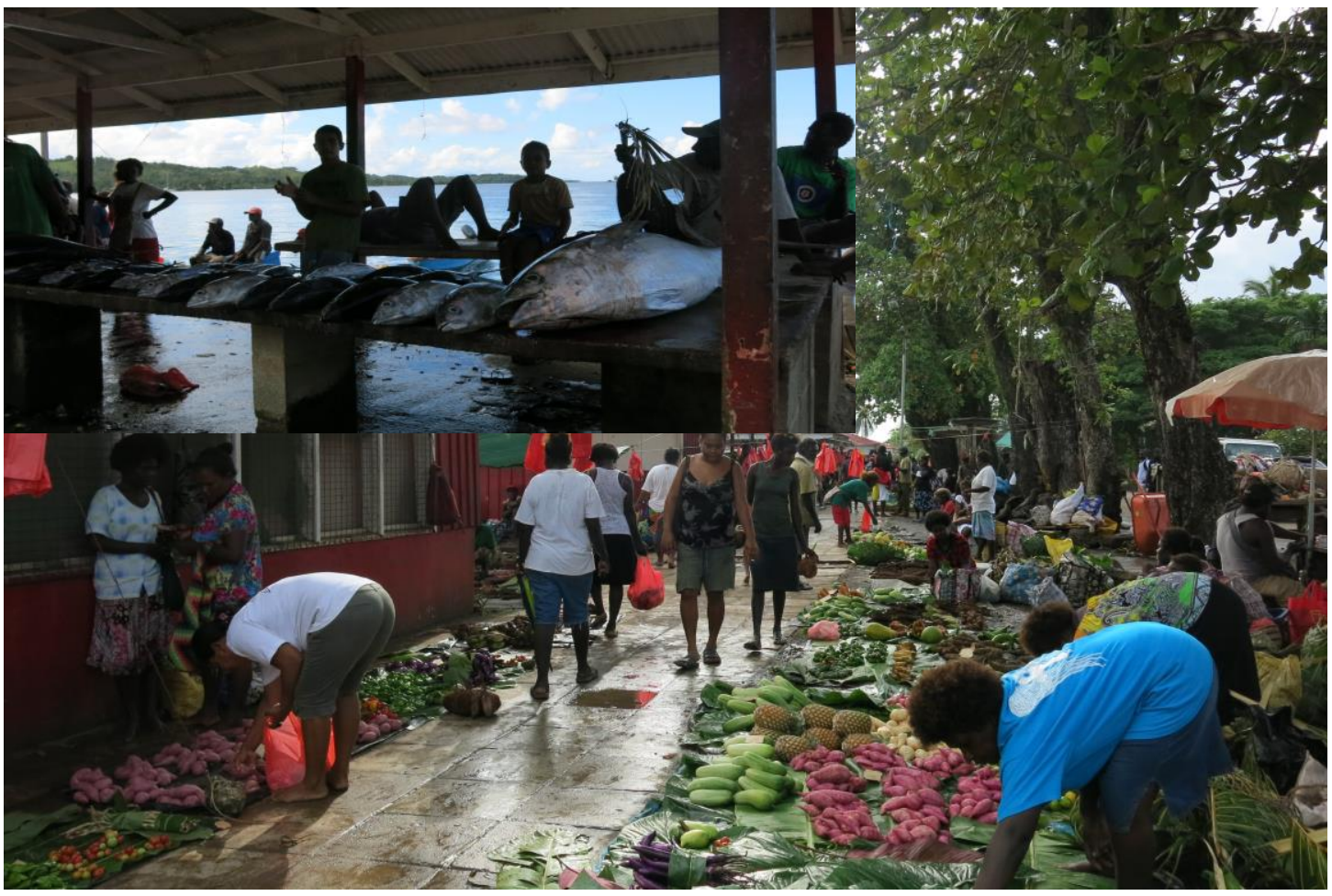

(Photo Kathy Fleming, 2014) 
By contrast the local market in Vatu, shown in Figure 5.5, is smaller and less formal. Located over an hours walk away, it operates three times a week, weather permitting. People only sell what they may have in surplus to supplying their extended family needs, making it an unreliable source of food. For example, on my visit to the market all the produce was sold by 9am, with only beetle nut and tobacco remaining. Putting food on the table in Vatu requires the careful planning and hard work of subsistence agriculture. In the tropical humidity food must be harvested, prepared and consumed within the same day, meaning a continual supply of crops is required.

Figure 5.5: Market Vatu

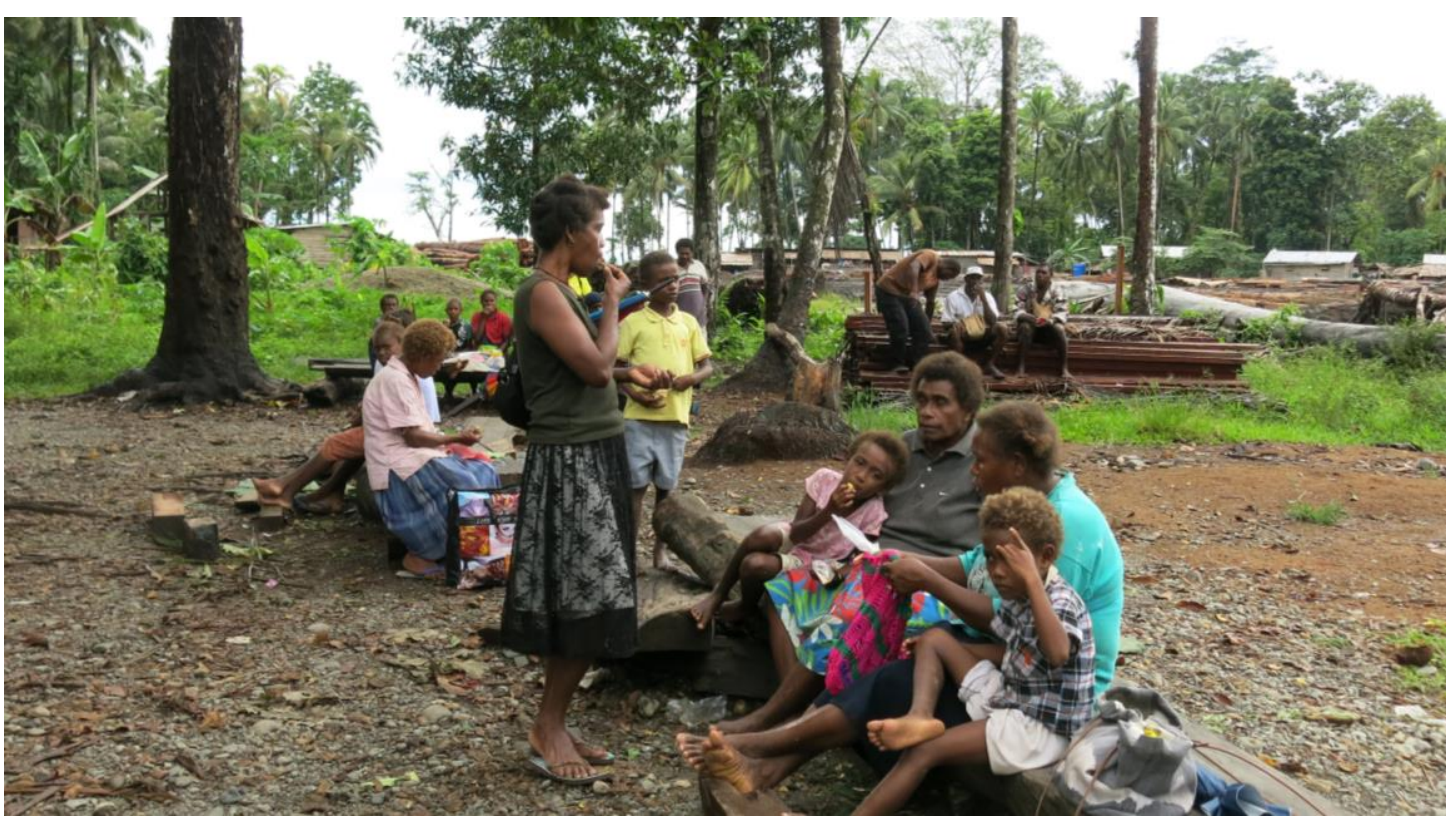

(Photo Kathy Fleming, 2014)

In addition to goods sold locally, there are micro industries producing goods for export. In Vatu a number of family owned cocoa and copra plantations operate. Harvesting these crops is hard physical work, without the use of machinery and reliant on manpower. Once harvested and semi processed (dried) they must be transported to Honiara to be sold, at considerable cost, as there are no local markets or dealers with which to trade. Goods are ultimately sold in the global market and are therefore dependent on fluctuating commodity prices. In Gizo there are also a number of copra plantations just outside of town. The product can be sold directly to middlemen within Gizo town and later sent to the capital for export. 


\section{Local businesses}

The main street of Gizo contains approximately 30 shops and two dozen local businesses. These range from general stores selling packaged goods and household supplies, to tailors, hardware shops, a timber company, fuel depot, phone shops and even a technology services provider. Most items can be purchased in Gizo, and the twice-weekly ship from Honiara keeps stocks in supply. Being a more rural, and subsistence driven environment, Vatu has few, if any, local businesses. Staples such as rice, flour and salt are purchased in bulk from Honiara. A few of the churches operate small shops where top ups can be purchased. However, with less cash flowing in the community and greater distances for access, these are infrequently used.

\section{Infrastructure and services}

\section{Transport}

The difference between a semi-urban and rural environment is acutely felt in access and availability of infrastructure and services. From Gizo, connecting to the capital is fast and frequent via a 1.5 hour flight-operating several times a day, although at a cost beyond most locals. The cheaper option is a once weekly overnight boat service. Although Vatu is geographically closer, access is less reliable, requiring a five hour trip in the back of a 4WD, or if you can track down someone local with a boat, the trip is only three hours by sea.

Gizo has a well connected water-based transport network, shown in Figure 5.6, with many relying on boats to travel to school, the market or perform business. It is also busy enough to have a taxi service and local bus (truck) that transports people to and from town on the single road that extends around most of the island. In Vatu, a 4WD road connects the coastal villages, extending all the way to Honiara. Apart from an occasional truck in which one can catch a ride, the only vehicles on the road tend to be logging vehicles. Local transport is mainly on foot, with very few private cars or boats. Communities residing in the 'bush' (inland) can only be accessed on foot. 
Figure 5.6: Transport map Gizo

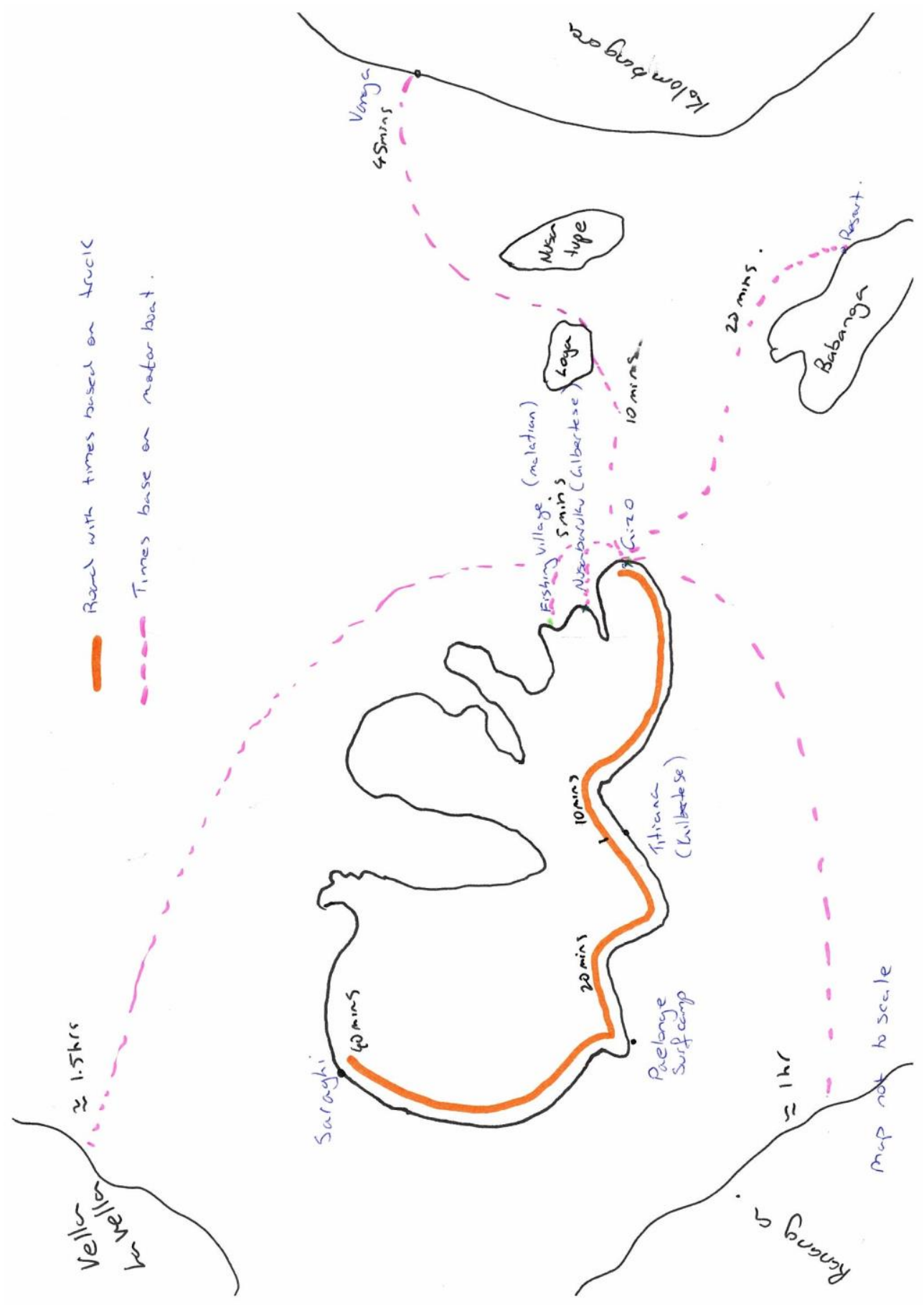

(Field Journal, 21/03/14) 


\section{Institutions and services}

As a provincial capital, Gizo is endowed with a range of public and private services. It contains the provincial office for most government departments, a post office, police station, airline office and a number of ATM and bank branches. The recently built hospital is regarded as one of the best in the country and operates a mobile clinic. Education wise, the town has a kindergarten, primary school, secondary school, and RTC, with additional schools in the surrounding villages. Gizo has a town water supply, although it is considered insufficient to meet needs, resulting in most people owning a personal water tank. The electricity grid is supplied by a large generator and a local rubbish collection operates daily. There are also several NGOs offices running projects around disaster resilience, marine conservation, child protection and community savings schemes.

Given its more remote location and lower prominence, Vatu does not share the same access to services as Gizo. Life is much more self and community reliant with infrastructure being localised to villages and households through solar panels, water tanks and petrol generators. Figure 5.7 presents a time map of Vatu demonstrating the considerable distances people need to walk to access services, the market or school. The only government services in the area are a small health clinic, a primary school, lower secondary school and the RTC. As I found out first hand during the floods, Vatu is practically cut off from modern communication, with no phone reception, Internet or television. So while actually closer to Honiara than Gizo, it feels far more remote and isolated. 
Figure 5.7: Time map Vatu

(Indicates walking distances)

\section{Bush Villages}

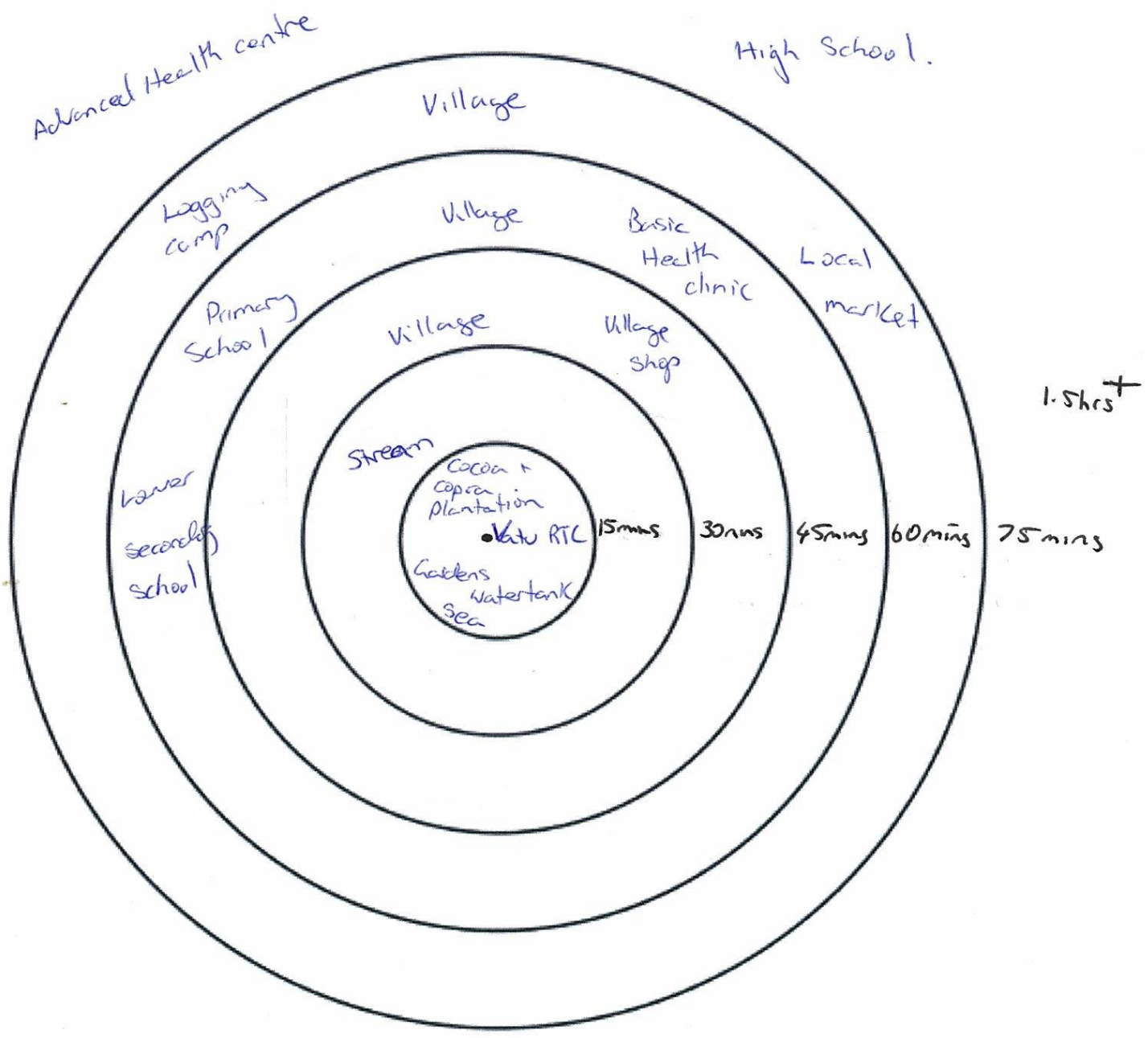

(Field Journal, 06/04/14) 


\section{Text box 5.1: The church}

In western society the church is typically viewed as part of the private sphere, concerned with spiritual well-being and perhaps social engagement, but separate from public and economic life. It is necessary to understand the role of the church and people's relationship to the church differently in a Solomon Islands context. The Christian church is integral to most people's lives. Not only do the vast majority of Solomon Islanders belong to one of the five major denominations: Catholic, Anglican, Seventh Day Adventist, Evangelical and Methodist; key facilities such as early childhood centres, RTCs, and until recently schools are funded (at least partially) and operated by churches. Church services happen on a daily basis and church related activities are often at the core of social and community life. In Gizo, for example, my residence was surrounded by three churches (of the seven in town). Each morning I was greeted by children playing comfortably in the church grounds and went to sleep most nights to the sound of singing practice, youth events or other church related activities. The church was also major employer and had an ambitious building project of investments and facilities. Even in the rural setting of Vatu, there were daily prayers in the open walled church, led by lay leaders, evening activities revolved around religious songs, and church services were seen as a way to bring the community together. In both locations, church funded educational scholarships featured as key ways through which members of the community were able to pursue further education. The church is integral to public and economic life, particularly within the domain of education.

\section{People and practices}

\section{Ethnicity and culture}

Almost everyone encountered in Gizo seems comes from somewhere else; other parts of the Western Province, the Solomon Islands or from Bougainville. It is an ethnically and culturally diverse community, as is often the case in more urban environments. There are two longterm migrant populations: the Chinese who tend to operate shops in town, and the Gilbertese (see Text box 5.2 on page 67). The cultural attitude towards women appears more liberal than in Honiara. For example I received encouragement and smiles when running in Gizo, as opposed to the sexual and abusive remarks in Honiara. Women wore wearing shorts and had their shoulders uncovered. There was also a clear influence of western music and dress. In contrast, Vatu had greater ethnic homogeneity, with networks of extended family 
amongst the villages. There were no immigrant communities and people from other parts of the Solomon Islands had usually married into the community. However, the relativity of being 'rural' or 'isolated' was apparent between those who lived on the coast, with fertile flat land and road access, and those who lived in the inland 'bush' area. Life in the bush was considered much harder, with poorer soil for crop production, difficulty transporting crops, and less varied diet with no fish. While Vatu is rural and remote compared to Gizo, it is relatively accessible and modern compared to the 'bush'.

\section{Wantok}

Affiliation and loyalty, as mentioned Chapter 2, are closely aligned with ones wantok. People take responsibility to care for their wantok and are expected to give preference to their wantok, resulting in a pooling or flowing exchange of resources. In Gizo and Vatu it was common for wantok to raise others' children, pay for school fees of wantok, house wantok and give money or goods when asked. The advantages and challenges of this system will be discussed from a diverse economies perspective later in this chapter 


\section{Text box 5.2: Sitting in the Maneaba}

During my research I held a focus group with the young people from a Gilbertese community located outside Gizo, and met with several others. The Gilbertese or (ikiribati) community was re-settled in the Solomon Islands in the 1950s after British nuclear testing in the pacific produced a land shortage in Kiribati. The Gilbertese are recognisably distinct from Solomon Islanders, being Micronesian, rather than Melanesian, with distinct facial features, straight hair and lighter skin. Their language is also of completely different origin, closely related to the languages of South East Asia.

I was invited to sit on a mat in the middle of the gable roofed Maneaba (the community meeting house) while the community sat around the periphery. The young people, one by one, came and joined me, sharing their stories and aspirations for the future. This community, while located on the main Island were not connected to the road. As a result children faced issues getting to school as the 10 minute motor-boat ride from Gizo depended on the availability and funds for a boat each day. A tour of the village revealed the relative poverty of the community. Housing was poorly constructed and children clad in ragged clothing. The amount of arable land was reduced by the 2007 tsumani, with the community forced onto the hillside accessed via coral bridges (see figure 5.8 below). It highlighted that within the marginalised context of the Solomon Islands, there were those who were more marginalised by their ethnicity, culture and land rights.

Figure 5.8: Coral bridges

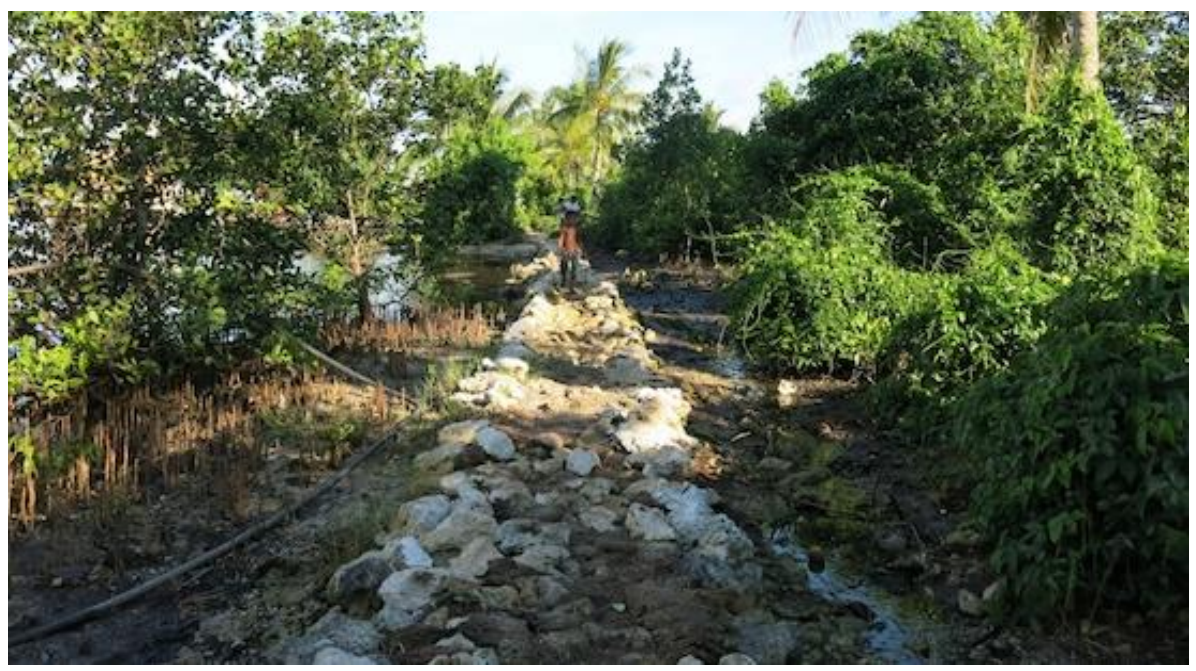

(Photo: Kathy Fleming 2014) 


\section{Conclusion}

The above comparison of Community Profiles for Gizo and Vatu gives a sense of place to frame this research. The contrast between Gizo as a semi-urban location, well resourced with services, and Vatu as a more isolated and rural location punctuates the importance of understanding the local context in development practice. However, while the Community Profiles often note things available in Gizo that are not available in Vatu, this is not a case of haves and have nots. As the diverse economies analysis and asset map a will show, life relies on different aspects in each of these locations. Removing the western hierarchy that places formal aspects of economy such as money, infrastructure and purchasing goods above all else, reveals the rich, thriving and strong community practices that currently support livelihoods in both locations.

\section{Diverse economies in Gizo and Vatu}

The Diverse Economies Framework is used to analyse the economic practices in Gizo and Vatu, as observed on site and spoken about by the research participants. The analysis employs the three different types of economy; Formal, Alternative, and Direct, that I have used to label the rows of Gibson-Graham's (2005) Diverse Economies Framework. The key ways in which each of these type of economic activities contribute to the livelihood of the community will be discussed in turn. A focus of depth rather than breadth is taken, to reveal what has been invisibilised or dis-credited by the capitalocentric view of economy. The comparison between the two sites of Gizo and Vatu continues, emphasising the difference local context makes in an expanded view of economy.

\section{The Formal economy}

The Formal economy in Gizo and Vatu, made up of market transactions, waged labour and capitalist enterprises, plays an active part supporting livelihoods. However, it is insufficient to meet people's needs, and secondary to the Alternative and Direct economic practices. Engagement with Formal market transactions occurs in both Gizo and Vatu between small producers of copra and cocoa (Vatu only) and the global commodity market. Participants spoke about the labour intensive nature of this work, for relatively small profits. These are exported as raw materials, meaning there is little added in the value chain, and at times price fluctuations make it not worthwhile selling. In Vatu, this has resulted for a preference for cocoa crops over copra, as global commodity prices tend to be higher and more stable. The power disparity in these Formal market transactions between family run rural producers 
and the global commodity market is apparent. This gap is particularly large given the position of the Solomon Islands on the periphery of the dominant global economic system by virtue of its size, isolation and political weight (International Labour Organization, 2009). Consequently, at the community level many people rely on Alternative and Direct economies to sustain their livelihood.

There are limited formal employment opportunities throughout the Solomon Islands, as discussed in Chapter 2. From a conventional economic perspective, this 'issue' stems from a skills mismatch and lack of industry activity (Close, 2012). Gizo as a semi-urban location has more Formal waged labour opportunities than Vatu, yet this supports a minority of the population. As Patricia, a woman in the Gizo community noted, "people are looking for the jobs but there are not many...more people make their own business through income generating [activities]" (Interview, 17/03/14). Numerous community members noted that even those with waged employment earned insufficient income to meet the high cost of living in Gizo. Frank, a local business man in Gizo described the way in which people, particularly women, turn to Alternative economic activities, such as selling cooked food at the market, to supplement waged income (Interview, Gizo, 20/03/14).

Formal capitalist enterprises also play a relatively small role in these communities. Frank, whom we met above, talked about the need to diversify if you want to succeed in business in Gizo, "Gizo is very slow with business if you concentrate on one particular business. So here in Gizo I'm like an octopus with eight legs" (Interview, 20/03/14). Similarly, another businessman, Anthony, described the eclectic way in which his family makes a livelihood, renting out two small bungalows for tourism homestay (Formal capitalist enterprise), farming copra (Formal market transaction) and growing food in the garden for subsistence (Direct unpaid labour) (Interview Gizo, 21/03/14). Formal capitalist enterprises are seemingly non-existent in Vatu, with the few small shops resembling Alternative capitalist enterprises, run by churches or the RTC and profits appropriated to the community.

Under a diverse economies perspective, the lack of formal economic opportunities in Gizo and Vatu is reframed, from deficit to difference. The Formal economy is viewed as one means, amongst many others, that plays a part in supporting livelihoods (Gibson-Graham, 2008). Given the different geographical and economic contexts, Formal economic activities play a smaller role in the economy of Vatu than Gizo, yet they are auxiliary in both (GibsonGraham, 2006). 


\section{Alternative economy}

Alternative economic activities are understandably more prevalent in Gizo than Vatu, as the semi-urban environment requires greater reliance cash based transactions. Under the Diverse Economies Framework, the local market in Gizo has been classified as an 'informal market' involving Alternative market transactions. Despite the involvement of cash, the decision to classify this as an Alternative rather than Formal practice was made on the basis of vendors not being registered, taxed or the market regulated in the way that would typically indicate a Formal market transaction. The only requirement is a) payment of 5 SBD (0.9 NZD) per day to cover rubbish collection and maintenance. This informal market is incredibly important to the community, as a means by which anyone can transform labour and resources into cash, as Frank explains:

You go out today with zero dollars in your pocket, you get a fishing line and a hook, you come back in the evening and you get two, three, four five hundred dollars (SBD). Because the fish that you just caught is free, from the sea. You can use the money to buy food for the evening meal or save it and a week later you can pay the school fees. (Interview, Gizo, 20/03/14)

Barnabas, a man in the community describes fishing and selling at the market as the main way of life for his community near Gizo:

In this community they mainly rely on the sea. Young men go out fishing with their fathers, help out. Mothers go to the market and sell the fish and they get money to buy their food. That's daily life. (Interview, Gizo, 21/03/14)

The sea in Gizo almost echoes Esteva's (2010) conception of 'commons', a resource over which no one can claim ownership to which everyone has access, thereby providing 'quick money. As frank asserts, "they have problem of meeting the cost of their kids going to school, and this is the quick money, fishing...the sea is open to everybody" (Interview with Frank, 20/03/14). However, as has been debated within the broader literature, this is not without issues. Fishing for surplus and profit within the community, as well as the use of coral for snuff, has resulted in overfishing in the area and consequently the destruction of the reef. Locally based NGO's are now engaging in marine conservation projects and education to look after this common resource.

Gizo appears to have a modernising economy, with increasing reliance on cash to purchase goods and services. To participants, this was seen as a mixed blessing. On the positive side 
they enjoyed the ease and immediate access to goods and services not seen in rural areas, as Patricia, a woman in Gizo, explains:

This is an urban area, not a rural area... it is different from the rural areas. Like here, what I need I can find a bit easily, because the shops are here, they have good resources. At home [referring to her rural home in the Shortland Islands] it is very good, but it's slow, it takes time. We have to wait for the ship or any transport so we can communicate. (Interview, 17/04/14)

On the negative side, the increased focus on a cash based system is having an impact on the types of labour and products that are valued, and limiting economic practices. As Hannah, a local community woman, reflects, "if they want to send their children to school, they cannot take a bag of kumara or woven mat to the school" (Interview, Gizo, 24/03/14). She goes on to describe how this is placing increased pressure on women to take on the additional role of income generation to support the cash needs of the family:

Traditionally women worked in the kitchen and the garden, and rearing children. As we go on in these times there is more focus on the economic aspect. Women are trying to get qualified and get jobs. For those without the access to such an education level, most of them are in the market, selling something to try and support the family's income. Now days the cost of living in the Solomon Islands is too high. (Interview, Gizo, 24/03/14).

As the influence of the capitalocentric view of economy system seeps in, work in the domestic sphere is devalued or deemed insufficient (Midgley, 2006). The dominant view of the economic system is also somewhat consciencised by the community themselves, with Hannah herself talking about an increased "economic focus" driving this change, as though the activities in the domestic sphere are outside of economic domain. The result of this pressure can be seen in the practices of many women in the town, who bake/cook items for sale at the market, along with working a paid job or juggling domestic duties. The women with land on the outer islands often sleep at the market for a period or days or weeks to sell their produce and generate some cash.

Alternative market transactions, such as bartering, were more prevalent in Vatu than in Gizo. For example, there were accounts of people paying school fees using timber or food, and tithes to the church were given with a mixture of produce and cash. While Vatu did not appear to have the same level of cash dependence as Gizo, issues arising out of integration with the global capitalist economic system could also be seen. The capitalist economic 
system assumes certain architecture is in place to support its transactions, such as banks and ATMs, not taking into account the context of remote and rural areas. The most obvious example observed was the payment of teacher's salaries. Teachers are required by the government to be paid into a bank account, with the closest bank four hours away in Honiara. Hence, in order to collect their salaries they needed to spend approximately one quarter of their fortnightly income on transport to and from the capital. Recent changes in the banking system also meant that each individual must attend personally, with no ability to access accounts on behalf of others. Hannah reflected a similar situation for those living in the more remote areas of the Western Province and the difficulty this created in saving money:

If you look at how the government has set up financial institutions it is not designed for people staying out in the rural areas. Here in Gizo we have commercial banks, also in Noro and Munda, but how can women from the Shortland's and the other islands save? It will cost them a lot to come to the commercial bank. (Interview Gizo, 24/03/14)

The modern global capitalist system assumes a certain architecture exits for economic relations to happen. However, in places like the Solomon Islands, outside of urban centres, this is often inaccessible and a constraint rather than an enabler.

\section{The Direct economy}

I refer the bottom row of Gibson-Graham's (2005) Diverse Economies Framework as the Direct economy. I use the term 'Direct' as a descriptor of the activities included in this category that typically remove the mediation of the market to denote a more direct form of living (Esteva, 2010). The intermediary of cash or other currency is removed, to obtain what is needed to support ones livelihood (food, shelter, care for loved ones etc...) from existing physical and human resources (Gibson-Graham, 2006).

The economy of Vatu relies heavily on Direct economic practices, particularly through subsistence living. Under a Diverse Economies Framework, subsistence activities are a form of Direct unpaid labour. Rather than being compensated financially for the work involved in producing items for consumption, as is the case with waged labour, the person supplying the labour shares in the benefit of what is produced (Gibson-Graham, 2006). For example, the labour a person contributes in planting, caring for crops, harvesting and preparing food is compensated through partaking in that food. This is typical practice in Vatu, where the 
consumer and their family farm the majority of food consumed, as Alice, a woman in the community, described:

All the village people plant vegetables in the garden, sometimes they sell the vegetables just to pay salt, to pay rice, just pay what they family needs at the shops, but usually people are eating local food from the garden. (Interview, Vatu, 05/04/14)

Subsistence activities are often regarded as slow, traditional and unmodernised under a capitalist economic model that "privileges solutions that require lots of capital rather than lots of labour" (Escobar, 1997, p. 90). Underpinning this interpretation is a set of western values and standards that focus on the material without taking into account the multiple other indicators of what supports a good life. While more 'developed' places than Vatu may have greater wealth and access to services, the conclusion that they have a better life is questionable (Ziai, 2007b). Postdevelopment theory reminds us to question the universality of these values and of a narrow capitalist view of economy, enabling the enormous benefits of subsistence living in Vatu to be revealed. A diverse economies perspective instead reveals the autonomy Direct economic practices produce. As Maya, a local woman in Vatu, reflected "I prefer to live in the rural area because almost everything is free" (Interview, 05/04/14). She sees the ability to be able to grow her own food, and make gardens with minimal external input as a positive attribute of Vatu as a geographical and social space (GibsonGraham, 2006). Similarly, Alice a health practitioner in Vatu, referred to the self-reliance this generates as an advantage over living in an urban space:

[People are] taking foods from garden, healthy food, not relying on food at the shops, like people in Honiara are buying [their] food at the shops. People in the rural areas they do not depend on the food at the shops. (Interview, 05/04/14).

Along with a greater independence, this also has health benefits, Alice noted that it is rare to see a malnourished child in Vatu. She attributes this to the subsistence lifestyle "...because mummies are planting vegetables and local food, feeding these to their children" (Interview, 05/04/14). The self-reliance of subsistence farming as a Direct economic practice can be seen to provide autonomy, food security, and support the physical health of the community.

In Gizo and Vatu, the wantok system stood out as a Direct economic practice that is invisibilised under a capitalocentric view, yet plays an important part in the local economy. As explained in the community profile section, the wantok system describes a network of relationships giving reciprocal support to kin (Nanau, 2011). From a mainstream 
development perspective, such practices are often depicted as regressive, and impediments to progress, as Rahnema notes, "the virtues of simplicity and conviviality, of noble forms of poverty, of the wisdom of relying on each other, and the arts of suffering were derided as signs of "underdevelopment" (1997, p. x). In contrast, a diverse economies perspective recognises the wantok system as key aspect of Melanesian culture that describes identity and bestows social capital (Nanau, 2011). In Gizo and Vatu "wantok business", as Patricia, a local woman, called it was "common practice", and supported livelihoods in multiple ways (Interview, Gizo, 14/04/14). A number of participants were raising a child that belonged to wantok living elsewhere. From a diverse economies perspective, this is a form of Direct unpaid labour, not normally counted by the mainstream economy. Household flows also extended to wantok, offering another source of money or goods when needed. As Patricia explained, "when they [wantok] know there is somebody who is working in the area, they ask for money for the school fees and other things" (Interviews, Gizo, 14/04/14). These Direct non-market transactions do not follow the rules of commensurability seen in the conventional economy, but rather are driven by cultural norms, highlighted in Patricia's description, "when you do not give them anything [wantok], you feel no good, your family too feels no good. Maybe this is the traditional way, Kustom" (Interview, Gizo, 14/04/14). Thus the compensation for such activities is considered social and cultural rather than something of financial value (Gibson-Graham, 2008).

However, not everything about diverse economic practices is inherently positive. A number of participants reflected on issues stemming from wantok business. These seemed to concentrate principally, though I am sure not exclusively, around areas that clashed with mainstream economic practices. For example, responsibilities toward wantok made it difficult to save money for ones own family, and preferential treatment of wantok made it difficult to run a successful business as wantok may not want to pay for goods or services from other wantok. At a macro level the wantok system is criticised encouraging nepotism in job opportunities and politics (Nanau, 2011). Gibson-Graham speak of "not shy[ing] away" from the power dynamics wound up in such practices, but rather to "explore their complexities" (2006, p. 71). 


\section{Text box 5.3: Elizabeth's story}

Elizabeth's story illustrates the way in which Formal, Alternative and Direct economic practices are combined to support livelihoods, and how this is influenced by the local context. Elizabeth is a married woman living in Gizo. She is employed by a church (Formal waged labour), giving her an income of 500 SBD (85 NZD) per fortnight, an decent wage for this type of work and higher than the country's GNI of 320 SBD per fortnight (Solomon Islands Chamber of Commerce and Industry, 2010; World Bank, 2014). In addition to one of her own children, she is raising two of her sister's children (Direct unpaid labour). Her wantok commitments go further, supporting her two younger siblings to attend school as her parents are deceased (Direct non-market transactions). Her ability to engage in subsistence activities is limited by her residence in town. With no land she cannot grow a garden to help feed the family and instead relies on fish and produce from the daily market. Life in Gizo is relatively expensive (e.g. a pineapple costs 15 SBD, a packet of eggs $50 \mathrm{SBD}$ and a family sized fish $30 \mathrm{SBD}$ ). Her income, together with her husband's income is insufficient to feed the family and pay for expenses such as school fees. Consequently, to supplement the family's income Elizabeth has teamed up with a friend to sell banana bread and ice blocks at the local market (Alternative market transaction). Her accommodation is provided by her employer (Alternative market transaction), and in difficult times they give her additional money to meet her needs (Direct market transaction). For non financial reasons she also volunteers for the church and for the local council in maintaining the market (Direct unpaid Labour). Under a diverse economies lens, all of Elizabeth's activities, paid or unpaid, incoming and outgoing, are illuminated in supporting the life of her family. Her incredible capacity as a wife, mother, sister, employee, church member and businesswoman are also revealed.

(Interview, 14/03/14)

\section{Implications of a diverse economies perspective}

A diverse economic analysis of Gizo and Vatu recognises the relatively minor role of Formal economic activities, representing the tip of the iceberg, beneath which a myriad of Alternative and Direct economic activities lie. The 'economy as an iceberg' is a metaphor used in diverse economies literature to illustrate how a capitalocentric view gives a distorted and incomplete picture of the economic reality of communities (Gibson-Graham, Cameron, \& Healy, 2013). Bringing these activities to the surface, and giving them equal credibility, 
results in a more complete picture of the economic reality of communities. A different foundation is laid from which development activities focussed on livelihood improvement can be launched. Gibson-Graham (2005) refer to this new conception of the economy as the 'community economy'. In addition to including activities that support well-being directly and alternatively, the community economy respects a shared commons, and is concerned with maintaining the ability of such commons to continue to support livelihoods in the future (Gibson-Graham, 2005).

\section{A conversation changer}

Consequently, a diverse economies reading of Gizo and Vatu opens up a new set of questions and opportunities that were previously invisible, with implications for development and education. If the Formal economy of Gizo and Vatu were considered the only one of importance, it would make sense for the development agenda to focus on increasing formal employment opportunities through actions such as supporting industry and investment, promoting business initiatives, adding to value chains and improving access to major markets. Similarly the role of education would be to create a skilled workforce to meet industry needs. In contrast, recognition of the importance of the Alternative and Direct economic activities, particularly in Vatu, prompts a different and more localised discussion. Questions are raised as to how development can strengthen Alternative practices while encouraging environmental responsibility. How development can protect the resilience and self-reliance of subsistence livelihoods in a modernising world. Education consequently focuses a wider variety of skills, both local and introduced (agricultural skills, money management, environmental awareness and home management) that young people are likely to needed such a reality.

Far from choosing to just focus on the positives, ignoring needs or problems within communities, a more holistic view of the economy reveals a deeper understanding of practices that support lives on a daily basis and a different set of issues. As Gibson-Graham point out, the community economy "exists in constant change and contradiction" with some practices undermining others $(2005$, p. 16). In Gizo, the practice of fishing and selling at the informal market to obtain money quickly and easily is beginning to destroy the marine environment that has supported lives for centuries. Likewise, the wantok system supports lives while at the same time creating demands that place families under pressure, particularly with an increasing importance on cash in the economy. A different analysis of 
what exists in the economy leads to a different understanding of where shortfalls exist. This raises the opportunity for different decisions to be made about what development intervention (if any) might improve lives of people in these communities, and how such interventions need serve the different contexts of Gizo and Vatu.

\section{Community assets maps}

The final section of this chapter presents the community assets maps of Gizo and Vatu, bringing together the community profiles and diverse economies analysis to display the strengths and capacity of these communities. Asset maps, following the model developed by McKnight and Kretzmann (1993) and used by Gibson-Graham (2005), include both social and physical 'assets', demonstrating what supports community resilience, identity and wellbeing. Conventional needs analysis in development practice asks communities to identify and prioritise issues. Focussing on what is lacking or problematic tends to represent communities feeling as inadequate and in need of external intervention. This influences how communities view themselves, as well as how others, such as donors, government, and NGOs view them. The asset maps of Gizo and Vatu were constructed using the opposite approach. Community members were asked about the strengths of their community, and what they liked about living in that place during interviews and informal conversations. In contrast to needs analysis, the asset mapping approach infuses confidence and positivity, guiding people to realise all the things they have and what they can do with these to improve the life of their community (Community Partnering for Local Development, 2010a). As a researcher I could visibly see the difference, even the surprise, in people's faces, when asked about assets. Ideas started to flow as they considered all the good things about their community and what was working well. For example one community woman in Gizo began to tell me how she would like to start a savings group in her home village, another woman in Vatu told me about her plans to begin an outreach literacy project. Hannah, a community woman in Gizo, reflected the 'can do' attitude cultivated through this approach when talking about skill sharing programmes among women in rural areas:

They have all the resources with them...they have their land, they can plant flowers, they have the sea there, they can go fishing. That's all. We don't really need big money we just make ourselves more crazy with financial strains and all this trying to create programmes that cost more money. We have to work and think about how we can utilise the current resources that we are having now. (Interview, Gizo, 24/03/14) 
Her ideas evolved during our discussion to contemplate taking a skills audit of woman in the rural areas to better enable skill sharing.

The community asset map for Vatu, displayed in Figure 5.9 below, highlights the rich social assets of this community that would not be apparent in a needs analysis. While having little infrastructure and services, compared with Gizo, Vatu has prominent physical resources, namely fertile land and strong skills and relationships that give the community great autonomy, resilience and health.

Figure 5.9: Community assets map Vatu

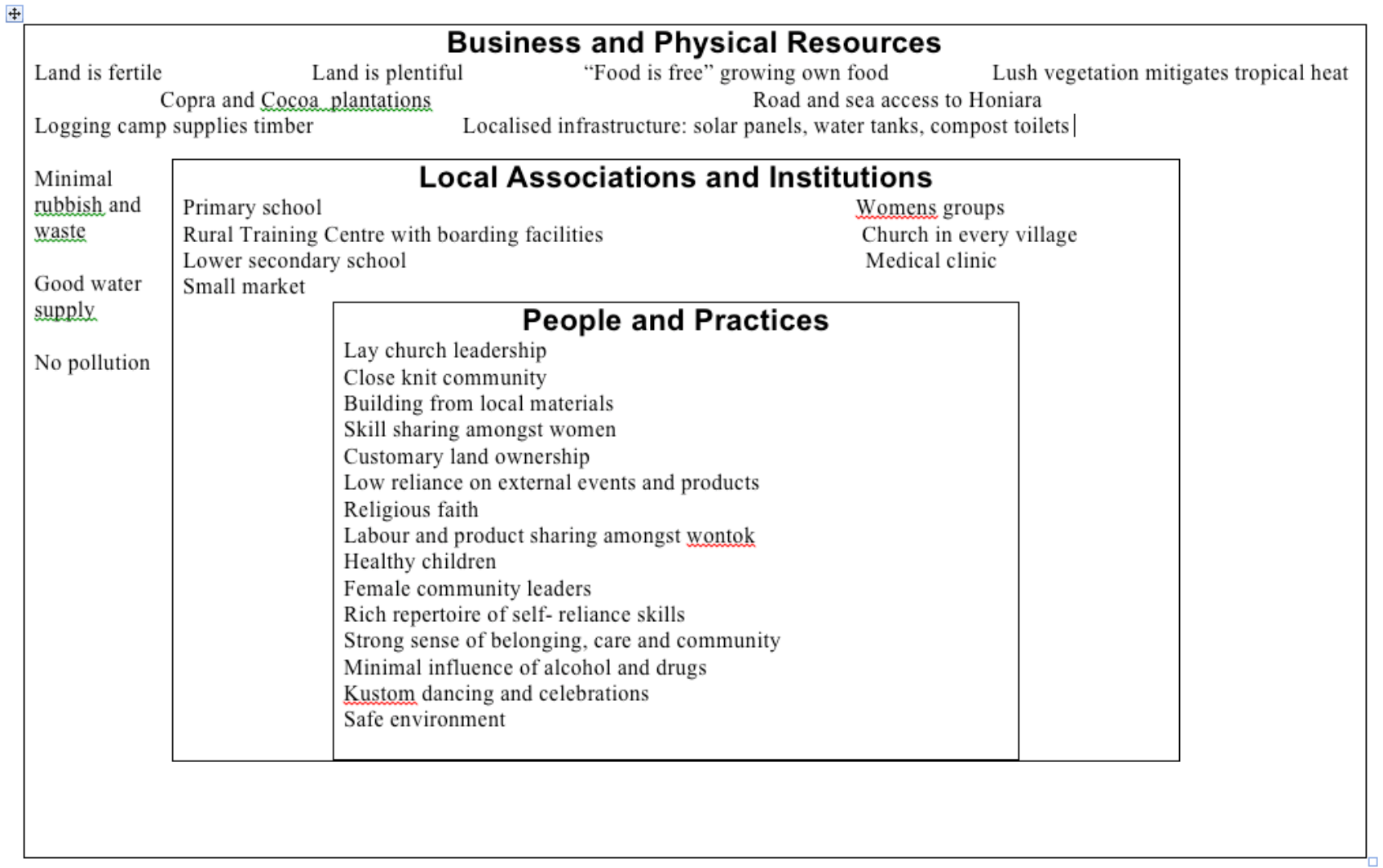

The community assets map for Gizo, displayed in Figure 5.10 below, reflects the abundance of resources and services available to the community. From here, opportunities to enhance the livelihoods of the community utilising these resources can be seen. While a needs analysis of Gizo might focus on the number of unemployed youth, the assets map highlights potential areas of future development, such as tourism. It also demonstrates the importance of supporting alternative means of livelihoods for youth, through fostering the continuance of local skills such as fishing and building from traditional materials. 
Figure 5.10: Community assets map Gizo

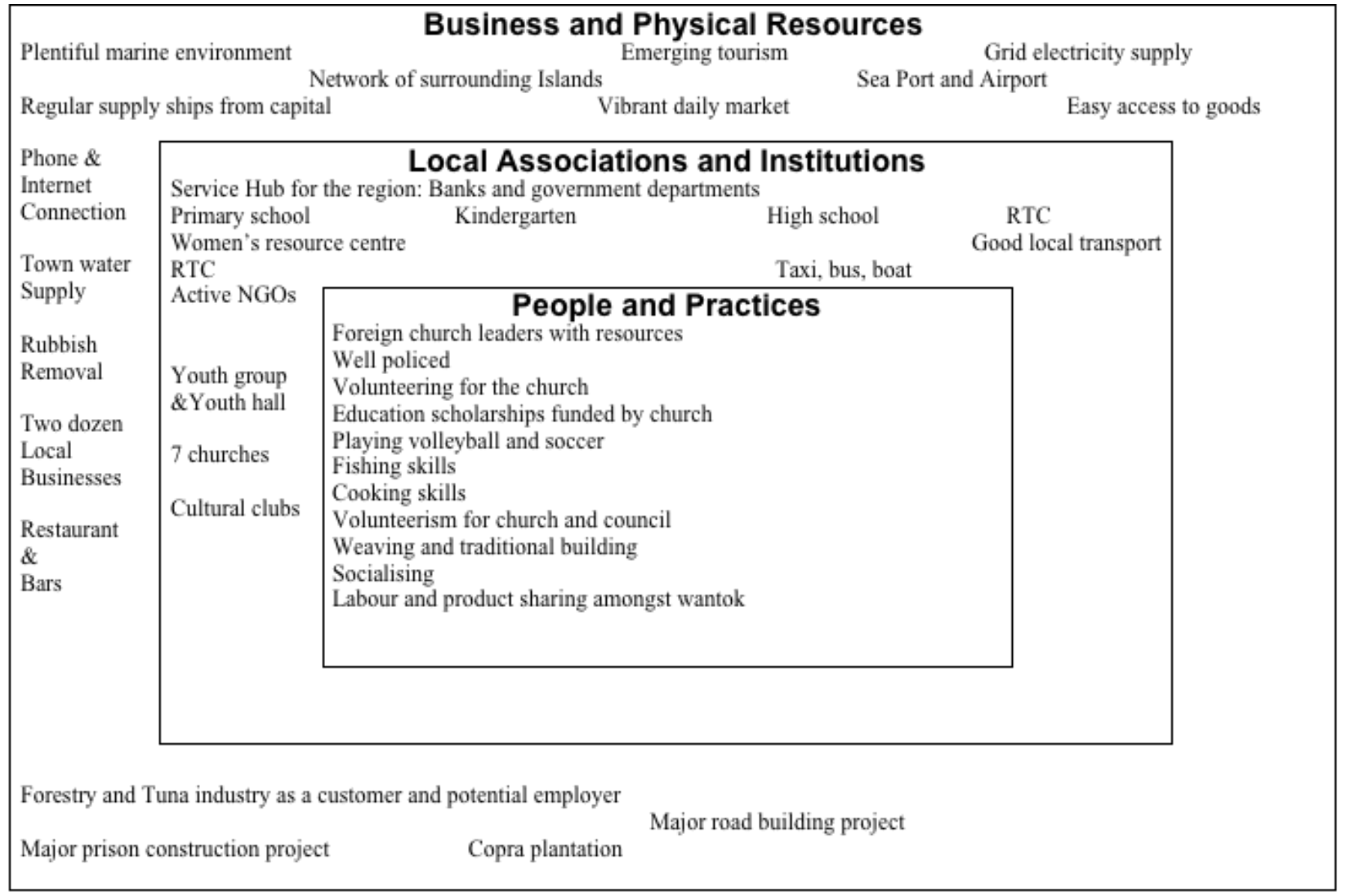

Chapter 2 presented a largely mainstream development view of the Solomon Islands. The view reflected by the World Bank, International Labour Organisation and various United Nations institutions was one of a vulnerable and volatile country on the periphery of the global economy, with poor levels of education and struggling to meet the basic needs of its population. The community profiles, diverse economies analysis and above assets maps of Vatu and Gizo paint a different picture. Stepping outside the hegemonic development discourse that defines these places as undeveloped, these communities can be seen to be full of resources and capacity to determine their own future. This denotes a very different starting point for development conversations.

\section{Conclusion}

The tyranny of the capitalocentric view of economy drives and constrains people to see their lives under a narrow reductionist view, steeped in notions of productivity and efficiency. It largely ignores the way in which this system destroys the environment and benefits a few rather than the majority. Worse still, it reinforces the subordination and exclusion of alternative forms of economy from credible discussion. By ignoring the diverse economic 
practices already taking place in First and Third world countries, it produces a distorted picture of what sustains livelihoods in reality. The contribution of populations, often labelled as marginalised, those living in rural areas and women, is devalued with much of their work considered outside the economic sphere. This has prompted a more realistic and holistic view of the economy to be sought through a diverse economies approach.

The community profiles of Gizo and Vatu set the scene of the environmental, economic and social situation of these communities, recognising the importance of local context to a more holistic understanding. Against this backdrop, a diverse economies analysis revealed the relatively limited part the Formal economy plays in Gizo and Vatu, compared to Alternative and Direct economic practices. The significance of these practices to the livelihoods of people in the community is evident, through the stories and voices of the research participants themselves. While such practices are not exempt from problems, they give a more realistic picture of what supports livelihoods so that "capitalist activity is knocked off its perch" (Gibson-Graham, 2005, p. 13). The community assets maps of Gizo and Vatu bring together the Community Profiles and diverse economies analysis to display the strengths, resources and capacity of these communities. This picture counteracts the hegemonic development discourse and changes the departure point for development discussions. As Gibson-Graham note:

A full audit of livelihood practices, including the contribution of non-market and unpaid labour transactions, allows for reflection on what the community is nourished by (rather than what it lacks) and public discussion of which of these practices could be strengthened or extended. (2005, p. 16)

Returning to Santos (2004), a diverse economies and asset based perspective has destabilises the monoculture of capitalist productivity and efficiency. The sociology of absences is expanded to incorporate an ecology of productivity, previously hidden and discredited. From this space the field of credible experiences is enlarged, and consequently new possibilities for the future can be imagined.

A more holistic and realistic understanding of what supports livelihoods in Vatu and Gizo, forms the basis for the broader discussion of relevance of Rural Training Centres, as a particular form of education. The next chapter will focus on the Rural Training Centres themselves, where they fit in the education hierarchy, what they do, and the aspirations of 
young people attending these centres for the future. The question of fit between the activities of RTCs, the desires of the future generation, and the community economies in which these people reside can then be considered. 


\section{Chapter 6: Monoculture of western scientific knowledge: Non-formal education through Rural Training Centres}

This chapter builds on the expanded view economy established in the previous chapter to explore an expanded view of education to support these diverse livelihoods. It begins by considering what has been omitted and subordinated by the dominant development discourse that exalts western scientific knowledge and formal education as the only credible options. Under this monoculture of western scientific knowledge alternative forms of knowledge, such as traditional and indigenous knowledge, are deemed inferior. Likewise education outside of the formal western framework, such as informal, vocational and direct learning, are marginalised by the global education agenda. In developing countries such as the Solomon Islands, where livelihoods rely on many informal and traditional practices, this raises the questions of purpose of education (education for what?) and its fit for context (education for who?).

The principal aim of this chapter is to examine the relevance of Rural Training Centres to their local communities from the perspective of young people, the local community and women under an expanded conception of education and knowledge. To do this an understanding of the aims and operations of the RTCs in Gizo and Vatu will first be established through RTC profiles. These profiles highlight the differences in approach between the RTCs, as reflects their locations and resource context. Through the drawings constructed in the dreaming exercise, the aspirations of youth for the future will then be explored. This informs a discussion of how RTCs align with these aspirations in terms of the type of skills taught and methods of delivery. More direct perceptions of RTCs are examined using focus group and interview data from students and the surrounding communities. Hence their relevance in terms of role in the community and quality can be considered from a local perspective.

Given the disparity between male and female enrolments in RTCs, and Solomon Islands education more broadly, specific attention is given to barriers to participation that women face. Finally, returning to the constructive and practical foundation of this research, the opportunities to increase the participation of women, as raised by the women within the communities themselves, are discussed. 


\section{Hegemony of western knowledge and education}

The Enlightenment period is often viewed as a time at which the dominance of western scientific knowledge was established. It was regarded as a liberating force, freeing mankind from being at the mercy of nature and promoting a new form of equality (Tikly, 2004). Modern science, emboldened with the tools of reason, systematic investigation and logic became " the sole criteria of truth" outside of which "all that is not legitimised by the canon is declared non-existent" (Santos, 2004, p. 238). This western conception of knowledge has become a powerful discourse that actively silences other forms of knowledge. By concealing, trivialising and discrediting alternative discourses, the hegemony is maintained and perpetuated. With other forms of knowledge derided as 'uncredible' under this discourse, western scientific knowledge appears efficient and coherent and therefore superior (Santos, 2004).

Postdevelopment questions this superiority, delving into what and who has been silenced through this supremacy and for what benefit. Santos (1999) exposes the epistemological flaw in the dominant conception of knowledge, pointing out that there is no fixed universal body of knowledge 'out there' that can somehow be attained. Rather, knowledge (and by contrast ignorance) is socially constructed, hence "what we ignore is always is always ignorance of a certain way of knowing...every act of knowing is a trajectory from a point $A$, that we designate as ignorance, to a point B that we designate as knowledge" (Santos, 1999, p. 36). Western scientific knowledge has been branded as the destination, while other forms of knowledge, such as traditional, indigenous and informal knowledge are regarded as starting points, a state of ignorance. The project of development, progressing societies from traditionalism to modernity, therefore an epistemological endeavour transforming ignorance to enlightenment (Nordtveit, 2010). However, a more critical view of the emancipation of knowledge achieved by enlightenment reveals it to be exclusive and regulatory. Certain groups, including slaves, the poor, indigenous populations, and women, did not share in this initial liberation. Instead, modern scientific knowledge has been used to regulate how these groups can operate in society (Santos, 1999). This leaves western societies, and more specifically western men, as the main beneficiaries of this hegemony.

\section{Development and the global education agenda}

Dovetailing with the monoculture of western scientific knowledge, is a monoculture of formal western education that neglects local context, ignores cultural diversity and omits other forms and institutions of knowledge (Coxon \& Munce, 2008). Formal western education is 
used to transmit knowledge and epistemology, "fostering modern cultural values" that support and propagate the existing hegemony of knowledge and development (Escobar, 1997, p. 86). Education, as a form of colonisation, and later development, for poor countries, is not new. However, the past three decades have seen unprecedented global efforts to achieve universal education targets. Education, particularly primary education, has become the cornerstone of development, and is viewed as the foundation on which success in other areas, such as income and health, will be achieved (Mundy, 2006). The result is a powerful new education agenda that propagates formal western education across the globe. A number of factors that have fostered the emergence of this agenda will be discussed below: evidence of the success of education in achieving development outcomes, ideological consensus on education, and practical harmonisation and coordination focussed around education.

Firstly, evidence for education as a means of achieving some of the key goals of development (economic growth, improved child health and population control) has been mounting. Girls' education, in particular, has been shown to have a positive impact on almost every aspect of development. According to UNICEF $(2004,2011)$ economic benefits include delayed age of marriage, lower birth rates, greater participation of women in the economy, and increased individual income. Health-wise, education reduces maternal mortality and the risk of HIV Aids and has an intergenerational effect, resulting in healthier children. Socially, education raises social status and builds resilience against sexual and labour exploitation (UN Millennium Project: Taskforce on Education and Gender Equality, 2005). Education appears to be a simple way to achieve multiple development outcomes simultaneously.

A second reason underpinning the rise of the global education agenda is an unlikely accord between opposing ideologies of development around the topic of education. The economic view of development, represented by the World Bank and other Bretton Woods institutions, operates on the underlying belief that increasing economic growth will take care of life's other necessities (Mundy, 2006). They seek the best investment for the greatest return, and education with a proven track record for increasing economic growth, fits the criteria. According to the World Bank:

The expansion of educational opportunity, which can simultaneously promote income equality and growth, is a win-win strategy that in most societies... education is one of the most powerful instruments known for reducing poverty and inequality and for laying the 
basis for sustained economic growth, sound governance and effective institutions. (2002, cited in Mundy, 2006, p. 33)

The opposing ideology, arights based perspective of development, views education as a basic human right inalienable, immutable and inseparable from other fundamental rights. This is enshrined in the Universal Declaration of Human Rights. Article 26 states that everyone should have the right to education, further stipulating that it should be compulsory and free at the elementary level (UN General Assembly, 1948). Thus, these two approaches that commonly clash in development, find consensus around the importance of education and further agreeing on prioritisation of primary education.

Thirdly, founded on this ideological consensus, more practical partnerships have enabled a shift from a fragmented and uncoordinated approach to education aid to a harmonised and targeted approach. The introduction of universal, measurable and time-bound targets, through the Millennium Development Goals (MDGs) and Education for All (EFA) commitment, have driven coordination and harmonisation amongst donors. This has resulted in unprecedented mobilisation of education policy and resources, whereby "universal public access to free basic education has now achieved status and legitimacy as a global public good" (Mundy, 2006, p. 45).

The evidence supporting education as a means to achieve development, the unity it finds in competing ideologies, and its targeted focus have all established the new global education agenda.

\section{Formal education: the only pathway}

In what appears to be a grand oversight of development the type of education being provided and its relevance to the context in which it is delivered has largely gone unquestioned. The accepted concept of education is that of a formal western system, built on western scientific knowledge. The global education agenda consequently promotes formal education, predominantly at the primary level. As a result investment in other types of education (e.g. informal and vocational) and other levels of education (e.g. tertiary being) has been redirected. Furthermore, progress at the primary level has exposed gaps and created unmet demand for education at the secondary level (Mundy, 2006). In its attempt to "redress the apparent failure of half a century of development efforts" the global education agenda has created a universal monoculture that neglects local context and ignores diversity 
(Coxon \& Munce, 2008, p. 147). The question of fit for context is largely ignored, with local, traditional and indigenous skills marginalised. A singular pathway has been established without consideration of it own contextual and historical roots.

Research on the benefits of education is typically based around formal primary and secondary schooling, without looking at the benefits of education more broadly, through non-formal institutions or direct practices of transmitting knowledge. Similarly, the economic and human rights approach to development are aligned in their focus on increasing primary education and gender equality in the formal system, ignoring other types of education. While this might be expected from western dominated development institutions, the acceptance of a narrow view of education can also be seen in the work of those claiming to represent alternatives to the western concept of development. For instance, working from a southern perspective based on experience with women in India, Nussbaum (2001) proposes Human Capabilities as an alternative conceptualization to the western notion of Human Rights. Despite an apparent non-western approach, her concept of education is clearly that of a formal nature, rooted in western scientific knowledge. Under the capability senses imagination and thought, Nussbaum refers to the ability to reason as being "truly human...a way informed and cultivated by an adequate education, including, but by no means limited to, literacy and basic mathematical and scientific training" (2001, p. 78).

The remainder of this section will discuss points of contestation with the dominance of formal western education, in particular questioning the purpose and relevance of such education in different contexts, and the other forms of knowledge excluded from the formal recognition.

\section{Education for what: Questions of purpose}

Under the hegemony of formal western education, debates in education have been reduced to a discussion of implementation strategies. How education is to be implemented has replaced the more foundational questions of why (purpose) and what (substance) of education (Nordtveit, 2010). Through the target driven approach of the EFA and MDGs, educational content and outcomes have been sidelined from discussion, which instead focuses on the logistics of achieving enrolment and completion targets. Postdevelopment critics argues that the central purpose of western education, like development more broadly, is a story of economic utility, a servant of the global capitalist economy, as Nordveit describes: 
Education inevitably supports this move towards a western-capitalistic discourse, not only by its structures (such as increasing privatization, standardization, and necessity to use private tutoring, etc), but also by its curriculum and thereby the identity formation of children and adults (2010, p. 326).

Evident in the quote above is the idea that formal western education is an incubator for western values and ideas, focused on producing people who will be 'productive' under the global capitalist system. Tikly (2004) takes this one step further arguing that education institutions are disciplinary tools extended from the subjectification of the colonial era to the new imperialism of development. The purpose of education, as he sees it, is to make countries economically useful to the capitalist economic system, and to mitigate social and political risk that might arise if different goals and values are allowed to mature. Formal western education upholds a promise of a "rich, cultivated and happy life" as defined by western values and interests (Nordtveit, 2010, p. 325). Through this, western values are internalised by people in developing countries as superior and the pursuit of western ideals becomes owned by the people themselves (Tikly, 2004). As Nordveit explains, "the dichotomy is perfect - the underdeveloped departs from a traditional world and becomes familiar with new tools for the economic improvement of his or her life (2010, p. 332). The existing hegemony becomes self perpetuating, and the pluralism, diversity of knowledge and education is eroded. This is evident in the Pacific, as modernisation and formal education replaces transmission of local and indigenous knowledge (Gegeo \& Watson-Gegeo, 2002)

Astoundingly, despite the economic discourse used to justify the implementation of western education in developing countries, such as the Solomon Islands, education does not typically encompass knowledge and skills that support economic wellbeing for the majority of people (Nordtveit, 2010). As discussed in the previous chapter, a narrow view of economy pervades, and formal education acts to prepare people for this narrow pathway focused on formal employment opportunities. If formal education only prepares people for Formal economic practices, what then does that mean for the Alternative and Direct economic practices that were established as vitally important in the previous chapter? Education that focuses on these practices, such as traditional, informal or indigenous knowledge is not given the same credibility or importance as 'legitimate' education (Nordtveit, 2010). Hence, the purpose of education remains to produce citizens that can serve the dominant model of economy, promoting global economic objectives rather than local prosperity (Nordtveit, 2010). 


\section{Education for who: Questions of relevance}

There appears to be a fundamental misalignment between the livelihoods of the majority in developing countries and the formal education system that they are compelled to follow. It is a system designed for western, developed and predominantly urban environments. The relevance of such a system for contexts outside of this is questionable. In the Solomon Islands where the population is highly dispersed, predominantly rural, and there are few formal employment opportunities outside of Honiara, the fit of formal western education is dubious. Furthermore, with $70 \%$ of young people pushed out of the formal system by exam filtering or dropping out before completing secondary education, they have little chance of gaining the few formal jobs that exist (UNICEF, 2013). Gegeo and Watson, speaking from a Solomon Island perspective, describe the resulting situation this creates for young people:

The schools with their emphasis on Anglo-European knowledge, inevitably prepare children for urban lifestyles and expectations. As most children fail or drop out of school after the early primary years, they return to the village ill prepared for the rural life they must lead. (2002, p. 401)

Contextually inappropriate education continues to ensure a small number achieve the intended employment outcomes, with progression to further training still largely dependent on having the financial or social resources required. Far from being an egalitarian process, location, ability to pay fees and the willingness of family to support progress to higher levels influences educational outcomes. In this way, formal western education in the Solomon Islands can actually be seen to advantage those who already have advantage, ultimately helping the rich, not the poor (Nordtveit, 2010).

Meanwhile, the majority of young people in the Solomon Islands are left with poor quality basic education that does not encompass the skills and knowledge relevant to the Alternative and Direct livelihood opportunities around them. These rely heavily on practical skills and indigenous values in contrast to an environment where education quality is defined by adherence to international standards, enrolment indicators, and rankings on international test scores. How well the educational content and pedagogy fit with local context is rarely considered (Nordtveit, 2010). As a result basic education has largely been taken to mean formal primary education in the Solomon Islands. Formal primary education assesses the ability of students to pass examinations, often in a language and context different from their own indigenous language and conception of learning. While alternative views that focus on learning values, knowledge and skills that are relevant to the life of the local community can 
be found, these are peripheral to the dominant global education agenda, "in this process, other more practical and cultural knowledge and skills, highly relevant to life in Pacific communities, but neither easily examinable nor deemed academically important, have been marginalised" (Coxon \& Munce, 2008, p. 152). Rural Training Centres, with their focus on developing practical skills that can be used for self reliance and income generation, offer a potentially relevant alternative, particularly for those who have been pushed or dropped out of the formal system.

\section{Indigenous knowledges}

In addition to failing to fit with the local livelihood context, formal western education fails to recognise the role of indigenous culture in shaping the everyday practices and social relationships of Pacific communities. Coxon and Munce point out the centrality of indigenous values, "to varying degrees, these communities are still characterised by socio-cultural ethics of redistribution, reciprocity and inclusiveness" (2008, p. 148). Indigenous culture is pivotal to knowledge and learning, meaning that educational content and structures need to include indigenous knowledge systems in order to be truly empowering and culturally appropriate.

Gegeo, an indigenous Solomon Islands scholar, critiques the way that indigenous knowledge, or more broadly indigenous epistemology, is treated by development policy and practice. He is particularly concerned about the way this has impacted rural youth in on his home island, Malaita. Indigenous epistemology is the process by which knowledge is constructed and validated, which then shapes thinking and behaviour (Gegeo \& Watson-Gegeo, 2002). Taking an epistemological point of view recognises that indigenous knowledge is not static, it is always evolving. Introduced knowledge can be indigenised as it is integrated and transformed to fit local practices (Gegeo, 1998). While there has been greater recognition of indigenous knowledge in the development literature, Gegeo and Watson-Gegeo (2002) note that it is still treated as a resource that can be extracted for its instrumentality, rather than the grounding paradigm.

In the Solomon Islands, indigenous knowledge includes relationship to the natural environment and to cultural values. Gegeo recognises the blend of ideas and cultures experienced by youth in the Solomon Islands as they are influenced by global culture, the capitalist economy and the forces of development. These youth face issues of limited local employment, poor education and increasing population pressure, as discussed in the Chapter 2,. Many who are drawn to the "glitter of urban life" find themselves "involved in 
petty crime, alcoholism, drugs and gangs" without the guidance of their family, and "separated from their indigenous cultural roots" (Gegeo \& Watson-Gegeo, 2002, p. 384). As such, he advocates for rural development grounded in indigenous knowledge and values. So that while it may borrow from introduced ideas, such as formal education, it is change that the people themselves bring about, emerging from their own perspective and culture (Gegeo, 1998).

The analysis that follows considers the link between the aspirations of youth and indigenous epistemology. It asks if RTCs are an example of education that bridges introduced and indigenous knowledge, informing the question of relevance to the community.

\section{The Rural Training Centres of Gizo and Vatu}

Just as the previous chapter contained Community Profiles, demonstrating how place shapes the economic opportunities and livelihoods of a community, so this section opens with profiles of the RTCs in Gizo and Vatu. RTCs represent an informal (or rather, to be consistent with postdevelopment discourse an 'alternative' form of education) that grew out of the communities themselves through wider church arteries. The RTC profiles that follow give an overview of the purpose, course structure, students and staff, facilities and funding and community links of these RTCs. This highlights the way in which RTCs differ from one another to reflect the context and needs of their surrounding communities.

\section{St Peter's RTC Gizo}

\section{History and focus}

St Peter's is a young RTC, founded by a long-term foreign Catholic Bishop in 2011 in response to youth unemployment, petty crime and promiscuous activity observed in the town. The vision for the RTC is to serve those who have no other education options, giving them skills to earn a living in the local community, to use in the home or to continue on to further education elsewhere. As Maria, an a staff member at the RTC said:

The best thing about St Peter's is that they provide access to young people. Girls and boys who would not have any chance at all come here...we take in young people who have had no schooling at all, who have had little primary, and who have had maybe three years of secondary. (Interview, 19/03/14, Gizo)

It is relatively small, with a total of 59 students. The capacity of most courses, particularly the trade-based courses, has already been met. The centre would like to expand, but cannot due to a scarcity of land in Gizo town centre. The limited size also means that St Peter's RTC 
operates as a day school only. Students need to live within the local area to be accepted. The model is based on a highly successful RTC in Honiara, previously established by the same Bishop.

\section{Courses}

Given its semi-urban location, St Peter's offers courses that reflect the type of work available and livelihood practices in the local community:

Mechanics - focussing on outboard motors that are heavily utilised for boat transport and fishing.

Electrical - encompassing wiring of solar panels and generators to enable students to install these at home or as a service.

Carpentry - complimenting the array of construction projections in the area and personal home building.

Life Skills - incorporating cooking, sewing, nutrition and other skills considered useful for women to look after the home and children, or make products for sale.

The centre would like to have an Agriculture course but lacks sufficient land. All courses are two years in duration and specialisation specific from commencement. Along with the core teaching, personal development is a key focus for the RTC, whereby students learn literacy, religion and values.

\section{Staff and students}

Student intake is restricted to youth aged $16-23$ years. Table 6.1 below gives a breakdown of 2014 student numbers by course and gender

Table 6.1: St Peter's RTC students by course and gender

\begin{tabular}{|llll|}
\hline Course & Males & Females & Course total \\
\hline Mechanics & 19 & 2 & $\mathbf{2 1}$ \\
\hline Electrical & 16 & 2 & $\mathbf{1 8}$ \\
\hline Carpentry & 8 & - & $\mathbf{8}$ \\
\hline Life Skills & - & 12 & $\mathbf{1 2}$ \\
\hline Gender total & $\mathbf{4 3}$ & $\mathbf{1 6}$ & $\mathbf{5 9}$ \\
\hline
\end{tabular}

The centre has a majority of male students $(73 \%)$, mostly as a result of male dominated courses in traditional trade areas. St Peter's encourages female enrolment into these 
courses, and has been successful in stretching the gender norms, but finds that few females still apply for trade-based courses. The Life Skills programme is exclusively female, and is the only course with capacity to take more students. However, the RTC has had difficulty in encouraging girls to apply, an issue that will be discussed in the section Women: Barriers and opportunities to RTC participation, later in this chapter.

There are five paid staff in total, one for each individual discipline, a deputy principle who teaches religion and values, and a principle. St Peter's has issues obtaining staff due to a housing shortage in Gizo, and currently lacks a Carpentry teacher. Classes are split into first and second year students, with the former often taught by a volunteer graduate from the previous year. This is regarded as service back to the RTC, and these students typically want to proceed to be teachers themselves.

\section{Facilities and funding}

St Peter's RTC resembles a modern teaching facility. Located on the Catholic Church premises, it has benefitted from a foreign bishop who is adept at obtaining funding from church networks overseas. This has ensured that the RTC is relatively well equipped with concrete classrooms, workshops with power tools and electric sewing machines, as displayed in Figure 6.1 below:

Figure 6.1: Mechanical and carpentry workshop at St Peter's RTC Gizo
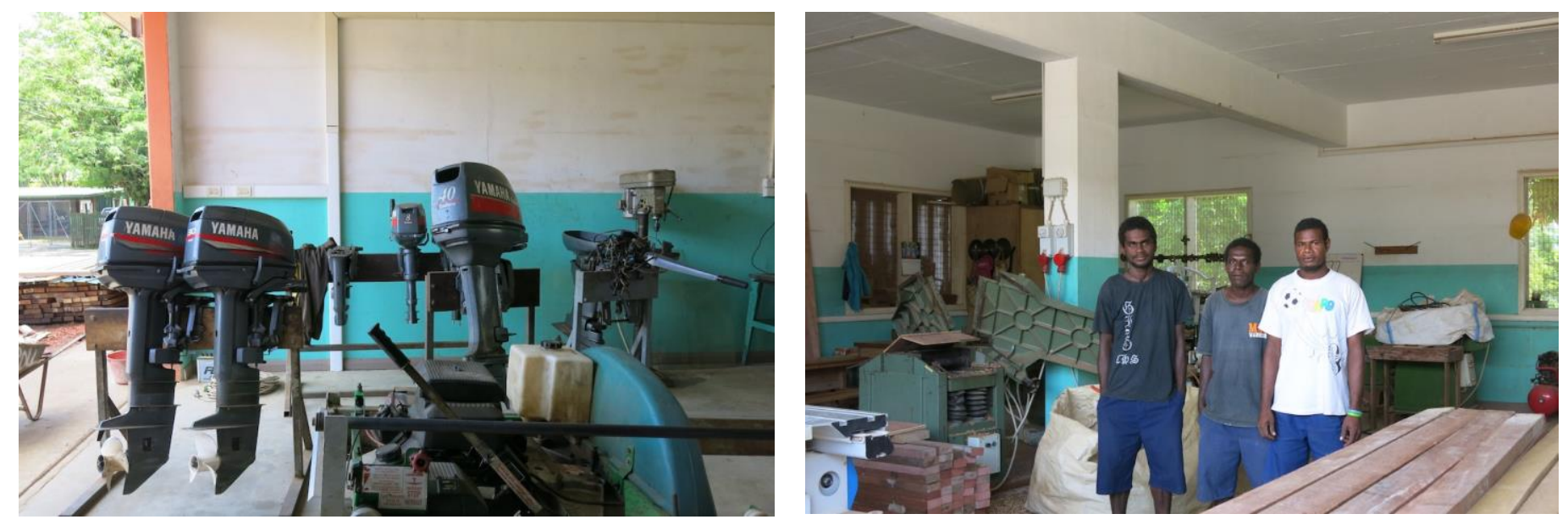

(Photo Kathy Fleming, 2014)

The centre is funded through a mixture of government, church and student funding. The bishop is well connected to catholic networks internationally, benefiting from funding opportunities. Staff are paid by the Ministry of Education and Human Development 
(MEHRD), provided that they are able to provide evidence of teaching qualifications. The centre also receives a per student grant of 400 SBD (62 NZD) per student per year. There have been problems with the timeliness of the government grant and only two teacher's salaries are currently funded due to qualification and paperwork issues. The government component, together with the student fee of 400 SBD, is insufficient to cover running costs of the RTC. As a result the church picks up the shortfall, paying for infrastructure, power, and most equipment and materials. The centre would like to engage income-generating activities, such as selling student made products through a shop or stall, to further aid funding.

\section{Work experience and community links}

The practical component of the courses is mostly performed on site, including work projects on church buildings, with plans to incorporate community based work experience into the second year of the programme in the future. This is currently performed in an ad hoc manner as work projects arise in the community. St Peter's would also like to give students the opportunity to save money throughout the programme by working on their own projects and selling them for profit. This could be used as capital or to buy tools at the end of their course, but they currently lack the space and funding to commence.

St Peter's has a strong link with the local Kiribati community, having made a determined effort to engage students from this marginalised and often disadvantaged group. Outside of the church, there are few other links with community or local business.

\section{Vatu Rural Training Centre}

\section{History and focus}

Vatu RTC has been operating for a longer period, established in 2002 by the incumbent principle, a local Solomon Islander, under the auspice of the Catholic Church. It is set on approximately a hectare of flat land, granted by the provincial government. Given the rural location, all staff and students live onsite in a village type environment. Vatu RTC has grown more organically and with less external support than St Peter's. Starting with just land and a few tools, classrooms, dormitories and staff houses have slowly been added, yet it still remains relatively small with just 34 students. The teaching philosophy at Vatu RTC focuses on equipping and modelling self-reliance and subsistence living. The centre aims to prepare young people for livelihoods in rural village environments, with a wide variety of skills 
needed to grow food, build housing and local infrastructure and care for the home, as well as run income generation through agricultural plantations.

\section{Courses}

The livelihoods of the communities around Vatu are predominantly subsistence and agricultural, as discussed in the previous chapter. Vatu RTC therefore operates a multidisciplinary rather than specialised course structure. Over the two-year programme, male students take a mixture of carpentry and mechanics and agriculture and female students undertake life skills and agriculture. Each afternoon students move off to the 'work line', rotating between the three agricultural areas, the cocoa plantation, the copra plantation and the vegetable garden. This model is based on the principle that offering specialised courses in rural areas is too narrow for the reality of rural livelihoods, while a multi-skilled approach reflects the wider variety of skills and greater self-reliance required in villages. Within each programme students learn a combination of modern and traditional skills. For example, one day the men might be learning to harvest and weave roofing from local materials (shown in Figure 6.2 below), and the next day firing up the generator for welding lessons. Similarly the women use manually powered sewing machines to sew clothes, as well as weaving of bags and baskets from traditional fibres.

Figure 6.2: Male students weaving a roof from local materials

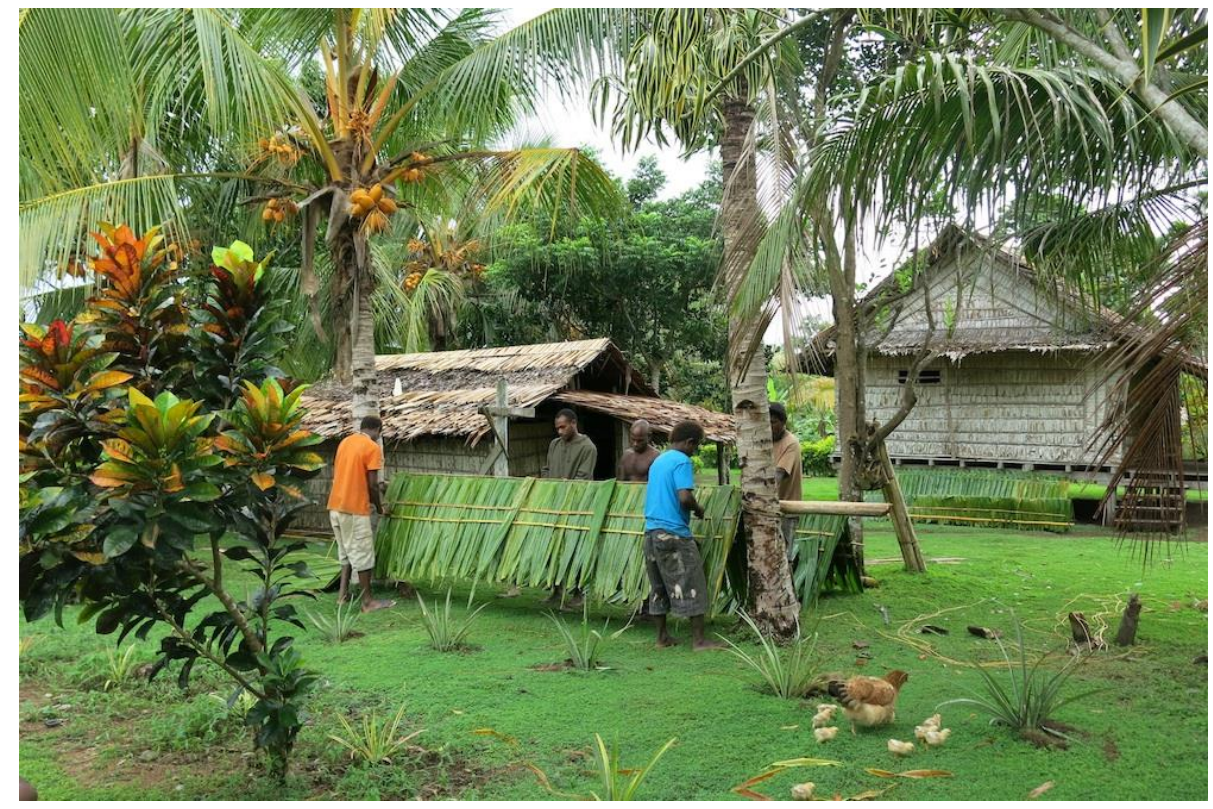

(Photo Kathy Fleming, 2014) 
Vatu RTC operates as "one community" with an atmosphere of camaraderie and cooperation (Student, 03/04/14). Male and female students work together to cook, clean, organise the daily schedule and socialise with recreational activities such as singing, dancing and sport in the evenings. This sense of support and affiliation, mentioned by the students, is particularly important given that the centre is home to staff and students for at least two years, and more than half an hour from the nearest village.

\section{Students and staff}

Similar to St Peter's in Gizo, Vatu has a male majority (79\%) of students, as shown in Table 6.2 below:

Table 6.2: Vatu RTC students by gender

\begin{tabular}{|llll|}
\hline & Male & Female & Year total \\
\hline First year & 19 & 3 & $\mathbf{2 2}$ \\
\hline Second year & 8 & 4 & $\mathbf{1 2}$ \\
\hline Gender total & $\mathbf{2 7}$ & $\mathbf{7}$ & $\mathbf{3 4}$ \\
\hline
\end{tabular}

While the centre nears the boarding capacity for male students, there is room for more female students. Vatu has a policy of rejecting no one. There are no age restrictions and even students with substance abuse problems are accepted.

Vatu RTC also takes a different approach to staffing, hiring a teacher for each discipline and year level, giving a total of two in each Agriculture, Mechanics, Carpentry and Life-Skills, plus a principal. The preference is for experienced staff with strong skills, rather than those with a qualification. Staff are highly dedicated, taking an active role in running the centre and forming a community with students beyond their teaching obligations.

\section{Facilities and funding}

While the buildings at Vatu RTC appear simple and traditional, the resources and infrastructure are comprehensive. The first thing to strike a visitor to the centre is the lush and impeccably maintained environment. The centre aims to be sustainable and self reliant on all fronts. Careful planning has gone into including water tanks, two wells for the dry season, solar power for lighting at night, rubbish disposal and where possible living by subsistence means. Facilities are simple, with a basic workshop, a few power tools and classrooms built from local materials. Key assets are the cocoa and copra plantation and 
drying facility on site which provide both practical experience for students and income generation for the centre.

Vatu RTC models self-reliance, using predominantly subsistence means and income generation to make up the shortfall from government and student funding. While student fees are higher, at SBD 1000 (NZD 157) per annum, this includes all food and board and goes little way to covering the actual costs of the centre. To meet day to day living needs as much food as possible is grown in the garden, and food that must be purchased (such as rice) is only eaten on a limited basis (twice per week). The cocoa plantation, pictured in figure 6.3, provides most of the additional income required for infrastructure and materials, with some further income coming from the copra plantation and selling produce at the small market. However, all of these sources of income generation depend on manpower, limiting how much can be raised.

\section{Figure 6.3: Author harvesting cocoa with the students}

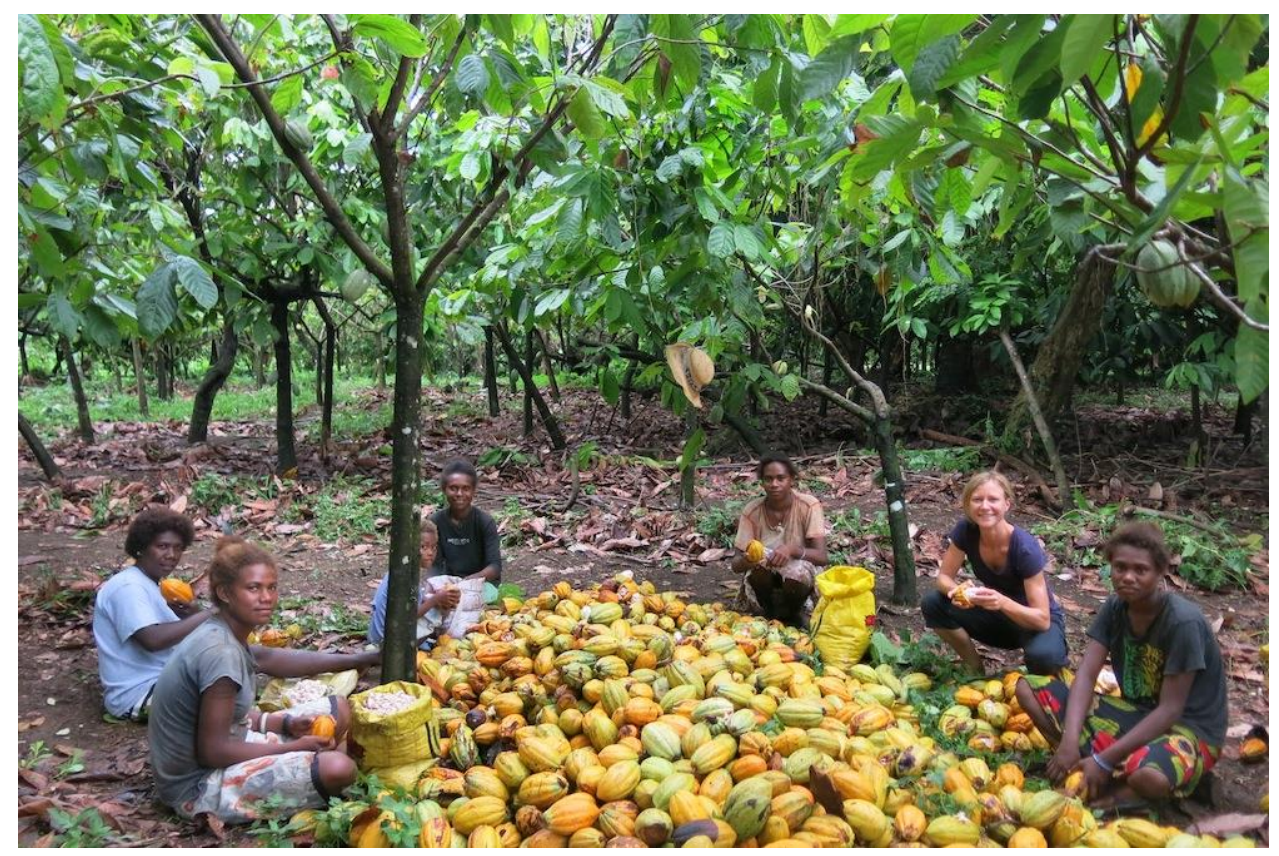

(Photo Kathy Fleming, 2014)

Vatu RTC has introduced some initiatives to help in the post graduation transition. In the second year, each student is given a small plot of land on which they can farm produce for profit. The income is saved and used to purchase tools on graduation. 


\section{Work experience and community links}

The expansion and maintenance of centre facilities provides the majority of work experience for students. Being involved in a project from the ground up, with close supervision, is seen as more valuable than sending students back to the village for work experience where there is minimal structure and guidance. Vatu RTC has strong links with local communities through family relationships and provision of services, including a small shop it operates selling staples like rice and sugar. There are plans to run a women's outreach programme to teach women in the remote 'bush' areas sewing, weaving, home management and agricultural skills. Essentially these would be short courses taught by the students with assistance from the staff. It is also one of the few centres that teaches well construction and has been approached by Caritas Australia to build a number of wells in the neighbouring province of Malaita.

\section{Aspirations of youth in Gizo and Vatu}

Postdevelopment literature raises important points about the dominance of western knowledge and education, which promotes western ideals that are often disconnected from the livelihood reality of many countries. However, as Storey (2000) counters this does not mean that people in developing countries do not genuinely desire aspects of the western lifestyle or material development. Hence, the aspirations of youth for their future have implications for the type of education and skills relevant to their goals. For instance, if there is a strong desire to move to urban centres and pursue formal employment opportunities, formal education may best prepare them. On the other hand if their aspirations are aligned with the local livelihoods, discussed in the previous chapter, the relevance of formal western education becomes questionable. This informs the overall examination of the relevance of the education provided by RTCs to these communities.

Aspirations of youth were explored in focus groups through the dreaming exercise. Youth were asked to draw their desired life in the future (five years) and explain their drawing to the group. The drawings and discussion have been analysed under the emerging themes: livelihood aspirations - linking to the diverse economies approach of the previous chapter, home or away - considering the link to home or desire for migration, diversification of livelihood activities, and indigenous values. It is important note that the majority of youth taking part in the exercise were RTC students. Their previous education varied from a few years of primary school to form 5 in secondary school. Only one group in Gizo represented a cross-section of youth beyond the RTC. 


\section{Livelihood aspirations}

The dreaming exercise enabled exploration of the types of livelihoods to which youth aspired. As established in the previous chapter, Alternative and Direct economic activities are incredibly important to the local economy these communities. However, the future generation may or may not see themselves fitting with the current context. The aspirations of youth revealed an incredible mixture of activities, analysed using the Diverse Economies Framework discussed in the previous chapter:

\section{Direct activities}

Direct economic activities are those that directly support life without the intermediary of money (Gibson-Graham, 2006). These featured strongly in the drawings of youth in both Gizo and Vatu. The Direct activities emerging included growing a garden for food, building one's own house, fishing for food, sewing clothes for the family and 'helping' the family more broadly.

\section{Alternative activities}

Alternative activities involve remuneration of some kind, but do not operate through the capitalist market system. These featured commonly in the drawings of young people, particularly self employment and income generation through making and sale of products locally. For example, many students in Gizo talked about building being self employed to provide services, making clothing for sale and establishing a homestay tourism operation. There were also a number of youth who wished to help the wider community by starting a RTC of their own.

\section{Formal activities}

A number of the young people in Gizo and Vatu expressed aspirations for formal employment, or to operate a formal business. Several of the women wished to be employed by as tailors or cooks and some of the men saw themselves working as electricians or builders, while others desired to operate formal businesses such as resorts or rental properties in town. Additionally it was a common aspiration in Vatu to grow and sell cash crops, copra and cocoa, for export.

A frequent aspiration that is not easy to classify is that of an RTC teacher. Around $20 \%$ of the youth wanted to become RTC teachers, recreating their experience for others. A number 
even wanted to start RTCs or lower level community based training centres in their home village. While RTC teachers are paid by the government, seemingly fitting the Formal employment category, the organisations themselves are community-based and fit more closely with Alternative enterprises.

\section{Diversification}

Significantly, a feature of every drawing was diversification of livelihoods. Those who saw themselves with Formal employment or business also saw themselves involved in Direct activities such as growing food or building their own house, and/or Alternative activities such as growing crops for market. Gegeo and Watson-Gegeo (2002) speak of diversification as arising out of indigenous knowledge based on agricultural practices, where sole dependency on one source or site for food is undesirable. This diversification also seemed to reflect the mixed influences affecting young people. While they live in rural communities surrounded by indigenous and traditional knowledge, the allure of western materialism has reached them through global culture and western education (Tikly, 2004). Hidden within those western values is not just the notion of a different way of life to their parents, but also the idea that it is a superior way of life (Ziai, 2007a). Figure 6.4 below, drawn by a male student in Gizo, reflects this diversification and complex influences:

Figure 6.4: Aspirations of male student at St Peter's RTC

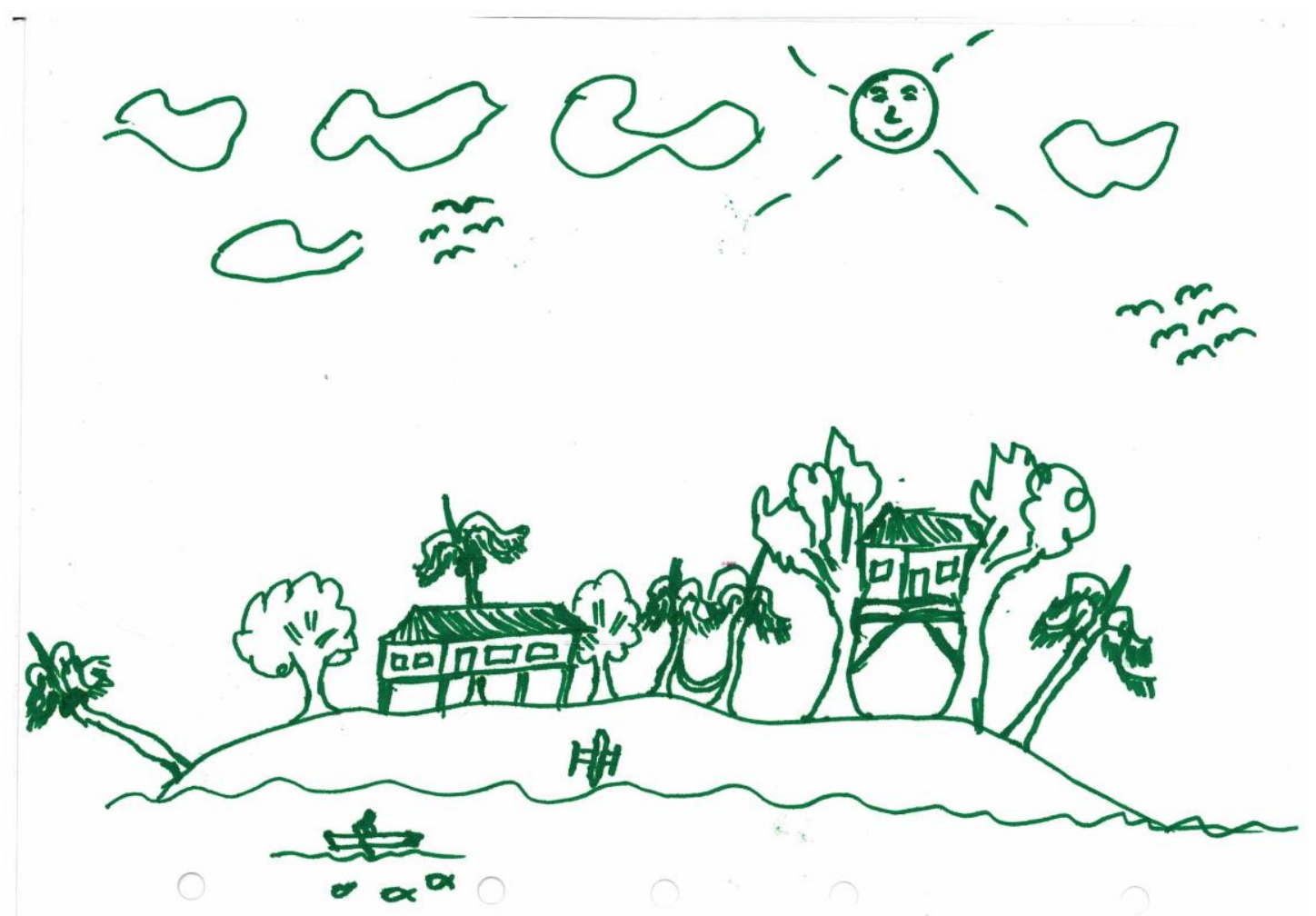


He would like to "have a job and go back to the island" that is his home village (Focus Group, 26/03/14). He sees himself with some sort of Formal employment in Gizo on a partial basis while living in his island home (pictured below). On the island he has drawn the house he wishes to build himself (Direct) and the tourist bungalows he wishes to build for income generation (Alternative). He has also drawn himself fishing, which can be both a Direct subsistence activity or used for Alternative income generation. The lush natural environment also provides a source of food and materials for subsistence living (Direct). The plurality of his livelihood in terms of economic practices and multiple sources of support is apparent. Furthermore, the influence of traditional activities, such as living off the land and sea, is combined with modern cash generating activities such as paid employment and tourism.

\section{At home or away}

In terms of urban vs rural living, youth in Gizo and Vatu expressed a strong affiliation and desire to live in the location in which they grew up. Even in Gizo this tended to be a rural environment located in one of the surrounding villages. A minority of youth saw themselves moving within proximity to home, to the semi-urban environment of Gizo, or to Honiara to take advantage of opportunities for work. However moving away to Honiara was usually seen as a temporary measure to earn money or create an income stream, after which they intended to return to the village to build a life and family. Figure 6.5 , over page, illustrates an example of this from a young women at Vatu RTC: 
Figure 6.5: Aspirations of female student at Vatu RTC

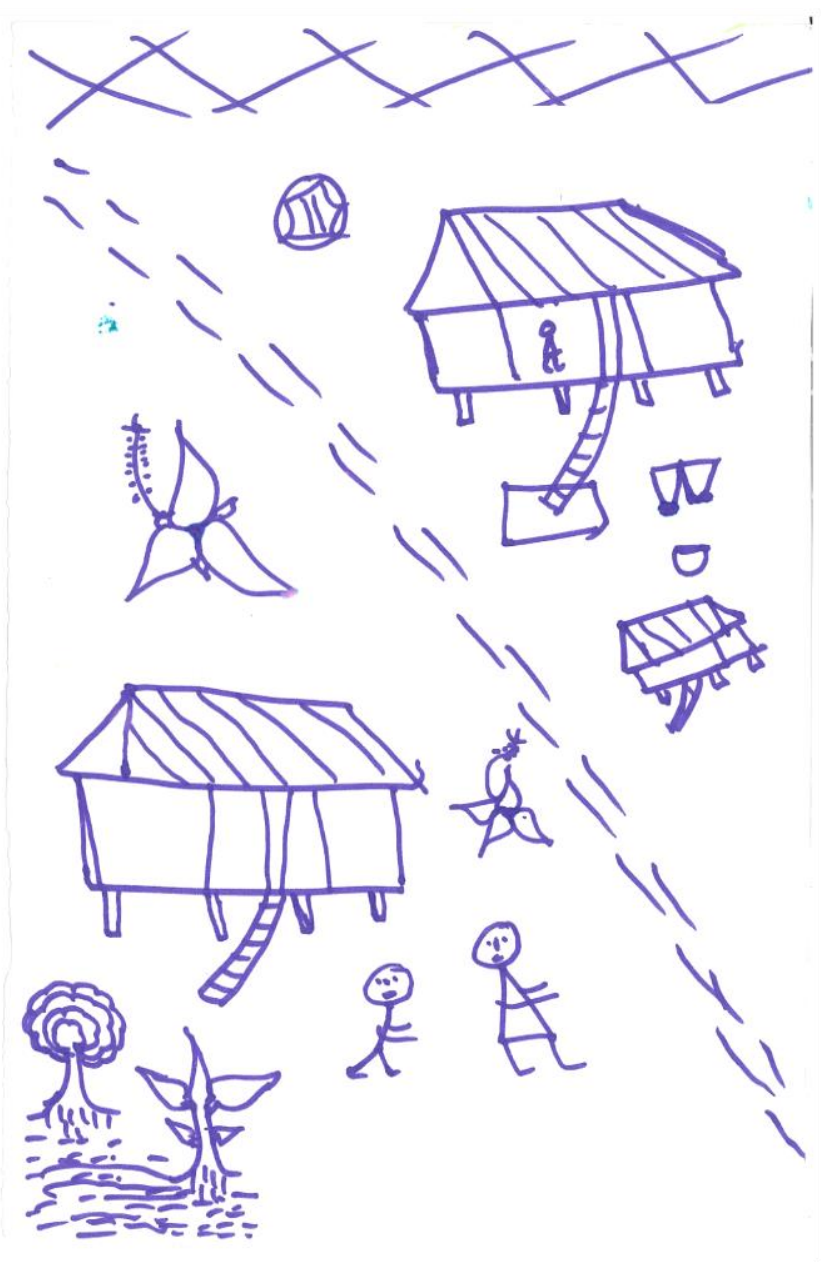

The right hand side of her drawing features some trousers and a skirt, which she plans to make while working as a tailor in Honiara. The building in the top right corner is the tailor shop. Following this, her life jumps to the other side of the stitching running diagonally down the page. She says that she will "then go back to the village, work in the garden, help my parents...grow vegetables" (Focus Group, 03/04/14, Vatu). Her future house in the village is pictured, along with flowers, trees and a garden representing the beauty and nature of the rural environment. The male figure in the picture is her brother, representing the family that she intends to return to and support in the future. The dilemma young people face in deciding whether to migrate to urban centres is discussed later in this chapter in Text box 6.1.

\section{Indigenous values}

The youth reflected a strong affiliation with indigenous values and practices through a connection to the environment (land and sea), a desire to support their family or wantok, 
and a desire to contribute to the wider community (Gegeo, 1998; Gegeo \& Watson-Gegeo, 2002). The vast majority of drawings displayed aspects of the living environment, including flowers, vegetable gardens, crops and the sea. Youth often conveyed the desire to care for or support their family, current and future, and give back to the wider community through the building of schools or community facilities, reflecting the way in which "to varying degrees, these communities are still characterised by socio-cultural ethics of redistribution, reciprocity and inclusiveness" (Coxon \& Munce, 2008, p. 148).

For example, a young man from the Kiribas community surrounding Gizo described his dream to support his local village and community: "my dream is I want to become someone who can help the community" (Focus group, 19/03/14, Gizo). His drawing, shown in Figure 6.6 below, displays elements of indigenous culture, as well as western culture:

Figure 6.6: Aspirations of community male youth in Gizo

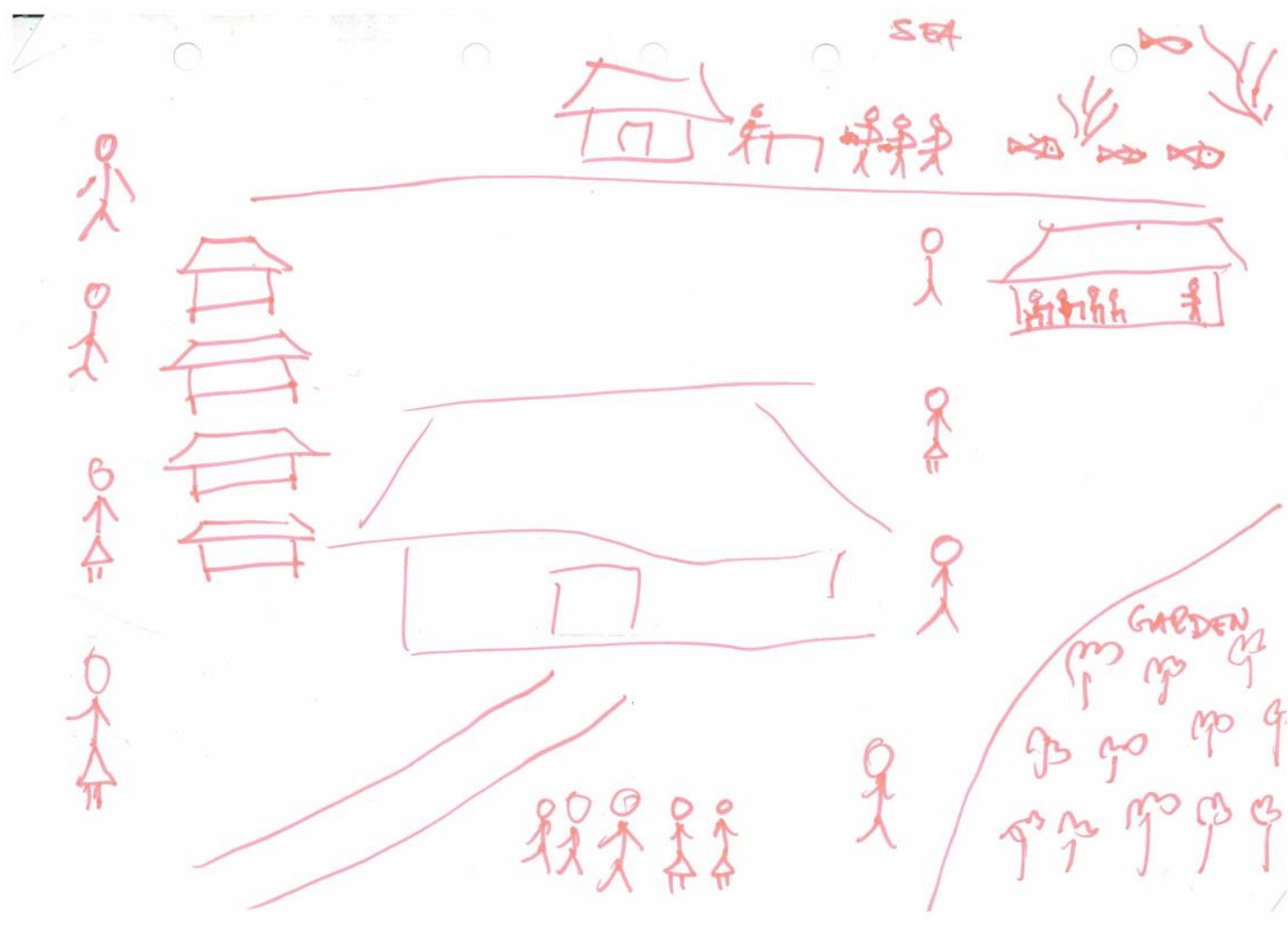

The central building is the Maneaba (community meeting house). Leading up to the Maneaba is a road that does not currently exist, connecting the village to Gizo. This young man would like a road built to improve access between the village and Gizo, presently only possible by boat. To the right of this is a garden where he would like to teach young people how to grow vegetables for food. In the top right corner is the sea, with fishing the 
predominant source of livelihood for this community. He would like to find a large buyer for the fish, such as a fishery, rather than selling the fish on a small scale at the local market. Below this he has drawn a village school that does not currently exist. He explained that access to the school in Gizo is a problem due to the boat ride and he would like to make it "easy for the children" to attend school by having one locally. Bordering the left hand side of the drawing are the community standing next to their houses. He would like to see improved housing for his community from the current leaf built housing (Focus group, 19/03/14, Gizo).

His dream, like many of his peers who participated in this research, shows an intermingling of indigenous culture and values with global, western capitalist influences. Subsistence farming, fishing, the meeting house and the cohesion of the community sit within the realm of indigenous knowledge, embedded in culture and history (Gegeo \& Watson-Gegeo, 2002). In contrast, the road, primary school, improved housing and fisheries can be seen as introduced concepts. Selling fish to a fishery rather than just catching enough for one's family reflects the increasing cash needs of communities, and subsequent engagement of small communities with large corporations. Roads provide an easier access to goods and services, and formal education holds up the promise of a "rich, cultivated and happy life". Does this mean his aspirations are diverging from the more traditional and indigenous ways? Gegeo (1998) gives an enlightening example of the way in which indigenous culture continues to evolve, incorporating new ideas, yet still remains indigenous:

Such changes are parallel to a village man who collects imported manufactured building materials for a permanent (iron roof, composite walls) house, but the choice of location of the house, the design and construction are his and his family's own...the house of nontraditional materials thus provides the tradition-based sense and experience of the "good life". (Gegeo, 1998, p. 291)

For this young man, his idea of what constitutes a good life may be different from previous generations due to exposure to different influences, displaying cultural hybridity. Bhabha (2012) challenges essentialised conceptions of culture that neatly categorise and homogenise something as representing one culture or another. Rather he views culture as difference, understood by the "relations between cultures" (Bhabha, 1996, p. 54). The cultural identities of the youth in Gizo and Vatu are hybridised, interweaving aspects of western and indigenous culture to create a new space in-between. This third space is more than the sum of its parts. Operating in this third space, youth continue to evolve producing 
new knowledge and culture. Under an expanded view of knowledge, and culture, the binary that postdevelopment is accused of creating, between modern/western and traditional/indigenous is abandoned to embrace hybridity and continual transformation of knowledge and identity. Thus, this young man's aspirations can be reconceptualised as a demonstrating hybridity, filled with negotiation, possibilities and innovation (Bhabha, 2012). The way in which RTCs navigate this third space is discussed in the coming section.

\section{Educational relevance of RTCs}

The aspirations of youth discussed above, can now be examined in terms of their fit with the content and purpose of Rural Training Centres and the wider education system in general. Most of the young people wished to remain in a rural village environment. The kind of education, or more broadly learning, that supports rural livelihoods is predominately skill based, involving practical learning, indigenous and localised knowledge of environment. With a focus on urban livelihoods and theoretical knowledge, this aspiration is not well supported by the formal western education system. Moreover, considering that most of these youth left or were pushed out of the formal system early, such education was unlikely to result in a successful formal employment outcome. The RTCs show potential to fill a large niche here, with an overall purpose oriented to supporting local rural based livelihoods and practical curriculum.

Direct and Alternative economic activities showed greater prominence than Formal economic activities in the type of livelihoods young people wished to pursue. Emphasis, however, was on diversification of means of support. This diversification seems to necessitate corresponding diversity in education, as Coxon and Munce describe it "the more practical and cultural knowledge highly relevant to life in pacific communities" (2008, p. 152). This infers education that incorporates a range of practical skills and responds to the localised options within the communities. RTCs fit this practical focus well with their 'learn by doing' curricula. They aim to provide young people with locally applicable skills for Direct economic activities, such as subsistence living and maintaining a household, along with activities that can generate income, through growing crops or working as a builder or mechanic.

Vatu RTC has also responded to the need for diversification with its multi-disciplinary approach, as Daniel, a staff member at the RTC reflected when I met with him in Honiara: 
I'm not favouring a specialised system.....all my students who come out, they are builders, they are agriculturalists, they are mechanics...I am happy about how I have set up this mindset....anywhere they go they fit in. (Interview, 02/04/14)

As a result graduates are not solely dependent on one form of economic activity for their livelihood, and have greater potential to be able to utilise their skills in rural areas. The $30 \%$ who do make it through the secondary system may have aspirations that reflect more formal livelihoods and with in an urban environment. The obvious limitation of this research is that it does not encompass the views of young people who are successful in the formal system. However, the role success in formal education plays is also unclear. Being unsuccessful in the formal system could influence aspirations to be locally and informally based, and similarly success may ignite urban and formal aspirations. In the other direction, aspirations may be the driver of continued engagement with the formal system or not.

The aspirations of young people were found to be rooted in indigenous values, hybridised with introduced knowledge and western capitalist ideas of what pertains to a good life. Gegeo suggests that indigenous knowledge should be incorporated into development by "learning and adapting introduced and new locally-created knowledge towards positive change that supports life and affects villagers' world views and systems of knowing, understanding and reasoning" (1998, p. 291). In other words, a model of education in which introduced information that can be absorbed and transformed by indigenous epistemologies, resulting in locally generated goals and means of achieving them. This would involve education with "curricula and pedagogies that speak directly to local knowledge systems, values and ways of relating" (Coxon and Munce, 2008, p. 161). These are not currently present in formal western education. While RTCs do not claim to use a model founded on indigenous epistemology, being community initiated and contextually responsive makes a degree of this inherent. For example, RTCs place value on holistic development of the individual to be a positive contributor to their local community. Ruth, a staff member at Vatu RTC, reflected the importance of character development and indigenous values when she spoke about what the students do after they graduate, "many work at home with their communities and they [the community] look at them as one of the leaders in the village... because of the quality they have, not just the skill, but some of the changes in life". More practically, the RTCs integrate a mixture of traditional/indigenous skills and modern technological skills within their programmes. For example when teaching building they utilise locally grown materials and techniques to construct leaf roofs and 
woven walls, along with power tools to cut timber and erect framing. Women learn to produce materials for weaving from local plants, as well as use sewing machines on purchased material. RTCs hybridise, adopt and adapt knowledge from a variety of sources, operating 'in between' cultures, in that same third space as young people.

RTCs appear to show strong educational alignment to the aspirations of young people across the themes analysed above. 


\section{Text box 6.1: Urbanisation - Daniel's story}

Over the past 15 years Honiara has experienced high population growth, reflecting a broader trend of urbanisation in the Pacific occurring at a rate of over 60\% (Lacey, 2011). With a cash based economy and formal education gaining greater influence, the 'urban drift' for young people has an increased allure. That's what made meeting Daniel so interesting. A young man in his early 20s, Daniel's parents were able to afford to send him to a reputable school in the capital and subsequently two years of formal tertiary study. Yet, the pot-holed streets of Honiara did not hold him for long, he was now back in Gizo with his parents. Here was an obviously intelligent and motivated young man who pursued a formal education pathway in the urban centre, living back in a semi-urban area. Having struggled to find consistent work since returning to Gizo, picking up the occasional contract job for a business or NGO, volunteering for the church, he often went for weeks with no work at all. As he put it:

It is a little bit difficult because there are not many opportunities to find work in Gizo... there are not as many opportunities as some of the other islands have, from the government or the private sector" (Interview, 21/03/14).

Given this, I asked the obvious question, why he had returned? In response Daniel explained some of the challenges of living in Honiara. Without a family home there, he felt like a burden to his wantok. Although there are more jobs, selection is often based on 'who you know not what you know', not to mention the high cost of living. By contrast, in Gizo "life is easy, life is simple and it's cheap" (Interview, 21/03/14).

Daniel's experience reflects the reality that many face in migrating to the capital. Poverty is higher in Honiara than in the rest of the country, with many living informally in shanty structures that they do not own. Without land people are unable to rely on subsistence activities and instead depend on their small cash incomes (Lacey, 2011). As heard often during my own time in Honiara, even those who were well educated with a good job, earned so little they could can seldom afford electricity or to eat more than two meals a day. For those who do not secure work, the demise into alcoholism, drugs and crime is all too common (Lacey, 2011). It was a pattern Daniel has also observed in his work with local youth, "they want to go out and explore new worlds, find something new for their lives, they go [to Honiara] and end up in trouble going out drinking and getting involved in alcohol abuse, and they come back to Gizo" (Interview, 21/03/14). Daniel's story highlights the complications with urbanisation, illustrating the harsh reality it involves. Given the pressure urban centres like Honiara already face it raises the question of why systems that lead to greater urbanisation are supported in preference to those that foster rural livelihoods, 


\section{Student and community perceptions of RTCs}

The measures used to determine the quality of education in the formal system are primarily based on compliance to global standards rather than relevance for local context (Nordtveit, 2010). The lack of fit of formal western education for many contexts, including the Pacific, has been criticised, as has the way in which its domination has marginalised other forms of education (Coxon \& Munce, 2008; Gegeo \& Watson-Gegeo, 2002; Mundy, 2006; Tikly, 2004). This research sought to examine the quality of RTC education according to the alternative criteria suggested by Nordtveit (2010), relevance to the local community. The previous section considered relevance in terms of alignment of the purpose and content of RTCs with the aspirations of youth. This section further considers the relevance of RTCs by examining the perceptions RTCs students and the wider community hold towards RTCs. This is done in light of the negative perceptions that have been reported about RTCs, outlined in the Chapter 2, namely that they are the last choice option and have a poor standard of training and facilities (WYG International, 2012). By investigating the perceptions of the RTC as seen by the students and the community, a more local assessment of quality and relevance can be made, rather than relying on donor or government perceptions.

\section{RTC students}

Students were asked to vote on a four-point scale according to what they thought of their experience as an RTC student so far on a scale of not happy (negative face), ok (neutral face) good (partially positive face) and happy (highly positive face). Voting was performed anonymously to the researcher, while the visual representation helped to mitigate the language barrier. Students were then asked as a group to explain the outcome of the voting, probing the specific positive and negative aspects of the RTC from their perspective.

At St Peter's RTC in Gizo 100\% (9/9) of the participating students voted for the happy option, reflecting a highly positive perception. The reasons students gave for this response was strongly linked to the feeling that they were learning new skills and knowledge that could be practically applied when they finished. One female student who had completed form five of high school prior to coming to the RTC described the difference in her learning experience between the two systems, "especially for me coming from secondary school, there I learn no skills, I come over here and I learn skills" (Focus Group 1, 26/03/14). Her view clearly places a low level of relevance on the formal education system, finding it not useful compared to the RTC. This is in direct contrast to the hierarchy established in education, which exalts the 
formal and academic over more pragmatic forms. However, in many ways the existing hierarchy had still been internalised, for example, students appeared to be ashamed of their early exit from the formal school system, particularly if they had not been to high school at all. This young woman had experienced both, and spoke with a greater level of confidence about her experience and decision to attend an RTC. For others it may have been less of a choice, and more the only option remaining after exiting school so young.

The centre was seen to have good facilities, and some students also appreciated the personal development aspects of the RTC, as one young man said "I like this school because it teaches about life, your life, and about Christian values, also teaching you about electricity for your future job and to help your family" (Focus Group 2, 26/03/14, Gizo). Students had very little criticism or suggestions for improvement regarding the RTC, with a number commenting "everything is good". The only negative aspect mentioned was that at times students were unable to obtain water on the campus if the water tanks were empty. These findings fit with the well-resourced nature of the centre, largely from foreign church funds, and the popularity it has experienced, growing to full capacity in less than three years.

In Vatu $80 \%(20 / 25)$ of the students voted for the happy option, with the remaining $20 \%$ (5) voting for the good option. Again the reason for student satisfaction emphasised learning practical skills and knowledge seen as directly applicable at home later, as one male student put it "you come here, you learn something, then you go back home with some skills to use at home" (Focus Group 1, 03/04/14, Vatu). Another student reflected on the nice balance between theory and practice "you come to class, then you go practical" (Focus Group 3, 03/04/14, Vatu). Appreciation of the direct applicability of learning at the RTCs reveals a counter hegemonic view of education, grounded in the reality of everyday life.

For the female students, the learning also appeared to fit with existing gender norms, as a female student at Vatu explained

I come and get skills to help me one day at home with my family, my community, help me to marry and have a family one day. What I learn here will help me to deal with my family when I'm married. We come here because we are girls and we get skills, I'm happy. (Focus Group 2, 03/04/14)

The role of RTCs in relation to reproducing or challenging gender roles for women is complicated. Arguably they have a function in doing both. For example, St Peter's RTC has 
graduated a number of female students in electrical and mechanics courses, against the normal trend for female courses. Similarly, males and females share the domestic duties of cooking and cleaning at Vatu RTC, in contrast with traditional gender role. This issue will be discussed at length later in this chapter in the section Women: Barriers and opportunities to RTC participation

Being a boarding facility where students live full-time, elements outside of the course content were also of importance to the students. Students liked the natural setting, the plentiful food and the "many flowers around the grounds, filled with beauty" (Focus Group 2,03/04/14, Vatu). Students also appreciated the social activities and sport offered at the RTC outside of class time. In a number of comments, there was a positive sense of community reflected, with men and women working together having fun together and helping one another.

In terms of negative aspects or areas of improvement, a number of these related to the facilities and equipment. Students cited a lack of tools for the mechanical and carpentry workshops, a broken cover over the greenhouse and the need for a new carpentry workshop space as issues. The only other negative remarks were that the RTC was located far from town, meaning students could not easily buy things they wanted. The workload was seen as high, yet worthwhile, as one student explained "sometimes we work too much, a little bit, but it's good as we will need to work hard at home" (Focus Group 2, 03/04/14, Vatu). The mixed perceptions from students at Vatu reflects the self-reliance model on the centre, dependant on agricultural work performed by the students and teachers for income to run the centre. This makes large expenditures, such as equipment and building, a slow process to acquire. Some staff also cited its rural isolated location as a detractor to enrolment numbers, yet a benefit in terms of available land and relevance to rural livelihoods.

While Gizo and Vatu RTCs operate different models, from a student perspective both appear to be at a more than satisfactory level. They are considered to be providing skills and knowledge relevant to future activities in the local area. The detracting elements seem to be largely due to material constraints. As mentioned in Chapter 3, there is potential that students were reluctant to express open criticism of these centres on the basis of my relationship with the NGO project, and by association positionality as a donor. 


\section{Community}

Perceptions of RTCs from members of the community were gathered during individual interviews. Due the flooding in Vatu, fewer interviews with surrounding community were conducted. Hence, the majority of themes that emerged were collected in Gizo, yet similar sentiments were observed in Vatu.

Overall the community perceptions of the RTCs were highly positive. RTCs were seen as a means by which young people could learn to be self -reliant, build skills for paid work and further their education. Frank, a local businessman in Gizo, explained the benefits of incorporating skills for self-reliance "if those boys and girls don't want to work in town, they can do it for themselves you know, instead of buying they can sew their own clothes" (Interview, 20/03/14). Anthony, a self-employed man from Gizo, reflected the community's support for RTCs as a viable pathway to young people finding work "RTCs are building young people to have skills and find a job. Everyone is happy about the RTC" (Interview, 21/03/14). Similarly, Patricia, a community woman in Gizo said "for me the RTC is the very most place where people learn a lot ...in general everywhere the RTC is highly regarded...most of the student from RTCs take jobs and are helping out people from the rural area" (Interview, 17/03/14).

People in the community also saw the RTCs playing an important role in stopping urban migration and the issues created by idle youth. Frank referred to these young people as "drifters" who came to town seeking "green patches"; "town is where the milk and honey is, that's how they look at it, forgetting that they have the best part of the place, the home [village]"(Interview, 20/03/14, Gizo). He went on to talk about the number of youth in his own home community who have returned after being educated in Honiara to take up traditional carving, as the money and lifestyle is better than what they found in the city. His view was that RTCs enabled young people to be productive at home, without needing to pursue the false promises of the city.

Rather than viewing RTCs as 'last choice' education, RTCs were positively regarded for providing opportunities for the many young people who are pushed out or drop out from the formal system. Barnabas, a man from the Gizo community described the impact he has observed, "lots of young people, they left school very early, they had no chances any more, since the Rural Training Centre gave them this opportunity, I have seen lots of young people 
improving very much" (Interview, 21/03/14, Gizo). RTCs were recognised by the community as an important alternative form of education that filled a gap left by the formal system.

Again RTCs alignment with existing gender roles emerged. RTCs were perceived as one of the only forms of available education that directly contributes to the role that the majority of women play in the Solomon Island society. Hannah, a women in the community explained, "I think that the Rural Training Centres, to me, are one of the only gateways to build up women, because they will prepare them to be mothers, its more based on life skills" (Interview, 24/03/14, Gizo). Likewise, Maya a community woman in Vatu when asked what skills would help women in rural areas explained, "life skills - train them to sew so they can sell the items and get money...the only way they can generate income is to sell their goods in the market" (Interview, 05/04/14).

The perspective of the community towards RTCs demonstrates a wider assessment of relevance, which takes into account Direct economic activities (self reliance) Alternative activities (selling at the market) and Formal activities (waged labour). Rather than just preparing young people for Formal activities, as the formal western education system has been criticised for doing, the RTCs were seen as being multifaceted, with content relevant to diverse livelihoods (Gegeo, 1998; Nordtveit, 2010). Along with social benefits, reducing urbanisation and being inclusive, the RTCs were perceived to reflect contextually appropriate education. That is, education that emphasises learning values, building a future of young people with healthy self-esteem, a sense of community belonging and the ability to access and use the resources around them (Coxon \& Munce, 2008).

\section{Women: Barriers and opportunities to RTC participation}

A key component of this research was to explore the barriers and opportunities faced by women, as a marginalised group in the Solomon Islands, in participating in RTC education. As outlined in the Chapter 2, women make up less than $25 \%$ of RTC students. Limited training places, fees, physical access, and cultural attitudes towards the value of women's education have all been cited as reasons for the gender disparity (WYG International, 2012). The RTCs in Gizo and Vatu have just 27\% and 21\% female students respectively, with neither at capacity in the female Life Skills programme. This raises the obvious question of why two centres that have a positive reputation in the community, are failing to attract female enrolments. The answer to this question was explored through interviews with community members and RTC staff, particularly women. The hope was to provide a more in-depth and 
local level understanding of barriers faced by women in education in general, and RTC education in particular. Consistent with the practical and constructive grounding of this research, suggestions for how RTCs could be more inclusive women were also explored.

\section{Barriers}

In both communities, Gizo and Vatu, the reasons for fewer female students echoed those previously reported. Physical access, domestic responsibilities and school fees were commonly cited as barriers to participation. Patricia, a community woman, explained how access can be difficult in Gizo

Here [in Gizo] is different from the other RTCs. People who live here [in town] are the ones in the school, the ones from the other villages need to find families or someone to live with in town, as there is no boarding facility. (Interview, 17/06/14)

Women are less likely to leave the village because of their tie to responsibilities within the home, as explained by Maya in Vatu, "girls don't go to the RTC as they are engaged in domestic work at home cooking, caring for babies and gardening...they just stay home and get married" (Interview, 05/04/14). In rural areas marriage for women was described as typically occurring at a very young age, from around 15 years, meaning that by the time young women reach the age of tertiary education they may have a strong responsibilities as a wife and possibly mother. Moreover, a difficulty in affording school fees and reluctance to pay fees for girls' education was a common theme as Maya from Vatu described "also the problem is school fees, people do not have enough money to pay for them, so they do not attend school" (Interview, 05/04/14). She went on to explain how the situation is worse in the more remote 'bush' areas "they don't have much money at all, its difficult for them to go and study, especially if they have small children. The school fee is only 100 SBD but most of them don't turn up" (Interview, 05/04/14). Because more rural and isolated the areas are less cash determined, the burden of fees for education is heavier. However, ultimately the above reasons do not seem to fully explain the disparity between male and female student numbers.

\section{A question of inequality or relevance?}

Underlying all of the above issues appears to be a central issue, revolving around the status of women in Solomon Island society and the domestic perception of their gender role. Hannah, a community woman in Gizo came to this conclusion when discussing the barriers women face: 
We live in a male dominated society. Priority is given to men and women are second priority...maybe according to the culture they give more priority to the men, more powers are given to them, and maybe that is one of the root causes. (Interview, 24/03/04)

She viewed this as a cultural attitude, underlying numerous challenges for women, of which education is one. Ruth, a staff member at Vatu RTC reflected a similar view "the problem is the gender balance, they put the girls low and the boys high" (Interview, 06/04/14). The result is a prioritisation of boys' rather than girls' education, particularly if there is financial pressure. As Maria, a RTC staff member in Gizo states, "value is not placed on girls education when they could be at home helping" (Interview, 19/03/14).

These comments reflect that the role of women in these communities is heavily linked to the domestic sphere, forming part of a social rather than economic space (Midgley, 2006). Education, which is promoted by the dominant development discourse as having economic utility, is therefore considered less important for females than males. Furthermore, this attitude appears to be rooted in strong cultural values about the role of women being primarily a wife and mother. Essentially, there is a clash between the global development discourse that promotes education for all (male and female), and traditional cultural views which assert other priorities. The situation is further complicated by the devaluing of traditional, domestic and unpaid work under the dominant capitalist view of economy (Midgley, 2006). This has led authors like Gegeo and Watson-Gegeo (2002) to argue that western development, of which western education is a part, disrupts cultural values. Western education exports western values, which are consumed in developing countries and internalised to create a perceived need for education in societies where that need did not previously exist (Coxon \& Munce, 2008). Thus, one might reach the controversial conclusion that women not participating equally in education merely reflects the lower relevance education has to their role in society, according to their culture. The need for women to be educated in an equal way to men, therefore, is simply an example of hegemony of western education and development destroying cultural identity.

However, few would find this to be a comfortable conclusion not marred by injustice. From a Human Rights perspective education is an entitlement that should be equally available to all. Significantly, Corbridge (1998) in his critique of postdevelopment's idolisation of traditional societies points out that culture cannot be used as an excuse to marginalise and discriminate against half of society. In the Solomon Islands education is in fact a right for all, and indeed 
the RTCs involved in this research were found to have no gender discriminating education policies. Yet, this has still not resulted in equal participation. Although I have previously critiqued Nussbaum's (2001) acceptance of the dominant view of education, her work, and that of her colleague Amartya Sen strike a chord on this issue. Sen (2000) points out that rights are not of importance in themselves, but rather they are important for the capability they afford a person. Development, therefore is based on freedoms rather than rights; the freedom to access opportunities and the freedom to make choices. Under this view, women and girls do not just need the right to education, but also the necessary social, political and economic freedom to avail of that right (A. Sen, 2000). Nussbaum (2001) takes this one step further by focussing on what women are actually in a position to be able to do. That is, the opportunities and liberties that they are capable of using. She identifies a set of core capabilities, of which education is a part, as being central to fully human functioning. She argues that "if people are systematically falling beneath the threshold in any of these core areas, this should be seen as a situation both unjust and tragic - in need of urgent attention" (Nussbaum, 2001, p. 71). The gender disparity in education is a sign of core capabilities not being met for women. This requires political and policy action to open up these opportunities to women, but also social action to address prevailing mindsets that continue to marginalise, despite the apparent freedom.

The ability to make choices about one's life or education assumes a level of knowledge or a world view that permits such choices. Given that prevailing discourses shape knowledge and social understanding of the world, such a choice, even if it is available, may not be so simple to come by. The classic ideas of Freire (1970) are useful in providing insight into how such a dilemma works. The prevailing cultural discourse, in this case, may be that women do not need education, or are of second priority to men. This view is not just held by the oppressors, in this case men, but becomes consciencised by those being oppressed, in this case women (Freire, 1970). So while women have the political freedom or right to education, they are not in an epistemological position to make such a choices. Their own world view prevents them from seeing the opportunity and benefit of education. The solution, according to Freire, is to awaken "critical consciousness" through education so that the women can see the way in which they are being constrained, leading to endogenous social change (1970, p. 43). Indeed the women I interviewed were all educated, and could be seen from Freire's perspective to have had their critical consciousness developed, enabling them to see beyond the prevailing cultural discourse. Arguably, though, a 'chicken and egg' situation has been 
reached; in order to make free choices about education, one needs to have first been made conscious of those choices, through education, as well as have economic and social resources to execute those choices.

\section{Opportunities}

The women interviewed had ideas about navigating this tricky terrain of cultural values vs the rights of women. A common suggestion was to promote awareness amongst the community of the value and relevance of female education at RTCs, as Maya from Vatu explained "one thing I see is, they need somebody to go and talk with them about education, the importance of education so that they can get better ideas and understanding about education so that they can send their young people" (interview, 05/04/14). The discussion above argued that womens education was seen as culturally irrelevant to role in which women play in society. However the previous sections on the aspirations of youth and perceptions of RTCs found that the content taught by RTCs, based on skills to improve the home and look after the family, was actually considered highly relevant to women's current role in Solomon Islands society. Maria, staff member at Gizo RTC touched on this point, "they don't understand that if they girls come here and learn more, they can do that work at home beautifully" (Interview, 19/03/14). An effective way to spread this knowledge according to Hannah, is to utilise women's networks "if they want to get more women, they use the existing women's network in the country" (Interview, 24/03/04, Gizo). Both Gizo and Vatu had established women's networks through the local government or church.

Another factor that could be limiting the enrolment of girls at RTCs is the typical spectrum of courses on offer. Apart from Life Skills and Agriculture, all the other programmes are trade based: Carpentry, Mechanics, and Electrical. Even in western countries, such as Australia and New Zealand where there has been important progress in gender equality, few women are attracted to these trades. Women in Gizo suggested that courses in hospitality and typing would be relevant, given the level of tourism and local businesses in the area. In both locations, money management and budgeting emerged as a key area in which women desired more skills, as Patricia, a women from the community in Gizo, explained "I think budgeting is the main one...all the women working here have the same problem of how to manage money" (Interview, 17/06/14). 
Currently all RTC courses are two years in length. Given the impact that domestic responsibilities and attitudes can have on women enrolling and travelling to RTCs, the idea of running shorter courses was also discussed. A number of women thought that courses of two to four week duration, where women could learn a few specific skills, such as sewing clothes or agriculture, would be highly valuable. In considering short courses, there were also ideas about turning the model of RTC delivery on its head. Rather than women coming to the RTC, students late in their RTC study could go out into the community, staying in villages for a few weeks to teach the women some practical skills. A concept of networks, collaboration and incorporation of indigenous skills began to emerge. Hannah enunciated this well, questioning the prevailing structure of skills only being able to be taught by 'qualified' teachers:

There are very smart women who can weave mats and baskets, they don't go to school, its been handed down from their parents. These are some of the skills we have to really recognise and see how we can set up short courses and involve these people. (Interview, 24/03/04, Gizo)

Many of the skills that have been formalised by western education, have in fact been long standing indigenous skills, where the best experts have never attended school. The suggestions of how to involve a greater number of women in RTCs were rich and often self reliant, using the people and resources that already existed, rather than bringing in expertise from elsewhere. These ideas often contest the dominant discourse on education and knowledge, offering new ways of thinking about what sort of knowledge is important, who is authorised to pass it on, and how it can be transmitted. A broader view of education, recognises multiple forms of authority to teach, beyond a formal qualifications system, and focuses on the outcome of learning rather than simply the method by which it is applied.

RTCs have the opportunity to play a dual role in the education of women. The can continue to focus areas relevant to prevailing gender roles in a way that supports and legitimises the work of these roles. Simultaneously they can integrates and promotes new opportunities and choices for women, particularly in light of the increased pressure women face to generate cash income.

\section{Conclusion}

The purpose of this chapter was to examine the relevance of Rural Training Centres to their local community and students in light of an expanded view of education and economy. Formal western education is underwritten by a hegemony of western scientific knowledge 
which has reduced other forms of knowledge to 'ignorance' (Santos, 1999). This perception of knowledge, entwined with western values and ideals, is propagated by a powerful global education agenda. Development, in its failure to eradicate poverty and inequality despite billions of dollars and half a century of activity, looks to education as a panacea that will help achieve multiple development goals. While there have been many documented positive benefits of education, little attention has been given to the model of education being promulgated and its relevance to many of the contexts in which it is applied.

RTCs offer one possible example of alternative education that takes a local focus, aiming to practically and socially develop young people for livelihoods in the local community. The RTCs profiles show that these centres can operate diversely, using different approaches, such as the specialised vs multi-disciplinary, and different resources to reflect best the skills and materials used in the local economy.

The aspirations of youth in Gizo and Vatu were found to show a mixture of influences, reflecting hybridity and a cultural third space, with greater complexity and linkages than the modern-traditional dichotomy allow (Bhabha, 2012). Youth showed a preference to stay or return to rural areas to build a home and family. Their aspirations were deeply rooted in indigenous values: connection to the environment, care for Wantok and contribution to the wider community. Similarly, they expressed desires characteristic of capitalism and modernity, such as waged employment, commercial business and formal schooling. The need to make money in some way in an increasingly cash dependent society was apparent. As a result young people saw themselves needing to undertake a diverse range of economic activities, Direct, Alternative and Formal, to support these two components of their dreams. The implications for education are that it needs to provide contextually relevant content to the economy of the community, and support self-reliance as well as income generation. RTCS are well placed, with their informality giving them greater flexibility, and the practical skills taught providing multiple applications using modern and traditional methods.

The perception of RTCs according to students was largely positive, reflecting their appreciation of the practical nature of their learning and the tangible outcomes they saw it providing. Criticism were typically related to resource constraints, these reflect some of the funding dilemma's RTCs face which will be discussed further in the next chapter. In the eyes of the communities, RTCs fill an important gap between formal education and the transition 
to paid or self-sustained livelihood. They encourage young people to stay in rural areas, stemming the urban drift, and give opportunity to the majority of youth who are pushed out of the formal system. Existing criticisms of varied quality, standards and levels of teaching may be accurate, however it is clear that they do not represent the full picture of RTCs, particularly in the eyes of the community.

However, the positive perception of RTCs and alignment with the current nature of women's livelihoods through the Life Skills programme, has not been sufficient to attract equal numbers of female students. The prevailing cultural attitude towards women as a lower priority than men, and the association of women with the domestic sphere rather than the economic sphere, act as deterrents to female engagement. In addition to experiencing social and economic barriers, women face an epistemological barrier, where the value and choice of education is not fully realised. Women from the communities of Gizo and Vatu suggest that raising educational awareness, through relationship with women in the community, and re-orienting the delivery model could encourage greater female participation. Teaching short courses in areas such as sewing, life skills, budgeting and cooking, located within the community offer a way to reduce the access and social barriers, although still reproducing current gender roles. They would also give visible examples of the value of women's RTC education, to influence social and cultural attitudes amongst women and men. RTCS also have the opportunity to push the boundaries of existing gender roles, integrating new areas of education and possibilities for women. They currently do this through encouraging women into trade based courses, and could further expand course selection into new areas of relevance to the local community.

In the Pacific, formal western education has been criticised for its lack of fit with the local economic and cultural context (Coxon \& Munce, 2008). It has been accused of preparing young people for urban and formal economic livelihoods, which ultimately they have very little chance of obtaining, particularly given the distribution of population and shortage of formal opportunities in places like the Solomon Islands (Gegeo \& Watson-Gegeo, 2002; Nordtveit, 2010). Rather than stop at this bleak picture of critique, recognising what has been silenced and discredited under the monoculture of western scientific knowledge gives rise to the opportunity to expand our view, developing ecologies of knowledge to combat the sociology of absences. Taking a diverse view of knowledge, and consequently education, moves away from the concept of a discrete body and type of knowledge to be attained. All 
knowledge is viewed as overcoming a certain form of ignorance and all ignorance as ignorance of a certain knowledge (Santos, 2004). Thus, the bounds of knowledge are expanded and western scientific knowledge is put in its place as one form of knowledge, overcoming one form of ignorance, amongst a myriad of other types and ways of knowing. The implication is an acceptance of pluralism in education that recognises multiple forms of knowledge, such as indigenous and traditional, and supports multiple ways of teaching and learning, including informal and direct transmission of knowledge. RTCs operate with some elements of such an expanded view through their practical, adaptive and locally grounded approach.

This chapter has also provided the background for a number of issues that will be taken up in the subsequent chapter: the funding of RTCs, the tension between the formal and informal systems of education and how success is measured by the global model of development. 


\section{Chapter 7: The monoculture of the universal and the global: Development policy in practice}

\section{Introduction}

The previous discussion chapters focused on the concepts of education and economy to examine the relevance of RTCs to Solomon Islands communities. This chapter represents a departure from the central question of relevance, to explore the intersection of RTCs with global development policy and local development practice. It recognises that RTCs operate in a landscape influenced by a myriad of actors, ideas and processes, based on a number of places and scales. In development, that which appeals to a universal or global position typically takes precedence of the national or national. The dominance of scale and standardisation dwarfs policy and practice that is generated locally and responsive to local context, creating a monoculture (Santos, 2004). The result is globally prescribed endpoints of development and a pre-laid trajectory that must be travelled. Donors and recipients alike are subject to universal and global frameworks and policy that influence development practice deeply at the local level. This chapter aims to consider the perspectives of multiple development actors, without taking sides. Rather it considers the rationale behind the decisions of donors and recipients, against the backdrop of global frameworks and international development policy.

The ubiquitous presence of universal targets and global indicators define and constrain the scope of development. Throughout this chapter theoretical debates about the influence of such frameworks are illustrated by examples of their impact on development actors, and subsequently the funding and status of RTCs. This poses a potential risk to the core purpose of RTCs. The tension of the aid relationship is further underlined by a power disparity between donors and recipients. As the more globally powerful, donors heavily influence development policy in the Solomon Islands. Recent examples of activities in the Technical and Vocational Education and Training (TVET) sector demonstrate how this influence is enacted, and the potentially detrimental effect is has on undermining local ownership.

This chapter emerged out of unexpected findings, based on meetings, observations and informal discussions with multiple development players (government, donors, civil society and recipients) in the field. Given the sensitive nature of aid relationships, and my privileged 
position as part of an NGO project, the terms 'donors' and 'government' are used generally in most instances to avoid identifying specific people and organisations. Where possible my observations are supported with written documentation. However, this is an environment where little of what really influences decision making is written down or in the public domain, further highlighting the importance of personal encounters to the depth of this research.

\section{The tyranny of targets and indicators}

Results based management has engulfed public policy in the west and found its way into international development policy and practice (Sjöstedt, 2013). Justified by a focus on outcomes, rather than activities, the rationale of measuring progress and return on investment is attractive. To implement this approach, development policy and practice is pervaded with global frameworks specifying universal targets, propped up by thousands of indicators, in an attempt to measure and incentivise progress (Manning, 2009). These "do the hard work of condensing complexity into single values that can be more easily digested and acted upon" (Morse \& Bell, 2011, p. 222). However, the power of such targets and indicators is seldom acknowledged. They act as powerful instruments to shape development policy and practice, becoming not only the measure of progress, but the yardstick of measurement itself (Morse \& Bell, 2011). The implications of this on education policy in the Solomon Islands and the operations of RTCs is considered.

The most prominent contemporary development agenda, the Millennium Development Goals (MDGs), provides an illustration of how universal targets and global indicators powerfully define and shape development to fit with the dominant discourse. While the concise focus and measurability of the MDGs has been praised for galvanising international support and collaboration, they have been criticised as a narrowing and tyrannical force (Saith, 2006; United Nations, 2014b). Three specific effects of this will be considered below: reduction of the scope of development, promotion of a top down and donor centric view of development, and production of a distorted picture of success.

\section{Narrowed scope of development}

The 8 goals, 18 targets and 48 indicators that comprise the MDGs have been commended for bringing unprecedented focus to addressing poverty and issues of human development. They were intended to operationalise the Millennium Declaration with a "comprehensive approach and a coordinated strategy, tackling many problems simultaneously across a broad 
front" (United Nations, 2001, p. 7). However, by omitting key dimensions of poverty present in the Millennium Declaration, including; human rights, empowerment, governance and inequality, they have been heavily criticised for narrowing and shallowing the scope of the development (Manning, 2009; Saith, 2006; Sumner \& Lawo, 2013). Instead, the MDGs uphold a few specific measures of absolute poverty and deprivation as representative of 'development'. These produce a much less ambitious conception than discussed and agreed at previous international summits (Saith, 2006).

Targets and indicators are inherently value laden, reflecting the dominant value system and stemming from cultural rather than scientific origins (Morse \& Bell, 2011). This gives them the power to misconstrue or dangerously redefine the concepts that they were designed to measure. An example of this is seen in Goal 1: Eradicate extreme poverty and hunger, where poverty, a complex and multidimensional issue, is defined by those living on less than \$1(PPP) per day. The deeper dimensions of poverty including equity and justice are lost. The concept of poverty is reduced to a single economic measure (Saith, 2006). This opens up the possibility that targets can be achieved, and yet the purpose behind the target missed entirely.

Critics, such as Saith (2006), argue that the economic focus reflects a neoliberal approach to development. However, Vandemoortele, co-architect of the MDGs, claims the selection of targets and indicators was done on a pragmatic basis; "in an age where numbers prevail" only targets with "agreed indicators" and "robust data" were included (2011, p. 4). Seemingly, selection was influenced more by what could be easily measured, rather than what was of the most value to human development, producing "a reductive view of the values of human life" (Morse \& Bell, 2011, p. 234).

\section{Top down and donor centric view of development}

Rather than reflecting a universal consensus on development, the MDGs were defined by a small group of rich nations, representing a top down and donor centric approach to development (Manning, 2009; Saith, 2006; Vandemoortele, 2011). This is illustrated most significantly by the omission of targets for developed countries. The problem of underdevelopment is located in the third world, emphasising what 'they' must do to change with the support of benevolent donors. Issues of poverty and inequality in rich countries, and structural inequalities at a global level that perpetuate poverty are off limits (Saith, 
2006). The exclusivity of the MDGs has been widely recognised as a weakness and work on the post 2015 agenda has deliberately included views from across the globe, civil society, academia and business. The new framework is also expected to include targets for all nations, not just poor countries (Boucoup, 2013).

In an effort to attach numerical measurement to complex concepts, universal targets and global indicators overlook local context and human understanding. This can give a distorted picture of what is happening on the ground. For example, Goal 2: Achieve universal primary education, is measured through national primary enrolment numbers. These figures say nothing about the quality of the education delivered, the relevance of that education or the medium to long-term plan for education (Saith, 2006). What ensues is a project of implementation, applied arbitrarily with a one size fits all approach rather than a focus on educational outcomes and relevance for context (Nordtveit, 2010).

Similarly patterns of inequality within countries are concealed. This is particularly critical as poverty is increasingly attributed to domestic inequality (Sumner \& Lawo, 2013). Vandemoortele (2011) argues that this is due to misappropriation of the MDGs; they were not designed for each country to meet the global targets, but rather to align priorities. Hence, it is not the tool that is the problem, but the way in which it is applied, interpreted and shaped into policy that sustains their "methodological tyranny" (Morse \& Bell, 2011, p. 225). As Manning concludes the MDGs are "good servants and bad masters" requiring adaption for local context rather than adoption as a planning framework $(2009$, p. 6).

\section{Success?}

With the 15-year deadline for the MDGs approaching, it is appropriate to ask how successful they have been. Measuring the impact of the MDGs is surprisingly difficult, partly due to a lack of research and evaluation, but also because there is no way of knowing what would have happened in their absence (Vandemoortele, 2011). The MDG score-card shows mixed results, with a smattering of targets achieved or not achieved across different regions (United Nations, 2014a). At a global level, goals in the areas of poverty, gender and water are consider 'on track' to achievement where as nutrition, primary education, and child mortality and material mortality are unlikely to be achieved (Sumner \& Lawo, 2013). The achievement of targets relies on the availability and accuracy of indicator data. However, although part of the MDG's appeal was their robust quantitative nature, issues of data 
reliability and honest representation of data undermine this integrity. For example, the indicator measuring the number of people living on \$1 (PPP) per day is not only conceptually one-dimensional, it is methodologically troublesome. Household surveys that determine levels of consumption or income are not standardised, PPP measures are known to have an urban bias and there is "no certainty that an international poverty line measures the same degree of need or deprivation across countries"(United Nations Statistics Division, n.d.). Embarrassingly, the World Bank, who calculate global poverty estimates, have previously reported systematically undercounting the number of people living in poverty by an error of up to 50\% (Vandemoortele, 2011). While universal targets and global indicators have widespread appeal for donors, they do not necessarily reflect an accurate or insightful picture of the situation on the ground.

\section{Implications for RTCs}

Focus on the universal and the global denies credibility to local and non-standard development policy and practice. This has implications for RTCS as informal education institutions that do not fit within the mainstream system. In reality universal targets and global indicators are not the infallible scientific measures that they appear to be. They are fraught with conceptual and methodological issues and commonly represent a narrow or particular perspective on development. They are successful in focussing development funding, although this can be at the expense of other important human investments. However, despite their flaws, universal targets and global indicators, such as the MDGs, are powerful in driving government development policy and donor activities. Consequently, there is a strong tendency to favour that which is standardised, measurable and that fits with conventional development paradigm. The themes discussed above can be recognised in the tensions between RTCs, government and donors. The donor centric and universal approach undermines the credibility of these informal centres, with funding used as a tool to reward standardisation. As a result RTCs face a dilemma, to retain their flexibility with poor funding, or fit with prevailing agenda and risk a gross narrowing of purpose. Essentially, the different approach of donors and government compared to RTCs reflects different understandings of what constitutes success. The former focussed on qualifications and industry needs, and the latter on local livelihood capabilities.

\section{Funding follows formality}

An increase in consistent funding is a common obvious need for all RTCs. The gap RTCs fill, by educating students pushed out of the formal system provides a clear rationale for their 
resourcing. However, the tendency of government and donor funding to align with standardised international frameworks disadvantages RTCs on two fronts. Firstly, as vocational institutions they fall outside of the dominant global frameworks (MDGs, EFA) which emphasise primary and secondary school. Secondly, as informal and decentralised bodies they do not fit the standard development approach, eroding their credibility in the eyes of government and donors. As a result they do not receive the same funding as formal education options.

The TVET sector in the Solomon Islands, under which RTCs fall, receives less than $3 \%$ of the education budget allocation (Bateman, 2014). Vocational education has suffered globally from the prioritisation of resources to primary and secondary education under the MDGs (Mundy, 2006). In the Solomon Islands this has been further exacerbated a legacy of colonial elitism and corruption in the tertiary sector. In 2012, $25 \%$ of the education budget benefited $1 \%$ of students, largely due to "out of control" tertiary scholarships to foreign institutions (Close, 2012, p. 23). Fortunately, many years of resourcing neglect in the TVET sector are beginning to be recognised due to an emerging skills shortage (Australian Government: Department of Foreign Affairs and Trade, 2014a; Close, 2012). As a result, improving the distribution of funds to different types and levels of education is now being considered in the National Education Action Plan 2013-15 (Ministry of Education and Human Resources Development, 2013).

RTCs began receiving government support in 2005 with agreement to pay salaries for registered teachers and a per student grant of SBD 400 per annum. This rate of funding has not been raised since (Interview with SIAVRTCs representative, 27/03/14, Honiara). Discussions and observations with donors and government in country indicate that more money is available in the education budget. However, the negative associations of informality act as barrier to this funding increasing. References are continually made to the low capacity of RTCs, the poor training standards, and lack of quality assurance. The result is that RTCs do not receive the same levels of funding as their formal counterparts - primary, secondary schools and the university. The umbrella body responsible for advocating and liaising with government and donors, the Solomon Islands Association for Vocational Rural Training Centres (SIAVRTCs), recently asked the government to:

Reconsider its policy on the school grant sharing between the formal (secondary/primary) and non formal schools (RTCs) so that RTC boarding schools grants in particular increased 
to align with the formal schools, since the welfare needs of the students (regardless of formal or non formal schools) are similar across the board. (SIAVRTCs, 2013, p. 2).

RTCs are disadvantaged because of their informal status, and the connotations informality brings in a system dominated by universal standards.

The informal status and decentralised ownership of RTCs also conflicts with the top-down and donor centric approach permeating development. As independent institutions RTCs do not have standard mechanisms of accountability and curriculum. From a government and donor perspective this is a red light for risk and control, expressed as a lack of quality assurance, measurability and certainty of outcomes. However, rather than viewing them as a disparate and disorganised group, an alternative view of development recognises the existing structure and cohesion of RTCs. SIAVRTCs, the umbrella body mentioned above, brings the RTCs together from their various church groups, facilitating advocacy, communication and funding coordination. The self-organisation of such a diverse group of church bodies working together can be seen as an incredible strength. It is bottom up rather than top down and focussed on what is happening on the ground As a representative of SIAVRTCs reflects, "the government talks about the policy and the formal part of it, but the practical aspect of getting things into the TVET sector to drive TVET, it comes from our access" (Interview, 27/03/14, Honiara). Revealed is an opportunity to work more closely to empower this body and connect the trans-scale, from government policy to the ground level.

\section{Funding vs flexibility}

Becoming more closely integrated with the formal system offers the promise of increased funding from government and donors, as a representative of SIAVRTCs noted, "there are a lot of opportunities...if we fit into the structure of the system" $(27 / 03 / 14$, Honiara). Yet, it also holds the risk of homogenising RTCs. The extent to which fitting with the system would reduce the flexibility of RTCs and disconnect them from their original purpose poses a dilemma. RTCs currently operate on a broader concept of education than is encompassed by the formal education system. One of their greatest strengths, highlighted in this research, is their flexibility to adapt to the context of the surrounding community and teach in a way that is specific and relevant. The objectives of RTCs also go beyond education to encompass social goals and holistic youth development. A representative of SIAVRTCs summarises the purpose to equip young people to: 
Sustain their livelihood...drive them to self-reliance (because the resources are in the community), participate with their skills to benefit the community...reduce the influx of [young people] into the urban centres. (Interview, 27/03/14, Honiara)

These expansive goals are the essence of why communities and churches established RTCs in the first place. Standardisation and formalisation are likely to narrow this focus and impinge on the flexibility that is currently such an advantage. The threat is movement to an agenda of implementing educational standards rather than continual consideration and adaptation for outcomes (Nordtveit, 2010) .

On the other hand RTCs do not see these two approaches as necessarily being mutually exclusive. In a recent petition to the prime minister, SIAVRTCs suggested that those RTCS that already possess the necessary resources and capabilities be upgraded to Technical Colleges, a formal institution. Other RTCs would remain as they are, informal (SIAVRTCs, 2013). In this way RTCs seek to leave no one behind, but offer multiple pathways and options for young people, rather than a singular trajectory.

\section{Qualifications vs capability}

Different understandings of success underlie the tension and dilemmas discussed above. Government and donors favour formal qualifications and industry satisfaction as the intended outcome of education, while RTCs focus on capability to make a local livelihood. The Solomon Islands does not currently have a national qualifications framework. Provision of qualifications is limited to a small number of selected tertiary providers (Bateman, 2014). The Ministry of Education and Human Development (MEHRD) is in the process of preparing a White Paper on the future direction of education in the Solomon Islands, including the development of a Solomon Islands Qualifications Framework (SIQF) (Bateman, 2014). Where RTCs will fit, if at all, in this qualification framework is not yet decided. While government and donors have expressed an opinion that RTCs teach at a pre-certificate 1 level, it is unclear if any mapping has actually been performed.

Qualifications provide a uniform way by which others, primarily employers, can know a standard of knowledge and skill has been reached, assuring employer confidence. They represent a labour market approach, which is adopted by highly influential international and domestic players in the Solomon Islands, including the World Bank, Australian Aid, the Solomon Islands Chamber of Commerce and MEHRD itself. Under this view the primary 
objective of TVET is to meet the needs of industry, filling the skills gap, and contributing to the higher goal of economic growth (Australian Aid, 2014; Australian Government: Department of Foreign Affairs and Trade, 2014a; Close, 2012). The National Education Action Plan 2013-15 refers to the establishment of TVET career pathways and transition to labour market entry, but mentions nothing of livelihood outcomes (Ministry of Education and Human Resources Development, 2013). Similarly, the biggest development partner in TVET, Australian Aid, is conducting a ten year project designed:

To strengthen the capacity of the nation's post-secondary education and training system to produce quality graduates who are in demand in the labour market and who have the skills and knowledge needed to increase national productivity and competitiveness.

So while the majority of livelihoods in the Solomon Islands, as discussed extensively through this thesis, are not supported by formal employment, 'industry' takes the spotlight in driving TVET policy. This influence of this on government has most likely come through global indicators and the powerful aid relationships that will be discussed later in this chapter.

RTCs, by contrast, take a livelihood approach. The most likely outcome for RTC students is self-employment or self-reliance, making the issuance a qualification less important than capability. If a graduate is not well skilled in agriculture, the family's food source could be compromised, rather than just being unsuccessful for a job. The relevance of qualification to RTCs seems secondary to their primary objective, particularly as qualifications are noted for their labour mobility. While not discouraging domestic or international movement, the primary objective of RTCs is preparation for a local livelihood.

Qualifications, with their associated assessment components, could also require levels of education, literacy and numeracy that RTC students are unlikely to be able to meet. The principal demographic for RTCs is the $70 \%$ of young people who exit the formal system early, "providing a second chance to the school push-outs, otherwise, there would be no alternative offered to cater for these innocent school dropouts which the National Education System has created" (SIAVRTCs, 2013, p. 4). Restricting entry or creating onerous assessment standards could have the same filtering effect seen in the formal system that has already excluded these young people. The focus for RTCs is not the $20-30 \%$ pursuing qualifications, but "getting down to the $80 \%$. Where the $80 \%$ of the people are, is the population and resources" (Interview with SIAVRTCs, 27/03/14, Honiara). Donors and government seem to 
expect a level of standardisation and formalisation before supporting RTCs more systematically, however they seem unwilling to provide the level of resourcing necessary to make such a transition possible.

The homogenisation that frameworks like the MDGs have bought in promoting types and approaches to education threatens the contextual relevance of RTCs. The preference for "global blueprints" and "universal trajectories" that reflect the modus operandus in developed countries strongly drives policy in a completely different context (Vandemoortele, 2011, p. 2). Lacey (2011) emphasises the importance of not assuming 'sameness' when talking about poverty in the Solomon Islands. Recognising the different challenges rural and urban areas face, and how these are different for a small pacific nation is key to addressing the situation. RTCs use curriculum and a style of teaching based at a very local level. They also "work with ideas of informality", essential to Solomon Island livelihoods, that universal targets and global measure struggle to quantify or incorporate (Lacey, 2011, p. 17).

\section{Tensions in the aid relationship}

The dominance of the universal and the global in development is often outworked through the aid relationship. The aid relationship inherently entails a complex mix of politics, ideologies and negotiation, underscored by a fundamental asymmetry of power (Cramer, Stein, \& Weeks, 2006). Aid is also far from a purely benevolent practice. Donor interests regarding trade, business, and security drive investment decision. Donors also bring strong beliefs about the forms and structure of government, often reflecting wider global discourses such as democracy and good governance, and export these values along with aid to developing countries. Treated as universal truths, these ideas are based on what has worked in the western developed world, and do not necessarily suit the political or cultural context of the recipient country (Booth, 2012).

The Solomon Islands is highly aid dependent with Official Development Assistance (ODA) accounting for $44 \%$ of gross national income (2012 figures) (OECD, 2013). Like many Pacific Island nations, the number of donors and interest in the area has increased in recent years with numerous bilateral and multilateral agreements in place (Wrighton \& Overton, 2012). Coupled with a post-conflict environment, the Solomon Islands is particularly vulnerable to being shaped and constrained by the aid relationship. While supporting the concept of country owned and driven development in rhetoric, in practice donors engage in activities 
that undermine and control development. Two recent examples will be explored showing how this has happened in the TVET sector and as a result have negatively impacted the sustainability of the sector and operation of RTCs. Additionally, the more pervasive donor influence at the structural level of government, though the state building activities of RAMSI, will be discussed. Underpinning these tensions, the power of the aid relationship proliferates the dominant global frameworks and discourses of development, driving domestic policy and development trajectory of countries like the Solomon Islands.

\section{Questioning ownership}

Endorsed by the Paris Declaration in 2005, the principle of 'ownership', development priorities being set and driven by the aid recipient country, is embedded as a central pillar of international development policy and practice. It is seen as a powerful way to increase aid effectiveness and essential for the long-term sustainability of development activities (Booth, 2012; Sjöstedt, 2013). In the Solomon Islands documentation from major donors attest to the importance recipient ownership (Australian Government: Department of Foreign Affairs and Trade, 2014a; Ministry of Foreign Affairs and Trade, 2012; Wright, 2013). However, in practice donors were observed to engage in activities that subvert ownership in the TVET sector.

An example that was frequently discussed in the field was the recent European Union project, which ended after seven years in 2013. Aimed at enhancing the quality and quantity of TVET training, the project has been criticised for its donor-centric approach, lack of investment in local capacity and complex bureaucratic funding mechanisms. As a result, three quarters of the intended project outcomes were not achieved and six million of the eight million Euro in funding returned to the donor (Douse, 2014). In addition to employing an unsustainable approach, the funding and policy space occupied by the EU project over such a long period resulted in resources from government and other donors being diverted away from TVET. The understanding that the EU project was comprehensively looking after the sector delayed investment in TVET policy and infrastructure by years.

The impact of this failed project is being felt acutely on the ground by the sole RTC teacher training institution at Vanga. Set up with EU funding, Vanga Teacher's Training College is now struggling to operate sustainably. Students and staff at the centre cited broken facilities, a lack of tools, money to pay for electricity, staff shortages and a lack of professional 
development as issues they were experiencing due to funding shortages (Interviews and focus group, 18/03/14, Vanga). By taking ownership of TVET, and of Vanga, the EU project created a funding and policy gap that now has to be retrospectively addressed. Vanga Teacher's Training College is the beginning of the teaching cycle; a lack of sustainable resourcing and training quality at the College has a knock on effect, flowing through to the whole network of RTCs.

A second practice observed was the tendency of donors to fund foreign experts in government positions. Often in senior roles, these experts can be highly influential in setting the policy and the development agenda. From a donor perspective, placement of these individuals addresses gaps in local capacity. It is also a way in which donors can mitigate fiduciary risk and ensure compliance to their reporting frameworks. However, having donor funded foreign staff driving strategic policy development from within government seems to create a layer of illusion, where policy appears to be government owned, yet may actually represent the values and interests of donors. In an environment of increasing domestic pressure to justify aid spending, donors are cautious and want to ensure demonstrated impact of aid (Tilley \& Tavakoli, 2012). Their willingness to relinquish control in practice is often painted as an exercise in risk mitigation and blamed on the poor implementing environment, as Swedlund notes:

Will donors really turn control over their taxpayers' money to governments that are often anything but democratic, frequently fail to implement "pro-poor" policies, have low levels of institutional capacity, and may have engaged in corrupt and/or neopatrimonial practices in the not so distant past? (2013, p. 357).

Rather than hand over control to the recipient country, these practices embed more deeply the power asymmetry of the aid relationship

\section{Rebuilding or re-engineering?}

At a broader level, the pervasive influence of donors on policy development and the structure of government in the Solomon Islands is evident through state building activities. The post-conflict context of the Solomon Islands has meant that the fundamental architecture of government, law and the economy are being reconstructed through heavy donor assistance. Combined with the small administration of a Pacific Island nation, that can struggle to absorb the number and complexity of donor activities, there is increased vulnerability to external influence (Wrighton \& Overton, 2012). RAMSI has played a pivotal 
role in state building over the last decade, bringing ideologies of government and economy. The distinctive neo-liberal economic focus can be seen through economic reforms made under RAMSI, such as:

- Creating a more comfortable environment for private sector business through reducing costs and start up times and modernised business law reforms.

- Inviting foreign investment through reduced restrictions and streamlined processes;

- Opening up of trade through the reduction of import tariffs.

- Increasing market competition in aviation and telecommunications.

(RAMSI, 2013).

Such re-engineering of the architecture of governance and the economy reflects the wider agenda of the key RAMSI players, Australia and New Zealand, as well as the dominant global economic paradigm. With RAMSI now replaced by development assistance, Australia and New Zealand continue their influence through the development agenda as the two largest donors.

The aid programmes of Australia and New Zealand have increasingly shifted to prioritise national interest and promote development through a pathway of economic growth (Australian Government: Department of Foreign Affairs and Trade, 2014b; Banks, Murray, Overton, \& Scheyvens, 2012; Ministry of Foreign Affairs and Trade, 2012). Together with the powerful results based management approach underpinning global aid paradigm, there seems to be little room left for recipient ownership. While it is beginning to be acknowledged internationally that development pathways and governance structures that have worked for developed countries do not necessarily suit the context of developing countries, in practice donors continue to push these agendas by only funding activities that align (Booth, 2012; Wrighton \& Overton, 2012).

\section{Navigating the murky waters of the aid relationship}

The reality of the aid environment is filled with difficult considerations that make applying a standard template of development practice unworkable. There are incentives driving development actors towards recipient ownership to increase aid effectiveness, whilst at the same time considerable risks and ideological concerns discouraging ownership. The discussion above has aimed to illustrate some examples of these complexities in practice. Yet, remaining is the issue of how countries can define their own development goals and trajectories without rejecting aid all together. Sjöstedt (2013) argues that the first step is to 
expose and acknowledge the tensions and conflicting incentives. Otherwise donors will be driven towards low hanging fruit, avoiding the more difficult situations in most need of assistance. Acknowledging the complexity and competing priorities may also mean accepting a higher level of risk and failure in the aid paradigm, as it seems that long-term sustainable results are often at odds with quick wins. In the meantime, it is clear that development practitioners in the Solomon Islands will continue to face "severe and competing demands" as the conflicting priorities of donors, global frameworks and local outcomes continue (Sjöstedt, 2013, p. 143).

\section{Conclusion}

This chapter has considered how development policy at the global level influences and impacts on development practice at the local level. The dominance of universal targets and global indicators constrains the scope of development, encouraging funding to follow that which is formal, standardised and aligned to international frameworks. This presents RTCS with a dilemma, whether to remain autonomous and therefore adaptable to their local context, or to pursue greater levels of government and donor funding by formalising? Fundamentally, RTC reflect a different focus to the globally endorsed mode, one centred on capability rather than qualifications.

Donor subscription to global agendas and frameworks is often outworked through the aid relationship, creating tensions around who is driving development. In the TVET sector donor activities have at times subverted local ownership, and as a consequence compromised the sustainability of initiatives, such as Vanga Teachers Training College. At a structural level, donor interests and values have been entrenched through the state building activities of RAMSI. The asymmetry of power embedded in the aid relationship makes defining and achieving ownership in development difficult.

Global influences on local development policy and practice create a serious of tensions and dilemmas for RTCS as they try to attain sustainable resourcing and remain contextually relevant to their communities. RTCs and other development actors in the Solomon Islands cannot remove the dominant paradigm of development policy. Simply ignoring these influences is not an option, rather there is a chance for all actors to acknowledge the pressures, and explore a way forward. Santos (2004) speaks of countering the monoculture of the universal and the global with an ecology of trans-scale. Essentially, this means 
legitimising, harnessing and proliferating local practice. Giving equal credibility to the local development practices of RTCs starts a new conversation. Even if government and donor attitudes and practices remain unchanged, by understanding how the universal and global are driving influence, RTCs are in a stronger position to make choices their future. Similar to Gibson-Graham's (2005) notion of more encompassing view of economy, this offers a more expansive view of development practice that acknowledges the dominant pressures, without simply bowing to their might. The result is a diverse range of practices to work with and beyond existing constraints.

This thesis has introduced alternative conceptualisations of economy, education and now development. These ideas invites a paradigm shift in thinking, while working with the reality of dominant frameworks remaining in place. By focussing on 'what is', and seeking to reveal, legitimise and add to the diversity already in operation, change can be realised immediately by any actor responding to this invitation. 


\section{Chapter 8: Conclusion}

The central purpose of this research was to examine the relevance of Rural Training Centres to communities in the Solomon Islands. This has been a process of unveiling, revealing hidden aspects of the economy, education and development, and repositioning discussion from a point of awareness and appreciation. Rather than create a romanticised or idealised vision of rural life, the goal has been to create a more realistic picture that reflects the myriad of views and activities overlooked by dominant discourses. Hence, the question of relevance can be addressed from this new standpoint.

By recognising the diverse economies of Gizo and Vatu and the value of women's work, a fuller picture of what supports livelihoods is made visible. Through understanding the situation of youth in the Solomon Islands and their aspirations for the future, western scientific knowledge and education are dethroned from their hegemony. Credibility is given to indigenous knowledge and alternative types of education. Admitting the tendency of development donors to take control in the development relationship, often funding activities aligned to global agendas at the expense of contextual relevance, invites reflective development practice, while acknowledging the complexities involved.

This chapter outlines the key findings of this research from an expanded conceptualisation of economy, education and development. The contribution this research has made so far, and future areas for research are also discussed. The thesis concludes by returning to the initial inspiration for this research: questioning the relevance of formal western education in different contexts.

\section{Expanding economy}

A diverse economies analysis of Gizo and Vatu found that Formal economic activities were of secondary importance in supporting livelihoods to Alternative and Direct economic activities. The garden and the sea were the predominant source of food, shelter and basis for income generation in the both sites. Direct economic activities played a larger role in the rural environment of Vatu, offering the added benefit of community autonomy and resilience by maintaining low reliance on cash income.

However, the increasing influence of a cash based economy cannot be ignored. Income, of some description is needed to fund basic necessities, such as school fees, clothing, transport 
and power. This influence was more apparent in Gizo, as a semi-urban location, where life was found to depend heavily on Alternative economic practices to convert natural resources, such as fish and agricultural products, into money. It also places increased pressure on these resources as they are no longer harvested on a micro scale to meet family needs, but on a scale that can be sold for profit. Socially this has resulted in women taking on the additional burden of income generation on top of their traditional gender role. An expanded view of economy, under a diverse economies approach, reveals the multi-layered and critical nature of previously invisibilised activities to everyday livelihoods.

\section{Expanding education}

The importance of Alternative and Direct economic activities has implications for education. Formal western education, as propagated by the powerful global education agenda, rests on claims of progress and wide spread ideological support. However, it largely fails to recognise contextual differences. Formal education chiefly prepares young people for activities in the Formal economy. This assumes availability of Formal opportunities, and generally relies on urbanisation or modernised rural living to deliver these opportunities. In the Solomon Islands, where there are insufficient formal employment opportunities for the growing number of youth, and people live in dispersed and rural locations, the relevance of such education for the majority is questionable. Underlying the formal model is actually a powerful discourse of the superiority of western scientific knowledge, upholding a rich western cultivated life that is simply not achievable for the majority. This discourse has become part of global culture, often internalised by people in developing countries themselves. Thus it would be unsurprising if it were reflected in the aspirations of young people for the future.

However, the aspirations of young people in this research were found to be varied, showing multiplicity and relationship to non-dominant discourses. The young people of Gizo and Vatu were indeed influenced by the global economy and promises of development, while at the same time being deeply rooted in indigenous knowledge and values. Youth showed a strong connection to their local environment as a source of life and pleasure, their local community, and to principles of sharing and reciprocity. Moving to 'town' was typically viewed as a temporary means of earning money, with their real future lying in the rural areas and supported by a diverse range of economic activities. At the same time, they identified the need for cash income and sought to adopt modern ideas of running businesses, working as 
employees and optimising returns to generate income. Diversity, hybridity and adaptation characterised their livelihood aspirations, reflecting a cultural third space that exists between and beyond the modern-traditional dichotomy.

Consequently, the dual approach of the RTCs, teaching skills for self-reliance and income generation, was found to have strong alignment the aspirations of youth. Despite criticisms from donors and government that RTCS are ill equipped and lack any form of standardisation, the communities in Vatu and Gizo viewed the RTCs as having a positive social and economic impact. Rather than being seen as a 'last resort', they were perceived as filling a vital gap left by the formal education system and offering an alternative to urban drift.

The students themselves were largely satisfied with the education they were receiving at the RTCs, specifically appreciating the practical nature of the skills being taught. Many were inspired to extend the experience by working for or creating a similar environment in their own community. The flexible and practical approach of the RTCS, along with their adaptability to local context, was found to be key to their relevance to local communities. From an expanded understanding of education, that incorporates indigenous knowledge and traditional skills, the high relevance of RTCs is apparent.

\section{Expanding development}

In the background is a model of development that elevates the universal and the global over the local and contextual. Under a results based management approach, targets and indicators dominate the focus of development. While these systems attract global funding and ensure safeguards for donors, they often fail to consider the context and relevance of what they are delivering. RTCs sit outside the formal education system and offer a type of education not promoted by global agendas. As a result they were found to suffer funding disadvantages. Pressure to formalise and standardise, in order to secure more funding, risks compromising the very strength they bring, flexibility to respond to the context of the surrounding community and a focus on local livelihoods.

However, the picture is not a simple case of donors dominating development agendas. The principals outlined in the Paris Declaration have attempted to hand over ownership to development recipients, by ensuring donor activities support national policies and as far as 
possible use budget support aid modalities. Yet, in the post-conflict environment of the Solomon Islands corruption and the capacity of government to administer social services is under constant strain. Consequently, donors were found to be heavily involved in setting development policy and implementing development practice, under a commitment capacity building and accountability. On the negative side, the heavy hand of donors has at times undermined ownership in the TVET sector and compromised sustainability in the future.

An expanded view of development recognises the influence of powerful global forces in development and the political realities of the aid relationship. From this point of view the tension RTCs face between formalising to increase funding, or retaining flexibility and selfreliance can be seen as part of a wider tension in development. Similarly, donors are caught in a tension of their own, with increasing pressure to justify non-domestic spending to domestic constituencies and show results for investment. RTCs have responded to this tension differently. Many are founded by foreign church leaders and rely on strong international connections to procure funding, such as Gizo RTC. In contrast, centres like Vatu RTC, founded by a local indigenous Solomon Islander are self-reliant. They have had to grow much more slowly, not benefitting from the same capital input, but arguably have a better chance of sustainability. Each is attempting to bridge the gap at a broader level, by applying different development practices at a local level.

\section{Expanding opportunities for women}

The dominant model of economy, prevailing cultural attitudes and the focus on economic development can all be seen to marginalise women in the Solomon Islands. The capitalocentric view of economy undervalues much of the work women undertake to support livelihoods. In Gizo and Vatu women were found to be experiencing pressure to perform activities that fit with more with this dominant model (e.g. generating cash income) in addition to responsibilities associated with their traditional gender role; thereby creating a dual burden.

RTCs struggle to attract female students, with those enrolled are concentrated in the Agriculture and Life Skills programmes. This was found to be influenced by some practical impediments, but largely based on deeper issues of relevance and inequality Women were perceived to hold a lower status than men and a have a domestic gender role. As a result 
families are less likely to outlay fees for female education or forfeit the work a female can provide in the home.

The western model of development heavily promotes education for girls and women, particularly on the basis of economic impact. However, it promotes a narrow form of education that associated with the formal economy. Donors in this research showed a reluctance to support education beneficial for the 'domestic' lives of women, as opposed to their economic lives. Much of the education women in the research mentioned does not need happen in a formal manner. It is simply a matter of empowering women (be it financially or organisationally) to recognise and share their existing skills within and between communities. RTCs have a potential dual role. Firstly, to value the traditional role of women, through areas such as the Life Skills programme. Secondly, to push the boundaries existing gender roles, integrating and introducing new skills areas for women, and helping them to navigate the new pressures they face around income generation. Both of these approaches would benefit from closer connections with the community, potentially through outreach courses and women's networks.

\section{Research contribution}

This research held a strong commitment to contribute to development practice. It provides a concrete example of how the gap between academia and professional development practice can be bridged successfully and for mutual benefit. In doing so, it advocates for wider and closer on-going engagement. Showing this is possible within the scope of a Master's thesis has opened up discussions for closer future collaboration.

The findings from this research have been utilised in the design and implementation approach of the development project, and excerpts incorporated into briefing and training documentation for New Zealand development actors A shorter and more pragmatic organisational report has been written for Caritas Aotearoa New Zealand. Feedback on the report, dialogue and research process indicated that the research was effective in expanding the development thinking of the organisation and providing practical learning. In particular, the organisation found that the findings gave theoretical and empirical grounding to many reflections from the field. As a result, these could be more directly considered in the project design and implementation. The research also enabled the voice of stakeholders in the 
community to be heard in a way that there is rarely time for in the busy world of development practice.

This research has also contributed to the exploration of burning issues at the forefront of development. It has tackled the inter-relationship between livelihood improvement and education and development in the 'disadvantaged' environment of the Solomon Islands. This has been done innovatively, moving across scales, between the locally grounded and globally informed. The result is a contribution to development literature in multiple areas, education, livelihoods, and aid policy in the Solomon Islands, and with relevance to multiple other contexts.

This research has engaged deeply with postdevelopment critique, while at the same time moving beyond critique towards action and practice. This has made the findings more applicable to the field of development practice, and illustrated how postdevelopment can be constructive and applied in a real project.

\section{Areas for further exploration}

The intentionally broad scope of this research (encompassing economy, education and development) lays a stepping-stone for further research in each of these areas. The changing nature of the economy in the Solomon Islands warrants further investigation in terms of the impact this is having, both positive and negative, on livelihoods. Similarly, this research was confined to RTCs. A comparative study of the outcomes of different forms of education, under a diverse economies perspective, would provide greater insight for development activities. There is also scope to foster cross pollination of good practice in terms of funding, curriculum and management with a study of RTCs and similar institutions across the Pacific.

The gap between policy, rhetoric and practice in development is an endless mine of research, though extremely sensitive in nature. Based on this research, two areas stand out for further exploration. Firstly, the challenge of funding reaching the ground. A continual observation was the complexity of layers and relationships that needed to align before an aid dollar reached the ground. Improvements in this area could see a much more responsive and agile sector. Secondly, a wider study of the influence of donors on policy formation in fragile states, such as the Solomon Islands, is warranted. 


\section{In closing}

The culmination of this thesis is a transition from a sociology of absences to a point where a sociology of emergences can begin to form.

At the heart of the matter, formal western education reinforces the promise of development, a "rich, cultivated and happy life for all" (Nordtveit, 2010, p. 325). Sadly this is a false promise that development has failed to deliver. The mainstream concept of development relies on maintaining global inequalities to propel economic growth and formal western education principally prepares young people for a place in this capitalocentric system. However, for the young person studying in the Solomon Islands or Nepal, largely these formal jobs do not exist. Meanwhile the skills of self-reliance passed down through generations, indigenous knowledge and values, become marginalised and eroded. The life known to many for millennia is defined by inferiority and lack under the dominant development discourse, which simultaneously promotes a western pathway to a supposed better life (Esteva, 2010; Ziai, 2007a). Should formal western education therefore be abandoned? Perhaps not, for some young people it reflects their aspirations and being able to read and write in the dominant language allows a person to appropriate their own learning. This is not about closing down opportunities, but opening them up.

Taking an expanded view of education that goes beyond western scientific knowledge, along with an acknowledgement of the range of economic activities that support livelihoods, beckons development to be practiced in a different way. A way that recognizes the root causes of so called of poverty and inequality often reside in behaviour and structures controlled by the west, rather than locating the problem only with the underdeveloped. A way that recognises the informal without regarding it as inferior, and respects and encourages a multiple pathways to achieve multiple development goals (Matthews, 2008; Santos, 2004).

This thesis has not sought to whole-heartedly reject dominant systems and frameworks, partly because that is an illusion beyond achievement, and partly because it is naively idealist to imagine perfect economic, education and development systems. Rather it has taken a pragmatic stance, starting with what is, and beginning to recognise and build. Despite the resourcing and political challenges Rural Training Centres face, from this perspective they can be seen to be an example of doing development differently. By placing livelihood 
outcomes and contextual relevance above standardisation and universal influences they support an alternative pathway for young people that is of equal, if not greater value than their formal counterparts. 


\section{Epilogue}

So what happened to Nyima, the young man from the small Himalayan village, son of our porter? I sat across from him in his home and asked what he would like to do in life, he said he wanted to finish school, especially to study the environment and social sciences. He explained in partial English that he had already begun studying by correspondence, as the local high school did not extend to the latter secondary years. I cannot deny the emotional component that swayed my decision, despite knowing the risks and potential false promise of development, my heart melted. How could I tell a young man he could not finish school? But outside of this discussion, Pemba and I schemed about how we could increase his chances of actually gaining work after finishing school. We decided to supplement formal education with trekking guide training and learning another language to give him an edge to work in tourism. I had wrestled with the decision from a human rights perspective, was finishing high school a human right when it seemed so contextually disconnected? From an economic perspective, I rationalised that even if Nyima ended up back in the village he would be better equipped with English, French and mathematical skills to make the most of the tourism and other economic opportunities. Currently, Nyima is still in school. Whether or not it was the right decision, I don't know, but the only reason that really convinced me in the end was that it was about choice. Unlike the little boy carrying the gas canister, I wanted Nyima to have more choices. 
When the farthest corner of the world has been conquered technologically and can be exploited economically; when any incident you like, in any place you like, at any time you like, becomes accessible as fast as you like; when you simultaneously 'experience' an assassination attempt against a king in France and a symphony concert in Tokyo; when time is nothing but speed, instantaneity, and simultaneity, and time as history has vanished from all Dasein of all peoples; when a boxer counts as the great man of a people; when the tallies of millions at mass meetings are a triumph; then, yes then, there still looms like a sceptre over all this uproar the question: what for? - where to? - and what then?

(Heidigger, 1918 cited in Nordtveit, 2010, p. 29) 


\section{References}

Agostino, A. (2008). Going beyond development monoculture: Critical reflections on the MDGs. Development, 51(2), 228-235.

Alldred, P. (1998). Ethnography and discourse analysis: Dilemmas in representing the voices of children. In R. Edwards \& J. Ribbens (Eds.), Feminist dilemmas in qualitative research: Public knowledge and private lives. London, United Kingdom: SAGE.

Allen, M. G. (2012). Land, identity and conflict on Guadalcanal, Solomon Islands. Australian Geographer, 43(2), 163-180.

Australian Aid. (2014). Solomon Islands skills for employability program design document draft. Author.

Australian Government: Department of Foreign Affairs and Trade. (2014a). Aid program performance report 2012-13 Solomon Islands.

Australian Government: Department of Foreign Affairs and Trade. (2014b). Australia's new development policy and performance framework: A summary. Author.

Banks, G., Murray, W., Overton, J., \& Scheyvens, R. (2012). Paddling on one side of the canoe? The changing nature of New Zealand's development assistance programme. Development Policy Review, 30(2), 169-186.

Bateman, A. (2014). Solomon Islands qualifications system (Briefing Paper). Bateman and Giles.

Baxter, J. (2010). Case studies in qualitative research. In I. Hay (Ed.), Qualitative research methods in human geography (3rd ed., pp. 81-98). Melbourne, Australia: Oxford University Press.

Bedford, R., \& Hugo, G. (2012). Population movement in the Pacific: A perspective on future prospects. Wellington, New Zealand: Department of Labour. 
Berner, E., \& Phillips, B. (2005). Left to their own devices? Community self-help between alternative development and neo-liberalism. Community Development Journal, $40(1), 17-29$.

Best, U. (2009). Critical geography. In R. Kitchin \& N. Thrift (Eds.), International encyclopedia of human geography (pp. 345-357). Oxford, United Kingdom: Elsevier.

Bhabha, H. K. (1996). Culture's in-between. In S. Hall \& P. Du Gay (Eds.), Questions of cultural identity (pp. 53-60). Sage London.

Bhabha, H. K. (2012). Location of culture (2nd ed.). Florence, SC: Routledge.

Booth, D. (2012). Aid effectiveness: bringing country ownership (and politics) back in. Conflict, Security \& Development, 12(5), 537-558.

Boucoup. (2013). A new global partnership: Eradicate poverty and transform economies through sustainable development (The report of the high-level panel of eminent persons on the post-2015 development agenda). New York, NY: United Nations.

Bradley, D. (2004). Participatory approaches: A facilitator's guide. London, United Kingdom: VSO.

Cameron, J., \& Gibson-Graham, J. K. (2007). Community enterprises: Imagining and enacting alternatives to capitalism. Social Alternatives, 26(1), 20-25.

Cammack, P. (2004). What the World Bank means by poverty reduction, and why it matters. New Political Economy, 9, 189-211.

Cammack, P. (2009). Making poverty work. Socialist Register, 38, 193-210.

Carmen, R. (1996). Autonomous development: Humanizing the landscape: An excursion into radical thinking and practice. London: Zed Books. Retrieved from http://www.getcited.org/pub/103302625

Chambers, R. (2007). PRA, PLA and pluralism: Practice and theory (IDS Working Paper 286). Brighton, UK: IDS. 
Close, S. (2012). Skills for Solomon Islands: Opening new opportunities. Sydney, Australia: World Bank.

Clough, P., \& Nutbrown, C. (2012). A student's guide to methodology. London, United Kingdom: SAGE. Retrieved from

Community Partnering for Local Development. (2010a). Asset based community development or $A B C D$. Retrieved from http://www.communitypartnering.info/assets64.html

Community Partnering for Local Development. (2010b). Diverse economies. Retrieved from http://www.communitypartnering.info/diverse59.html

Corbridge, S. (1998). "Beneath the pavement only soil": The poverty of post-development. Journal of Development Studies, 34(6), 138-148.

Coxon, E., \& Munce, K. (2008). The global education agenda and the delivery of aid to Pacific education. Comparative Education, 44(2), 147-165.

Cramer, C., Stein, H., \& Weeks, J. (2006). Ownership and donorship: Analytical issues and a Tanzanian case study. Journal of Contemporary African Studies, 24(3), 415-436.

Crang, M., \& Cook, I. (2007). Doing ethnographies. London, United Kingdom: SAGE.

Cupples, J., \& Kindon, S. (2003). Returning to university and writing the field. In R. Scheyvens \& D. Storey (Eds.), Development fieldwork (pp. 217-233). London, United Kingdom: SAGE.

Daly, H. E. (2005). Economics in a full world. Scientific American, 293, 100-107.

Dinnen, S. (2002). Winners and losers: Politics and disorder in the Solomon Islands 20002002. The Journal of Pacific History, 37(3), 285-298.

Douse, M. (2014). Aide-memoire: Programme for the integration of Technical, Vocational Education and Training (TVET) into the Solomon Islands education system (End of term evaluation aide-memoire). Honiara, Solomon Islands: ARS Progetti. 
Dowling, R. (2010). Power, subjectivity, and ethics in qualitative research. In I. Hay (Ed.), Qualitative research methods in human geography (3rd ed., pp. 26-39). Melbourne, Australia: Oxford University Press.

England, K. V. L. (1994). Getting personal: Reflexivity, positionality, and feminist research*. The Professional Geographer, 46, 80-89.

Escobar, A. (1997). The making and unmaking of the third world. In M. Rahnema \& V. Bawtree (Eds.), The post-development reader (pp. 85-93). London, United Kingdom: Zed Books.

Escobar, A. (2007). "Post-development" as concept and social practice. In A. Ziai (Ed.), Exploring post-development: theory and practice, problems and perspectives (pp. 1832). Tailor \& Francis e-Library.

Esteva, G. (2010). Development. In W. Sachs (Ed.), The development dictionary : A guide to knowledge as power (2nd ed., pp. 1-23). London: Zed Books.

Fraenkel, J. (2004). The manipulation of custom: From uprising to intervention in the Solomon Islands. Wellington, New Zealand: Victoria University Press.

Freire, P. (1970). Pedagogy of the oppressed (New revised 20th Anniversary Edition.). New York, NY: Continuim.

Gegeo, D. W. (1998). Indigenous knowledge and empowerment: Rural development examined from within. Contemporary Pacific, 10(2), 289.

Gegeo, D. W., \& Watson-Gegeo, K. A. (2002). Whose knowledge? Epistemological collisions in Solomon Islands community development. The Contemporary Pacific, 14(2), 377409.

Gibson-Graham, J. K. (2005). Surplus possibilities: Postdevelopment and community economies. Singapore Journal of Tropical Geography, 26(1), 4-26.

Gibson-Graham, J. K. (2006). A postcapitalist politics. Minneapolis, MN: University of Minnesota Press. 
Gibson-Graham, J. K. (2008). Diverse economies: Performative practices for 'other worlds'. Progress in Human Geography, 32(5), 613-632.

Gibson-Graham, J. K., Cameron, J., \& Healy, S. (2013). Take back the economy: An ethical guide for transforming our communities. Minneapolis, MN: University of Minnesota Press.

Hall, S. (2002). The west and the rest: Discourse and power. In S. S. and J. Haggis (Ed.), Development: A cultural studies reader (pp. 56-64). Oxford: Blackwell.

Harriss-White, B. (2006). Poverty and capitalism. Economic and Political Weekly, 1241-1246. International Labour Organization. (2009). Decent work country programme Solomon Islands. Honiara, Solomon Islands: Author.

International Labour Organization. (2013). Global employment trends for youth 2013: A generation at risk. Geneva.

Joint geospatial support facility: NZ Defence Force. (2007). Solomon Islands map. Retrieved from http://www.bibliotecapleyades.net/imagenes_ciencia/flyingobjects43_01.jpg Kapoor, I. (2005). Participatory development, complicity and desire. Third World Quarterly, 26(8), 1203-1220.

Kitchin, R., \& Tate, N. J. (2000). Conducting research in human geography: Theory, methodology and practice. Harlow, ND: Prentice Hall.

Lacey, A. (2011). Honiara, Solomon Islands: New urbanization challenges, a new development imagination? (Working paper no.4) (p. 14). Auckland, New Zealand: UoA Centre for Development Studies.

Manning, R. (2009). Using indicators to encourage development: Lessons from the millennium development goals (No. 2009:01). Danish Institute for International Studies. 
Matthews, S. (2008). The role of the privileged in responding to poverty: Perspectives emerging from the post-development debate. Third World Quarterly, 29(6), 10351049.

Max-Neef, M. (2010). The world on a collision course and the need for a new economy. Ambio, 39, 200-210.

McDougall, D. (2004). Intervention in Solomon Islands. The Round Table, 93(374), 213-223.

McGregor, A. (2009). New possibilities? Shifts in post-development theory and practice. Geography Compass, 3(5), 1688-1702.

McKnight, J., \& Kretzmann, J. (1993). Building communities from the inside out: A path toward finding and mobilizing a community's assets. Evanston, IL: Center for Urban Affairs and Policy Research, Northwestern University.

Merriam, S. B., Johnson-Bailey, J., Lee, M.-Y., Kee, Y., Ntseane, G., \& Muhamad, M. (2001). Power and positionality: Negotiating insider/outsider status within and across cultures. International Journal of Lifelong Education, 20(5), 405-416.

Midgley, J. (2006). Gendered economies: Transferring private gender roles into the public realm through rural community development. Journal of Rural Studies, 22(2), 217231.

Ministry of Education and Human Resources Development. (2013). National Education Action Plan 2013-15. Solomon Islands Government.

Ministry of Foreign Affairs and Trade. (2012). Development that delivers: New Zealand Aid Programme strategic plan 2012-15. New Zealand Government.

Morse, S., \& Bell, S. (2011). Sustainable development indicators: The tyranny of methodology revisited. Consilience: The Journal of Sustainable Development, 6(1), 222-239.

Mundy, K. (2006). Education for all and the new development compact. Review of Education, $52,23-48$. 
Murray, W. E., \& Overton, J. (2003). Designing development research. In R. Scheyvens \& D. Storey (Eds.), Development fieldwork (pp. 18-36). London, United Kingdom: SAGE.

Nagar, R., \& Ali, F. (2003). Collaboration across borders: Moving beyond positionality. Singapore Journal of Tropical Geography, 24, 356-372.

Nanau, G. L. (2011). The wantok system as a socio-economic and political network in Melanesia. OMNES: The Journal of Multicultural Society, 2(1), 31-55.

Nelson, N., \& Wright, S. (1995). Participation and power. In Nelson, Nici \& Wright, Susan (Eds.), Power and participatory development: theory and practice. (pp. 1-18). London, United Kingdom: Intermediate Technology Publications. Retrieved from http://www.cabdirect.org/abstracts/19951807843.html

Nordtveit, B. H. (2010). Towards post-globalisation? On the hegemony of western education and development discourses. Globalisation, Societies and Education, 8(3), 321-337.

Nussbaum, M. C. (2001). Women and human development: The capabilities approach (Vol. 3). Cambridge, United Kingdom: Cambridge University Press.

OECD. (2013). Solomon Islands.

O'Leary, Z. (2010). The Essential Guide to Doing Your Research Project. London, United Kingdom: SAGE.

Pieterse, J. N. (2009). Postdevelopment. In R. Kitchin \& N. Thrift (Eds.), International encyclopedia of human geography (pp. 339-343). Oxford, United Kingdom: Elsevier.

Pollard, B. (2005). Solomon Islands education and donor assistance in the post-conflict period. In K. Sanga \& A. Taufe'ulungaki (Eds.), International aid impacts on Pacific education (pp. 155-195). Wellington, New Zealand: He Parekereke, Institute for Research and Development in Maori and Pacific Education, Victoria University.

Rahnema, M. (1997). Introduction. In M. Rahnema \& V. Bawtree (Eds.), The postdevelopment reader (pp. ix - xix). London, United Kingdom: Zed Books. 
Rahnema, M., \& Bawtree, V. (Eds.). (1997). The post-development reader. London, United Kingdom: Zed Books.

RAMSI. (2013). Background briefing for the Pacific Islands Forum: RAMSI's achievements: 2003-2013.

Rapley, J. (2008). End of development or age of development? Progress in Development Studies, 8(2), 177-182.

Reed, J. (2007). Appreciative inquiry: Research for change. Thousand Oaks: SAGE.

Sachs, W. (Ed.). (1992). The development dictionary: A guide to knowledge as power. London, United Kingdom: Zed Books.

Sachs, W. (2010). Introduction. In W. Sachs (Ed.), The development dictionary : A guide to knowledge as power (2nd ed., pp. xv-xx). London, United Kingdom: Zed Books.

Saith, A. (2006). From universal values to Millennium Development Goals: Lost in translation. Development and Change, 37(6), 1167-1199.

Santos, B. de S. (1999). On opositional postmodernism. In R. Munck \& D. O’Hearn (Eds.), Critical development theory (pp. 29-43). London: Zed.

Santos, B. de S. (2004). The World Social Forum: Toward a counter-hegemonic globalisation (Part I). In J. Sen, A. Anad, A. Escobar, \& P. Waterman (Eds.), World Social Forum: Challenging empires (In Sen, J., Anand, A., Escobar, A. and Waterman, P., editors, The World Social Forum: challenging empires, New Delhi: The Viveka Foundation, 23545., pp. 235-45). New Delhi, India: The Viveka Foundation.

Scheyvens, R., Nowak, B., \& Scheyvens, H. (2003). Ethical issues. In D. Storey \& R. Scheyvens (Eds.), Development fieldwork (pp. 140-166). London, United Kingdom: SAGE.

Sen, A. (2000). Development as freedom. New Delhi, India: Oxford University Press. SIAVRTCs. (2013). SIAVRTC principals' 20th conference: Petition to prime minister. Author. SIAVRTCs. (2014a). Annual report 2013. Honiara, Solomon Islands: Author. SIAVRTCs. (2014b). History. Retrieved from http://www.siartc.org.sb/history.html 
Sjöstedt, M. (2013). Aid effectiveness and the Paris Declaration: A mismatch between ownership and results-based management? Public Administration and Development, 33(2), 143-155.

Solomon Islands Government, \& RAMSI. (2011). Gender action plan 2011-2013. RAMSI.

Solomon Islands National University. (2014). About us. Retrieved from http://www.sinu.edu.sb/AboutUs.html

Stewart-Withers, R., Banks, G., McGregor, A., \& Meo-Sewabu, L. (2014). Qualitative research. In R. Scheyvens (Ed.), Development fieldwork (2nd ed., pp. 59-80). London, United Kingdom: SAGE.

Storey, A. (2000). Post-development theory: Romanticism and Pontius Pilate politics. Development, 43(4), 40-46.

Sultana, F. (2007). Reflexivity, positionality and participatory ethics: Negotiating fieldwork dilemmas in international research. $A C M E, 6(3)$.

Summers, L. (1992). Investing in all the people. Presented at the Annual General Meeting of the World Bank, Washington DC.

Sumner, A., \& Lawo, T. (2013). The post-2015 development agenda: A review of the debate and potential elements of a joint EU strategy. European Associoation of Development Research and Training Institutes.

Swedlund, H. J. (2013). From donorship to ownership? Budget support and donor influence in Rwanda and Tanzania. Public Administration and Development, 33(5), 357-370.

Thomas, A. (2000). Poverty and the "end of development." In T. Allen \& A. Thomas (Eds.), Poverty and development into the 21st Century. (pp. 3-22). Oxford, United Kingdom: Oxford University Press.

Tikly, L. (2004). Education and the new imperialism. Comparative Education, 40(2), 173-198. Tilley, H., \& Tavakoli, H. (2012). Better aid modalities: are we risking real results? (Literature Review). London, UK: Overseas Development Institute. 
UNdata. (2014). Solomon Islands. Retrieved from

http://data.un.org/CountryProfile.aspx?crname=Solomon\%20lslands

UNDP. (2010). Millennium Development Goals progress report for Solomon Islands 2010. Honiara.

UNDP. (2013). International human development indicators. Retrieved from http://hdrstats.undp.org/en/countries/profiles/SLB.html

UNDP. (2014a). Human development index (HDI). Retrieved from http://hdr.undp.org/en/content/human-development-index-hdi-table

UNDP. (2014b, August 4). International human development indicators: Country profiles. Retrieved from http://hdr.undp.org/en/countries

UN General Assembly. (1948). Universal declaration of human rights. Author.

UNICEF. (2004). The state of the world's children 2004: Girls, education and development. New York, NY: Author.

UNICEF. (2011). State of the world's children 2011. Adolescence, an age of opportunity. New York, NY: Author.

UNICEF. (2013). Childinfo.org: Statistics by Area - Education - Secondary school enrolment and attendance ratios. Retrieved from http://www.childinfo.org/education_secondary.php

United Nations. (2001). Road map towards the implementation of the United Nations Millennium Declaration (Report of the Secretary General No. A/56/326). Author. United Nations. (2014a). Millennium Development Goals: 2014 progress chart. Statistics Division, Department of Economic and Social Affairs, United Nations.

United Nations. (2014b). The Millennium Development Goals report 2014. New York, NY: Author.

United Nations Statistics Division. (n.d.). Series metadata: Goal 1. Retrieved from http://mdgs.un.org/unsd/mdg/Metadata.aspx?Indicatorld=0\&Seriesld=580 
UN Millennium Project: Taskforce on Education and Gender Equality. (2005). Taking action: Achieving gender equality and empowering women. London, United Kingdom: Earthscan.

Vandemoortele, J. (2011). The MDG story: intention denied. Development and Change, 42(1), 1-21.

Whalan, J. (2010). Background paper prepared for the education for all global monitoring report 2011: The hidden crisis: Armed conflict and education. UNESCO.

Winchester, H., \& Rofe, M. (2010). Qualitative research and its place in human geography. In I. Hay (Ed.), Qualitative research methods in human geography (3rd ed., pp. 3-24). Melbourne, Australia: Oxford University Press.

Woodward, K., Dixon, D. P., \& Jones III, J. P. (2009). Poststructuralism/Poststructuralist Geographies. In R. Kitchin \& N. Thrift (Eds.), International encyclopedia of human geography (pp. 396-407). Oxford, United Kingdom: Elsevier.

World Bank. (2010). Solomon Islands growth prospects : Constraints and policy priorities (Discussion Note). Author.

World Bank. (2013). Skills for Solomon Islands women: Opening new opportunities. Author. World Bank. (2014). Data: Solomon Islands. Retrieved from http://data.worldbank.org/country/solomon-islands

Wright, N. (2013). Integration of Vocational Education and Training into the formal and nonformal education system in the Solomon Islands: A strategic communications intervention for TVET in the Solomon Islands (Draft). European Union.

Wrighton, N., \& Overton, J. (2012). Coping with participation in small island states: the case of aid in Tuvalu. Development in Practice, 22(2), 244-255.

WYG International. (2012). Integration of Technical and Vocational Education and Training (TVET) into the formal and non-formal education system: Labour market and community skills needs analysis. Honiara, Solomon Islands: European Union. 
Ziai, A. (2007a). Development discourse and its critics: An introduction to post-development.

In A. Ziai (Ed.), Exploring post-development: Theory and practice, problems and perspectives (pp. 3-17). Tailor \& Francis e-Library.

Ziai, A. (2007b). Exploring post-development: Theory and practice, problems and perspectives. Tailor \& Francis e-Library. 


\title{
Appendices
}

\section{Appendix 1: Participant information sheet and consent form}

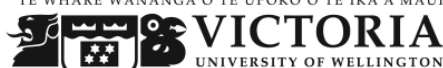 \\ PARTICIPANT INFORMATION SHEET - INTERVIEWS \\ Connecting youth to local livelihoods: The relevance of Rural Training Centres in Solomon Island \\ Communities

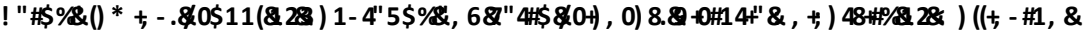 \\ My name is Kathy Fleming. I am Australian, but live in Wellington New Zealand where I am studying a \\ Master's in Development studies at Victoria University. As part of this degree I am completing a research \\ project, leading to a thesis. The project looks at livelihood opportunities for young people in rural communities \\ in the Solomon Islands and how Rural Training Centres (RTC) can support such opportunities. I am \\ conducting this research independently under the university, however the findings of this research will be \\ shared with Caritas Aotearoa to assist with their project to strengthen a number of RTCs.
}

I am inviting local community leaders, young people, RTC students, local women, and RTC teachers in training to participate in this research through interviews and small groups. I invite you as a member of this community to participate in an interview about what supports livelihoods in this community, the opportunities for young people and the role RTCs can play in connecting young people to these livelihoods.

You are under no obligation to participate, and if you choose to participate I will ask you to give your consent orally on a tape recorder or by signing a form. I would also ask that you agree to have this interview recorded so that I can refer to it at a later time and not rely on my memory.

Responses will form the basis for my research project, presented in a professional report for Caritas and my thesis. All material collected will be kept confidential, and only seen by myself, my supervisor and a transcriber who will also sign a confidentiality agreement. To make sure you are not identified I will use another name for you (pseudonym), unless you choose otherwise and state so in a form.

If you decide to participate, you have the right to:

Withdraw at any time without having to give any reason during the interview

Withdraw from the project before $1^{\text {st }}$ June 2014

Not answer any question

Ask for the tape recorder to be turned off

Ask questions about the research

All written, recorded and visual information from this interview will be kept secure, under lock and password protection while I am in the Solomon Islands and when I return to New Zealand. The findings from this research will be prepared into a report for Caritas, a copy of which will be sent to the Rural Training Centre for you to access. The findings will form part of my Masters thesis, and may be submitted in publication in scholarly journals, or professional presentations. If you have any further questions or would like an electronic copy of the report please contact me or my supervisor. If you have any further questions or would like an electronic copy of the report or thesis please contact me or my supervisor.

\begin{tabular}{|l|l|}
\hline My contact details are: & My supervisors contact details are: \\
Kathy Fleming & Marcela Palomina-Schalscha \\
149 Aro St, Aro Valley & Master of Development Studies Programme \\
Wellington, 6021 & University of Victoria, Wellington \\
New Zealand & New Zealand \\
Ph: +64223511928 & Ph: +644635899 \\
kathyacefleming@gmail.com & Marcella.palomino-schalscha@vuw.ac.nz \\
\hline
\end{tabular}




\section{TE WHARE WÃNANGA TE OPOKO O TE IKA M MÃUI \\ :}

PARTICIPANT INFORMATION SHEET - INTERVIEWS

!

Connecting youth to local livelihoods: The relevance of Rural Training Centres in Solomon Island

Communities

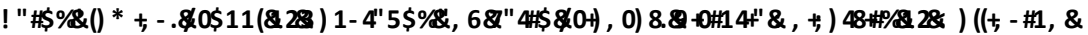

\&

My name is Kathy Fleming. I am Australian, but live in Wellington New Zealand where I am studying a Master's in Development studies at Victoria University. As part of this degree I am completing a research project, leading to a thesis. The project looks at livelihood opportunities for young people in rural communities in the Solomon Islands and how Rural Training Centres (RTC) can support such opportunities. I am conducting this research independently under the university, however the findings of this research will be shared with Caritas Aotearoa to assist with their project to strengthen a number of RTCs.

I am inviting local community leaders, young people, RTC students, local women, and RTC teachers in training to participate in this research through interviews and small groups. I invite you as a member of this community to participate in an interview about what supports livelihoods in this community, the opportunities for young people and the role RTCs can play in connecting young people to these livelihoods.

You are under no obligation to participate, and if you choose to participate I will ask you to give your consent orally on a tape recorder or by signing a form. I would also ask that you agree to have this interview recorded so that I can refer to it at a later time and not rely on my memory.

Responses will form the basis for my research project, presented in a professional report for Caritas and my thesis. All material collected will be kept confidential, and only seen by myself, my supervisor and a transcriber who will also sign a confidentiality agreement. To make sure you are not identified I will use another name for you (pseudonym), unless you choose otherwise and state so in a form.

If you decide to participate, you have the right to:

Withdraw at any time without having to give any reason during the interview Withdraw from the project before $1^{\text {st }}$ June 2014

Not answer any question

Ask for the tape recorder to be turned off

Ask questions about the research

All written, recorded and visual information from this interview will be kept secure, under lock and password protection while I am in the Solomon Islands and when I return to New Zealand. The findings from this research will be prepared into a report for Caritas, a copy of which will be sent to the Rural Training Centre for you to access. The findings will form part of my Masters thesis, and may be submitted in publication in scholarly journals, or professional presentations. If you have any further questions or would like an electronic copy of the report please contact me or my supervisor. If you have any further questions or would like an electronic copy of the report or thesis please contact me or my supervisor.

\begin{tabular}{|l|l|}
\hline My contact details are: & My supervisors contact details are: \\
Kathy Fleming & Marcela Palomina-Schalscha \\
149 Aro St, Aro Valley & Master of Development Studies Programme \\
Wellington, 6021 & University of Victoria, Wellington \\
New Zealand & New Zealand \\
Ph: +64223511928 & Ph: +64 4635899 \\
kathyacefleming@gmail.com & Marcella.palomino-schalscha@vuw.ac.nz \\
\hline
\end{tabular}


CONSENT TO PARTICIPATE IN RESEARCH - Interviews

Connecting youth to local livelihoods: The relevance of Rural Training Centres in Solomon Island Communities

Kathy Fleming, School of Geography and Earth Sciences, Victoria University of Wellington

\begin{abstract}
I have been given and understood an explanation of this research project. I have had the opportunity to ask questions and have them answered to my satisfaction. I understand that I may withdraw from this project at any time during this interview and until the $1^{\text {st }}$ June 2014 . I also understand that during the interview I am free not to answer one or more questions if I choose to do so, that I can also mention issues l'd rather not discuss in the interview, or request that recording be turned off.

I understand that any information I provide will be kept confidential, the published results will not use my name, and that no opinions will be attributed to me in any way that can identify me unless I choose otherwise and state so in this form.

I understand that the results of this project might be published as journal article(s), book chapter(s) or conference presentation(s) and professional report(s) for Caritas Aoteraora that I can be given a copy if I request it.

I understand that I can give recorded oral consent if I choose to do so instead of written consent without question, including my answers to all the questions below.

! I understand that the information I provide will not be used for any purposes other than those listed above or released to others without my written consent.

! I would like to receive copies of future publications emerging from this research

! I would like my identity to be disclosed and my opinions to be attributed to me in the research report and any further publications (DO NOT TICK IF YOU WISH YOUR IDENTITY TO REMAIN CONFIDENTIAL)
\end{abstract}

Signed:

Name of participant:

Date:

Would you like to receive a summary of your interview ! YES ! NO

Please choose the method by which you will receive this:

! Directly via emal or postal address (please write below):

! Via local community member (name of local translator/recruiter) 
CONSENT TO PARTICIPATE IN RESEARCH - Interviews

Connecting youth to local livelihoods: The relevance of Rural Training Centres in Solomon Island Communities

Kathy Fleming, School of Geography and Earth Sciences, Victoria University of Wellington

\begin{abstract}
I have been given and understood an explanation of this research project. I have had the opportunity to ask questions and have them answered to my satisfaction. I understand that I may withdraw from this project at any time during this interview and until the $1^{\text {st }}$ June 2014 . I also understand that during the interview I am free not to answer one or more questions if I choose to do so, that I can also mention issues l'd rather not discuss in the interview, or request that recording be turned off.

I understand that any information I provide will be kept confidential, the published results will not use my name, and that no opinions will be attributed to me in any way that can identify me unless I choose otherwise and state so in this form.

I understand that the results of this project might be published as journal article(s), book chapter(s) or conference presentation(s) and professional report(s) for Caritas Aoteraora that I can be given a copy if I request it.

I understand that I can give recorded oral consent if I choose to do so instead of written consent without question, including my answers to all the questions below.

! I understand that the information I provide will not be used for any purposes other than those listed above or released to others without my written consent.

! I would like to receive copies of future publications emerging from this research

! I would like my identity to be disclosed and my opinions to be attributed to me in the research report and any further publications (DO NOT TICK IF YOU WISH YOUR IDENTITY TO REMAIN CONFIDENTIAL)
\end{abstract}

Signed:

Name of participant:

Date:

Would you like to receive a summary of your interview ! YES ! NO

Please choose the method by which you will receive this:

! Directly via emal or postal address (please write below):

! Via local community member (name of local translator/recruiter) 


\section{Appendix 2: Interview schedule}

The following questions were used as a guide of potential topic discussion areas. These evolved in the field.

\section{Pre-Interview checklist:}

Put some time in so they have seen you about and hence relaxed

Confirm location where to sit etc...

Introduce myself and explain purpose of research and topics to be covered in interview Go through formal ethics protocol and give information sheet.

Check in with them, are they nervous about anything, do they have any questions?

Confirm willingness to participate and ask to record interview.

Start recording and confirm consent.

\section{Participants:}

- RTC Administrators

- Women

- Community leaders

- Young people/RTC students

\section{Questions:}

\section{Background}

Community Leaders/Women - Where did you grow up? What was it like, how is it different to now? What was your experience of education and how did it prepare you for supporting your family? (location, education and transition to work).

RTC Administrators - History of this RTC? How and when did it start, how has it developed or changed over the years? What courses are offered and why?

Young people - what was their experience of education? What are some of the most important things they learned in school? Since leaving school what have they been doing? Community Strengths and Assets

What are the strengths of the community, the good things about living here?

Probe - what do you think is good about:

environment, business, 
Local services and facilities

Peoples and culture, religion (family culture etc.. )

\section{Livelihoods and diverse economies}

How do people support themselves and their families here?

What are the main ways people earn cash? Other than cash, how do people feed their family, provide housing etc...

\section{Future for Young People}

What do you think of the future for young people here?

Do they stay or leave? What happens if they stay here? What are the opportunities here, what are the limitations?

How do they fit with the livelihoods mentioned?

What are the opportunities, what are the limitations? What happens to young people after school? Do they stay or leave and why? What are the impacts of this on the community?

\section{Opportunities for young people}

What would make the opportunities for young people better here? Why?

What would need to happen to do this? If you could name 3 things that would make the future for young people here better what would it be?

Young people/RTC students- what do they see themselves doing for a livelihood in the future?

\section{Perception of RTCs}

What do you think of the RTCs?

Score them on a rating of 1-5 as an option for young people

Who attends RTCs?

Why are they good/bad etc..?

Do they connect young people with ways to support themselves and family?

What do others think of RTCs? How and why? What are RTCs doing well and what could be done better? 
RTC administrators - are the RTCs involved with any of the businesses or institutions in the community? What are these and how are they going? Are they involved in any income generating activities? Do they see any opportunities to be involved? What has worked well and what has not worked well? How could they better support the transition to work for young people?

\section{Women -}

What do you think of the RTC as an option for women? What 3 things could RTCs do to enhance the lives of women in the community Would you send your daughter to an RTC? Why, why not? Some girls do mechanics courses now, is this something you would want for your daughter?

Is there anything else you would like to add? 


\section{Appendix 3: Focus group schedule:}

The following was used to prepare for and guide focus group activities and discussion. These were reduced significantly in the field.

\section{Set Up:}

Opening - Ice breaker activity. Something fun, makes us laugh and interact.

Explain purpose of research, consent and confidentiality etc... Explain role of translator if relevant.

Begin recording

Most important are Q 2, 3 and 4

\begin{tabular}{|c|c|}
\hline h Question and Prompt & Activity \\
\hline $\begin{array}{l}\text { 1. Asset Map - What are the Assets of the } \\
\text { community (optional) } \\
\text { Intention - a picture of the strengths and } \\
\text { assets of the community as valued by them } \\
\text { What are the good things (assets) about living } \\
\text { here? } \\
\text { These things might be: } \\
\text { Business, environment, infrastructure } \\
\text { Services, groups, institutions, People, culture } \\
\text { What makes this community strong? } \\
\text { What is working well? }\end{array}$ & $\begin{array}{l}\text { Blank Asset Map- Answers on cards } \\
\text { Participants draw or write on cards what the } \\
\text { good things are about this community } \\
\text { Draw up the three categories } \\
\text { Gives as many cards as they want in } 5 \\
\text { minutes. Ask them to stick on the board and } \\
\text { interview the cards } \\
\text { Probes: } \\
\text { Tell me about ..... } \\
\text { What do you like about that } \\
\text { What do you mean by.... } \\
\text { Can you give me an example of .... }\end{array}$ \\
\hline $\begin{array}{l}\text { 2. What are the livelihood strategies of the } \\
\text { community } \\
\text { Intention - a picture of how the community } \\
\text { makes a livelihood, some of the diverse } \\
\text { economic strategies. } \\
\text { Livelihoods - What do people here (in this } \\
\text { community) do to make a living? What do they } \\
\text { do to feed and provide for their family? } \\
\text { What other activities do they do to obtain food } \\
\text { and other necessities for life? }\end{array}$ & $\begin{array}{l}\text { Group brainstorm drawing. } \\
\text { Ask the group to call out how people } \\
\text { support themselves and I draw it up on a } \\
\text { piece of butchers paper. Allow them to } \\
\text { correct me, make fun of my drawing and } \\
\text { have a laugh! Note what the item is below in } \\
\text { English. } \\
\text { Probes: } \\
\text { How do you feed your family? How did your } \\
\text { family eat this week - where did the food } \\
\text { come from? } \\
\text { How did you get a house }\end{array}$ \\
\hline
\end{tabular}




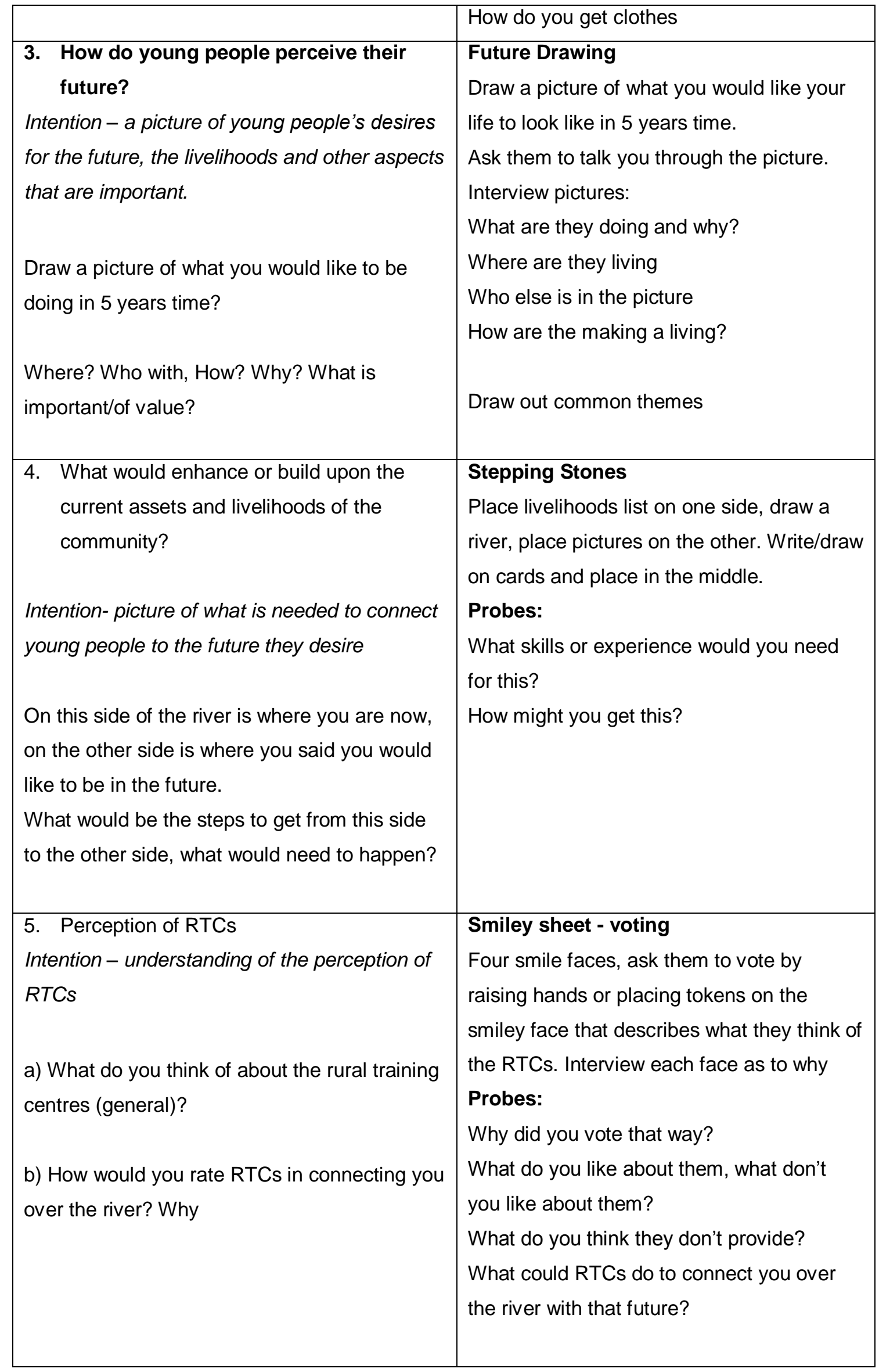




\section{Appendix 4: Human ethics approval}

TE WHARE WĀNANGA O TE ŪPOKO O TE IKA A MĀUI

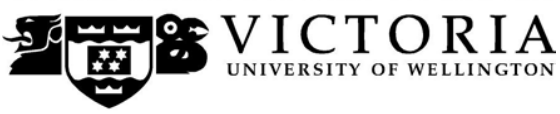

MEMORANDUM

Phone $\quad 0-4-4635676$

Fax 0-4-4635209

Email_Allison.kirkman@vuw.ac.nz

\begin{tabular}{l|l}
\hline TO & Kathryn Fleming \\
\hline COPY TO & Marcela Palomino-Schalscha \\
\hline FROM & Dr Allison Kirkman, Convener, Human Ethics Committee \\
\hline
\end{tabular}

\begin{tabular}{l|l}
\hline DATE & 7 March 2014 \\
\hline PAGES & 1 \\
\hline
\end{tabular}

SUBJECT $\quad$ Ethics Approval: 20619

Connecting youth to local livelihoods: the relevance of Rural Training Centres in Solomon Island communities

Thank you for your application for ethical approval, which has now been considered by the Standing Committee of the Human Ethics Committee.

Your application has been approved from the above date and this approval continues until 24 February 2015. If your data collection is not completed by this date you should apply to the Human Ethics Committee for an extension to this approval.

Best wishes with the research.

Allison Kirkman

Human Ethics Committee

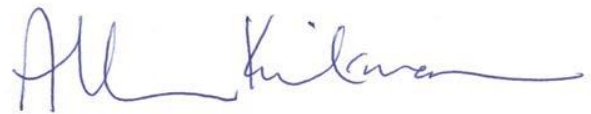


